\title{
Review
}

\section{Inorganic Fillers in Composite Gel Polymer Electrolytes for High-Performance Lithium and Non-Lithium Polymer Batteries}

\author{
Vo Pham Hoang Huy, Seongjoon So and Jaehyun Hur *(i) \\ Department of Chemical and Biological Engineering, Gachon University, Seongnam 13120, Korea; \\ vophamhoanghuy@yahoo.com.vn (V.P.H.H.); tjdwns7594@naver.com (S.S.) \\ * Correspondence: jhhur@gachon.ac.kr
}

check for updates

Citation: Hoang Huy, V.P.; So, S.; Hur, J. Inorganic Fillers in Composite Gel Polymer Electrolytes for High-Performance Lithium and Non-Lithium Polymer Batteries. Nanomaterials 2021, 11, 614. https:// doi.org/10.3390/nano11030614

Academic Editor: Christian M. Julien

Received: 19 January 2021

Accepted: 26 February 2021

Published: 1 March 2021

Publisher's Note: MDPI stays neutral with regard to jurisdictional claims in published maps and institutional affiliations.

Copyright: (c) 2021 by the authors. Licensee MDPI, Basel, Switzerland. This article is an open access article distributed under the terms and conditions of the Creative Commons Attribution (CC BY) license (https:// creativecommons.org/licenses/by/ $4.0 /)$.

\begin{abstract}
Among the various types of polymer electrolytes, gel polymer electrolytes have been considered as promising electrolytes for high-performance lithium and non-lithium batteries. The introduction of inorganic fillers into the polymer-salt system of gel polymer electrolytes has emerged as an effective strategy to achieve high ionic conductivity and excellent interfacial contact with the electrode. In this review, the detailed roles of inorganic fillers in composite gel polymer electrolytes are presented based on their physical and electrochemical properties in lithium and non-lithium polymer batteries. First, we summarize the historical developments of gel polymer electrolytes. Then, a list of detailed fillers applied in gel polymer electrolytes is presented. Possible mechanisms of conductivity enhancement by the addition of inorganic fillers are discussed for each inorganic filler. Subsequently, inorganic filler/polymer composite electrolytes studied for use in various battery systems, including Li-, Na-, Mg-, and Zn-ion batteries, are discussed. Finally, the future perspectives and requirements of the current composite gel polymer electrolyte technologies are highlighted.
\end{abstract}

Keywords: inorganic filler; gel polymer electrolytes; $\mathrm{TiO}_{2} ; \mathrm{Al}_{2} \mathrm{O}_{3} ; \mathrm{SiO}_{2} ; \mathrm{ZrO}_{2} ; \mathrm{CeO}_{2} ; \mathrm{BaTiO}_{3}$; lithium polymer batteries

\section{Introduction}

Electrolytes serve as the transportation medium for charge carriers between a pair of electrodes that are ubiquitous in electrolyte cells, fuel cells, and batteries [1]. For several decades, liquid electrolytes (LEs) have been employed extensively in electrochemical devices owing to their high electrolytic conductance $\left(10^{1}-10^{2} \mathrm{mS} \mathrm{cm}^{-1}\right.$ for aqueous electrolytes and $10^{0}-10^{1} \mathrm{mS} \mathrm{cm}^{-1}$ for organic electrolytes). However, the safety issues associated with LEs in terms of electrolyte leakage from flammable organic solvents have hindered the commercialization of lithium-metal (Li-metal) electrodes in lithium-ion batteries (LIBs) [2-11]. Another limitation associated with LEs is the inevitable dendrite growth of lithium due to uneven current when using porous separators [12-18]. Furthermore, increasing the energy density in LIBs using high-voltage materials often leads to electrode degradation as it requires electrode-electrolyte compatibility [19-25]. Therefore, the development of new electrolytes is essential to overcome the aforementioned issues in LIB applications.

Solid polymer electrolytes (SPEs) without a liquid solvent have the potential to overcome the limitations associated with Les [26,27]. One of the interesting concepts recently demonstrated is "polymer-in-ceramic" configuration. Zhang et al. synthesized SPE with a flexible and self-standing membrane by incorporating $75 \mathrm{wt} \%$ ceramic particles into polymer matrix [28]. Poly( $\varepsilon$-caprolactone) (PCL) was proved to be a great polymer matrix that can accommodate high content of ceramic particles compared to other polymers due to its good mechanical strength and ability of structural rearrangement. The high concentration of ceramic in polymer-in-ceramic can be favorable in enhancing the ionic conductivity. For example, in poly(ethylene oxide)-garnet electrolyte $\mathrm{SPE}, \mathrm{Li}^{+}$ion transport is highly enhanced when the content of ceramic garnet reaches the percolation threshold. 
While the conductivity of the SPE is dominated by the polymer chain movement when the ceramic concentration is below the percolation threshold, the conductivity is boosted when ceramic concentration reaches the percolation threshold. This is because of the additional $\mathrm{Li}^{+}$ion transport pathway formed by the ionic conducting ceramic. Therefore, above the percolation threshold, the presence of ceramic in SPE can dominantly affect the ionic conductivity [29]. However, the utilization of SPEs in electrochemical cells is still limited owing to their low ionic conductivities $\left(10^{-5}-10^{-2} \mathrm{mS} \mathrm{cm}^{-1}\right)$, poor contact at the electrode-electrolyte interface, and narrow electrochemical window, resulting in a degenerated cyclic performance [30,31]. Recently, plastic crystalline electrolytes (PCEs) have been extensively studied for their high electrical conductivity, soft texture, and good thermal stability. Succinonitrile (SN)-based PCE is synthesized as an alternate layer to resolve the interfacial instability between solid electrolyte (SE) and Li metal, allowing for the widespread use of Li metal anode in the solid-state lithium batteries. Besides, chemical compatibility between SE and PCE ensures the prolonged life of solid-state batteries [32,33]. Tong et al. synthesized the SE interface by incorporating SN-based PCE in combination with salt and $\mathrm{Li}_{7} \mathrm{La}_{3} \mathrm{Zr}_{1.4} \mathrm{Ta}_{0.6} \mathrm{O}_{12}$ (LLZTO), which enhances surface stability for Li metal anode and $\mathrm{Li}_{1.5} \mathrm{Al}_{0.5} \mathrm{Ge}_{1.5}\left(\mathrm{PO}_{4}\right)_{3}$ (LAGP)-based ceramic electrolyte [34]. The presence of the PCE interface helps to protect the ceramic electrolyte from reduction and promotes good interface stability with Li metal anode and LAGP due to its soft texture. In the absence of the PCE interface, the cell achieved a discharge capacity of $80 \mathrm{mAh} \mathrm{g}^{-1}$ at $0.05 \mathrm{C}$, whereas the cell with PCE interface showed an increase in discharge capacity of $126 \mathrm{mAh} \mathrm{g}^{-1}$ at $0.05 \mathrm{C}$. Thus, PCE that can act as a combination agent between the LAGP and Li metal anode prevents the penetration of dendrites into LAGP-based ceramic electrolyte. Compared with SPEs, gel polymer electrolytes (GPEs) are promising candidates for LIBs and non-LIBs as they combine the advantages of both LEs and SPEs in terms of ionic conductivity and mechanical properties [1,35-41]. Figure 1 shows the general advantages and disadvantages of LEs, SPEs, and GPEs.

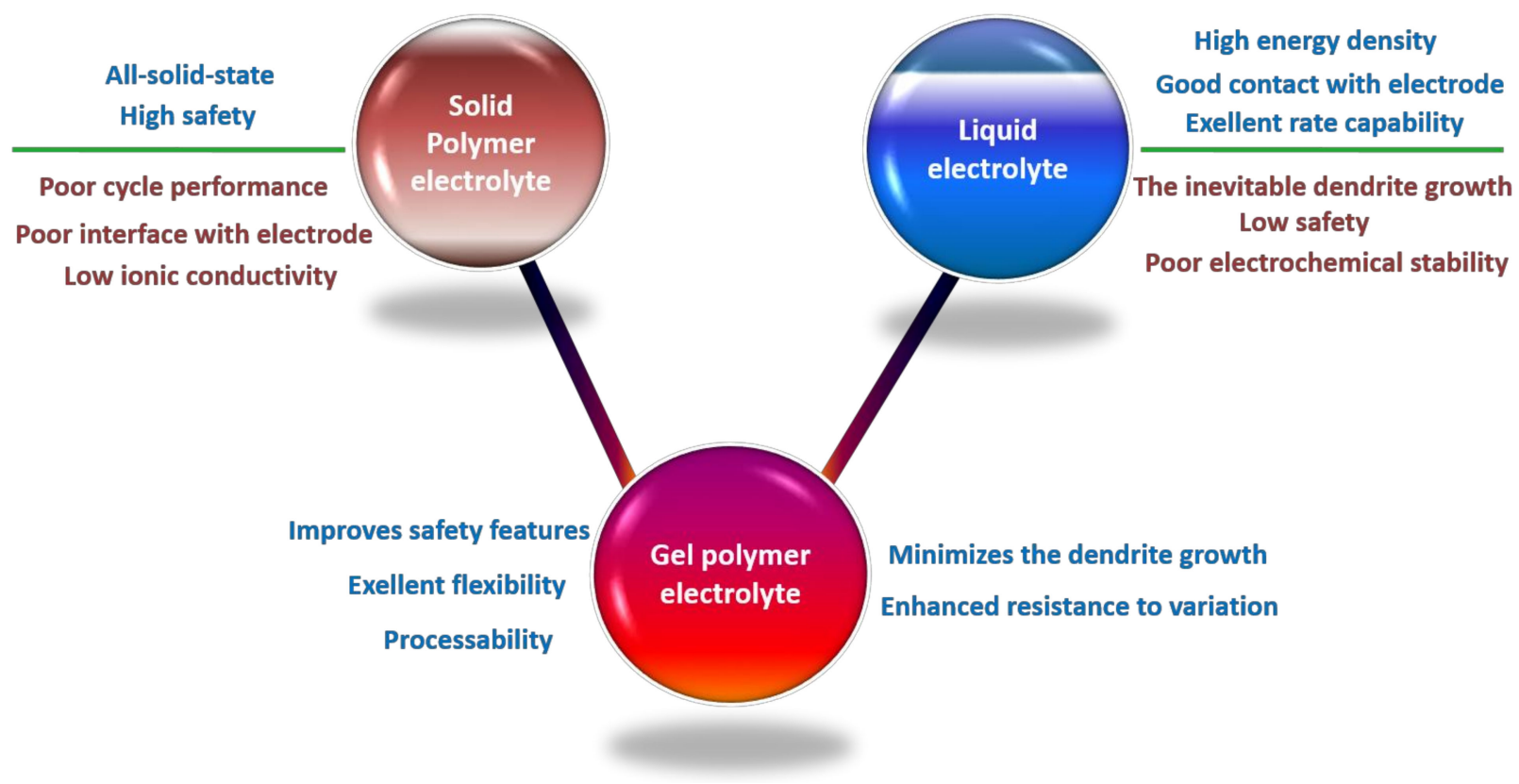

Figure 1. Advantages and disadvantages of solid polymer electrolytes (SPEs), liquid electrolytes (LEs), and gel polymer electrolytes (GPEs).

GPEs generally comprise a polymer matrix-lithium salt (Li-salt) system, small amount of integrated liquid plasticizer, and/or solvent, as shown in Figure 2 [42]. GPEs are characterized as homogeneous (uniform) and heterogeneous (phase-separated) gels. Typically, heterogeneous GPEs consist of a polymer framework of which the interconnected pores 
are filled with LEs. Thus, lithium ion $\left(\mathrm{Li}^{+}\right.$ion) transport mainly proceeds in the swollen gel phase or liquid phase in heterogeneous GPEs, which has a higher electrolytic conductance than SPEs. In addition, owing to their high safety and flexibility, GPEs are increasingly utilized for the manufacturing of advanced energy storage devices [43,44]. Several types of polymer matrices have been investigated as frameworks for GPEs, including polyethylene oxide (PEO), polyacrylonitrile (PAN), poly(vinylidene fluoride-cohexafluoropropylene) (PVDF-HFP), poly(ethylene oxide-co-ethylene carbonate) (P(EOEC)), poly(methyl methacrylate) (PMMA), poly(vinyl alcohol) (PVA), poly(vinyl chloride) (PVC), poly(propylene glycol) (PPG) [42-45]. In addition, the elastomeric polymer (polydimethylsiloxane (PDMS)) was used in the GPE nanocomposite due to its mechanical flexibility as well as chemical and thermal stability; thus, the nanocomposite PDMS-based membrane provides good electrochemical performance with high mechanical flexibility [46-49]. Owing to the combination of a polymer-salt system with a plasticizer, the mechanical strength of GPEs is mainly determined by the polymer matrix, while the plasticizer reduces the crystallized phase of the polymer matrix. This promotes segmental motion of the polymer matrix and affects the ionic conductivity of the GPE [50].

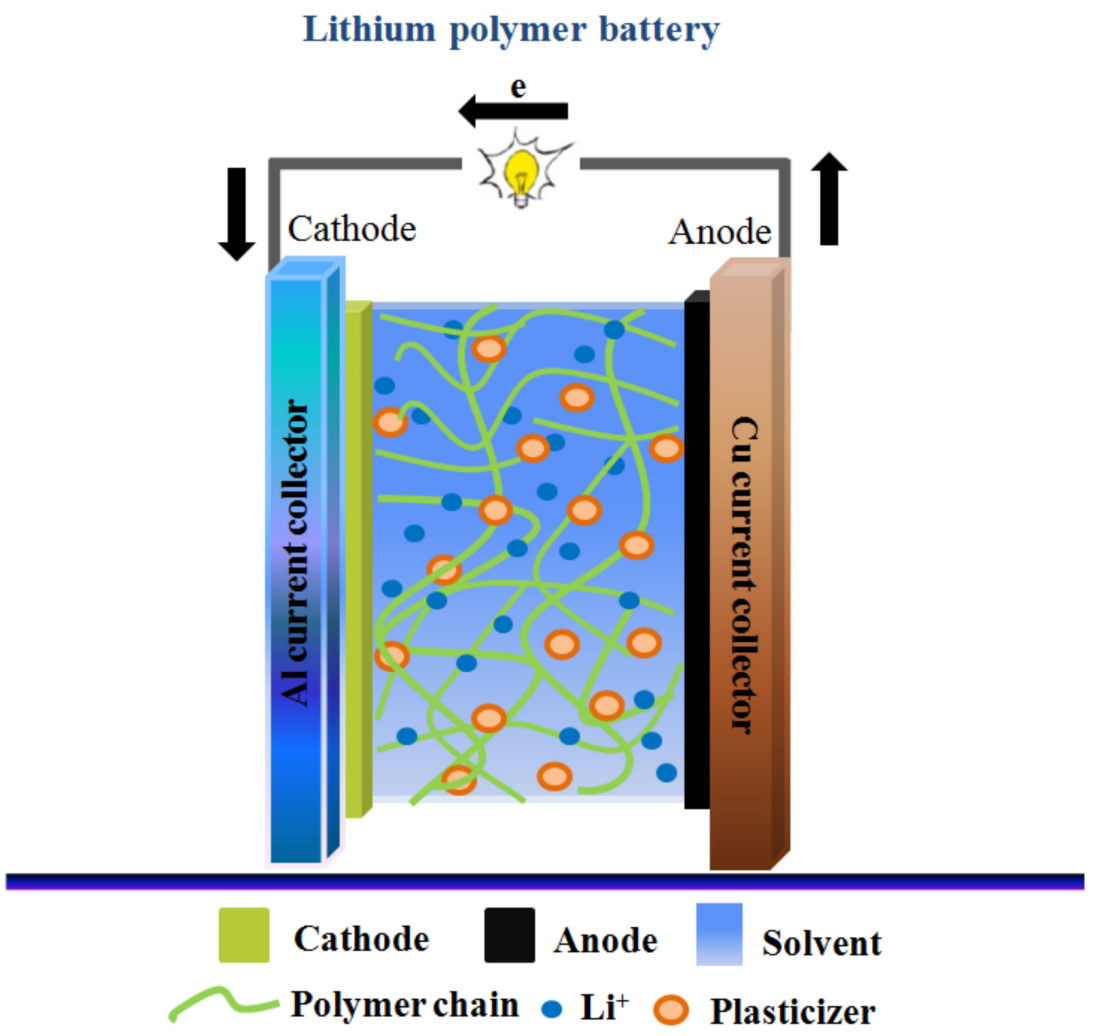

Figure 2. Schematic of a lithium polymer battery based on GPEs.

However, when incorporating an excess of plasticizer, it can deteriorate the mechanical strength of the film and its thermal stability, resulting in safety hazards [13,51]. Generally, blending, copolymerization, and crosslinking are used to improve the properties of polymer matrices and produce GPEs that perform well in LIBs. However, more importantly, the use of appropriate inorganic fillers in GPEs has recently emerged as one of the most promising methods to enhance the strength of the membranes, ionic conductivity, and $\mathrm{Li}^{+}$ion transfer, which results in the GPEs performing well in LIBs [43].

Recently, a series of new approaches for incorporation of inorganic fillers have been developed to improve the electrochemical properties of GPEs. Besides, the incorporation of inorganic fillers in shape memory polymer (SMP) has been studied as an effective method for enhancing the mechanical properties and allowing multiple functionalities. 
SMP is a kind of material that can highly interact with stimulants such as temperature, light, and electromagnetic field to recover its original shape, suggesting this material as an important smart polymer which widely applied in industry [52]. In an attempt to enhance SMP's recovery, Park et al. studied the effect of $\mathrm{SiO}_{2}$ fillers on polyurethane (PU) properties [53]. A cross-linking formed between the PU chains and hydroxide on the surface of $\mathrm{SiO}_{2}$ has improved the shape memory effect and enhanced the mechanical properties with $0.2 \mathrm{wt} \% \mathrm{SiO}_{2}$. Besides, with the advantages of mechanical strengths as well as high elastic modulus, CNTs were used as effective fillers in improving the recovery of SMPs. CNTs-based nanocomposite showed excellent shape fixation ability with the recovery up to $90 \%$, much higher than pristine SMP. Thus, SMP composite can be widely utilized in the industry [54,55]. GPEs have become one of the most effective electrolytes for applications such as wearable devices that require multiple functionalities, including flexibility, deformability, stretchability, and compressibility. Nevertheless, there has been a lack of discussion regarding the fundamental aspects of GPEs, including the materials used, preparation processes, their properties (mechanical, optical, and electrochemical), and their mechanism [56-59]. To obtain an overall comprehension of the recent studies on inorganic fillers and highlight their representative achievements, it is necessary to summarize the important findings for future studies on GPEs with an aim at developing high electrochemical energy storage properties.

In this review, the historical development of inorganic fillers in GPEs is first introduced. In the following sections, the details of inorganic fillers applied in GPEs along with various synthetic routes are presented. Subsequently, the mechanism of conductivity enhancement in the presence of inorganic fillers is discussed in detail. Finally, the application of GPEs in various battery systems ( $\mathrm{Li}, \mathrm{Na}, \mathrm{Mg}$, and $\mathrm{Zn}$ batteries) is discussed.

\section{Historical Overview of GPEs}

GPEs can be divided into three different categories based on the constituents of the mixture: plasticizer-added GPEs, inorganic filler-added GPEs, and a combination of plasticizer and inorganic filler-added GPEs. Lithium salt is responsible for the transportation of ions in the polymer framework, whereas the polymer accommodates the electrolyte to provide mechanical strength. The development of inorganic fillers in GPEs goes back to the early 1980s, when an attempt was made to improve the mechanical stability of the polymer matrix using an aprotic solution containing an alkali metal [60]. In the 1990s, the role of inert fillers in GPE composite systems started to be actively recognized. The addition of fillers to polymer segments has been reported to enhance $\mathrm{Li}^{+}$-polymer interactions and $\mathrm{Li}^{+}$ ion transport because of the dominant $\mathrm{Li}^{+}$ion movement along the filler surface rather than through the polymer segment [61,62]. Since then, research on the incorporation of inorganic fillers into GPEs has rapidly expanded. In the 2000s, the effect of particle size of inorganic fillers in GPEs was extensively studied. Wang et al. prepared GPEs containing PVDF-HFP with a novel hierarchical mesoporous $\mathrm{SiO}_{2}$ network, which exhibited mechanical stability and higher ionic conductivity compared with $\mathrm{GPEs}$ without $\mathrm{SiO}_{2}$, or with fumed $\mathrm{SiO}_{2}$ [63]. Yang et al. synthesized $\mathrm{SiO}_{2}$ (m-SBA15) with enhanced ionic conductivity owing to the liquid electrolyte being trapped by the mesoporous structure and the large specific surface area of m-SBA15 [64]. In the 2010s, another effective method, surface modification, was proposed to improve the dispersion and affinity of inorganic fillers within organic compounds. A significant effort has been made to develop GPEs based on inorganic fillers, such as $\mathrm{BaTiO}_{3}$ [65], $\mathrm{Al}_{2} \mathrm{O}_{3}$ [66], $\mathrm{TiO}_{2}$ [67], $\mathrm{ZnS}$ [68], and $\mathrm{CeO}_{2}$ [69]. Figure 3 shows a historical overview of the development of inorganic fillers in GPEs. 


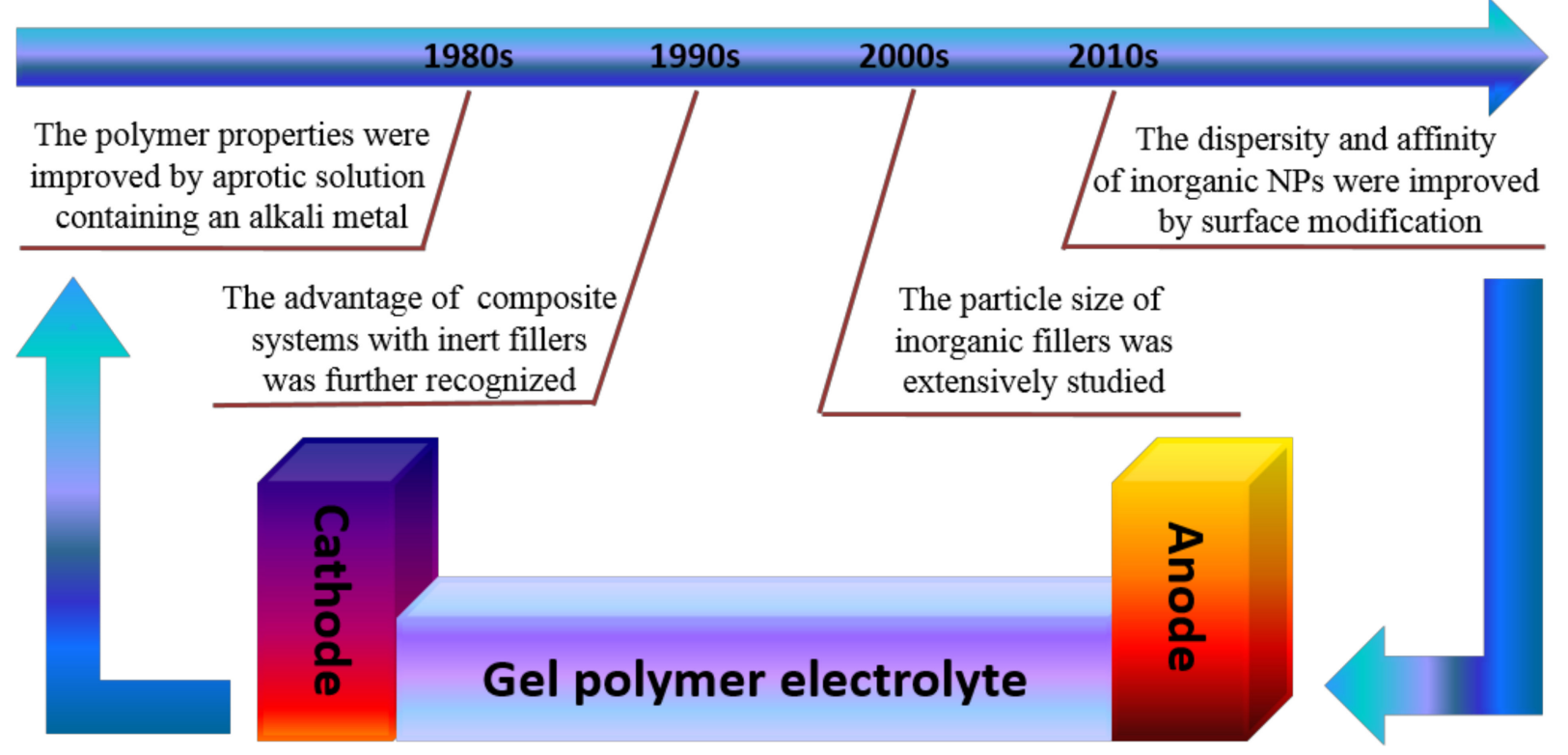

Figure 3. Historical overview of the developments of inorganic fillers in GPEs.

The implementation of GPEs in a variety of battery systems, including LIBs and Li-sulfur batteries, has been increasingly studied. The presence of plasticizers in GPEs increases $\mathrm{Li}^{+}$ion transfer; however, it simultaneously deteriorates the mechanical properties of the polymer matrix. Furthermore, electrode degradation may occur because of redox reactions between the plasticizer and electrodes. Consequently, to overcome the limitations of plasticizers, inorganic fillers have been proposed as additive materials to increase the electrolytic conductance and mechanical stability of GPEs. Osinska et al. [70] modified the surface of inorganic fillers to improve electrolyte absorption, thereby providing a more favorable medium for ion transport. A new ion transport pathway was discovered by Kumar et al. [71] by introducing spatially charged layers that tend to overlap with the concentrated filler grains dispersed in GPEs. The polymer chain containing active sites and surface groups of the inorganic fillers are affected by Lewis acid-base interactions. This interaction mostly occurs between the carbonyl groups of poly(acrylamide) (PAM) and surface groups of $\mathrm{Al}_{2} \mathrm{O}_{3}$, resulting in changes in the morphology of the GPEs [72].

\section{Details of the Inorganic Fillers Applied in GPEs}

The key functionalities of inorganic fillers in GPEs are to enhance $\mathrm{Li}^{+}$ion transfer and mechanical stability, wherein the polymer provides the conduction pathway for the ions, whereas the fillers influence the physical durability of the polymer to support ion transport. In addition, the inorganic filler particles can be used as a "solid plasticizer," which reduces the crystallinity of the host polymer and increases the transport properties. In this section, the addition of different types of inorganic fillers to enhance the mechanical properties and electrolytic conductance of GPEs is described in detail. Various inorganic fillers are listed according to research prevalence from the early 2000s to the present.

\subsection{Titanium Dioxide $\left(\mathrm{TiO}_{2}\right)$}

Chung et al. [73] investigated the effect of $\mathrm{TiO}_{2}$ nanoparticle (NP) addition in (PEO)$\mathrm{LiClO}_{4}$ for the improvement of electrochemical performance of GPEs. This study provided a model for the effects of inorganic fillers on the overall $\mathrm{Li}^{+}$ion transport in nanocomposite electrolytes. In addition, the specific role of inorganic filler was interpreted in terms of Lewis acid-base interactions. Over a wide temperature range, two structural modifications occurred at the ceramic surface. First, the morphology of the polymer was modified by the structural groups on the surface of the particles, which provided crosslinking opportunities for the PEO segments and X-anion. This resulted in a reduction in the energy 
barrier of the reorganized PEOs, where appropriate $\mathrm{Li}^{+}$ion-conducting pathways were established at the ceramic surface. Second, an "ion-ceramic complex" was formed through the dissociation of salt due to the interaction between polar groups on the surface of the fillers and ions of the electrolyte. These two structural variations can account for the improvement in the electrolytic conductance of inorganic fillers in GPEs. Liu et al. [67] reported that GPEs with a $\mathrm{TiO}_{2}$ ceramic filler exhibited higher $\mathrm{Li}^{+}$ion transfer numbers than GPEs without $\mathrm{TiO}_{2}$. The interaction between the fillers, anions, and polymer chains enhanced $\mathrm{Li}^{+}$ion transfer. Kim et al. [74] investigated the influence of filler content on the morphology of GPE membranes. As the $\mathrm{TiO}_{2}$ content increased, the surface of the membrane coarsened, and small aggregates appeared; however, the $\mathrm{TiO}_{2} \mathrm{NPs}$ remained well distributed over the entire surface area of the membrane with an increase in the content to $60 \mathrm{wt} \%$ (Figure 4). In addition, the ionic conductivity was enhanced owing to the nanopores in the liquid medium, as well as the effective ion transport achieved by the presence of $\mathrm{TiO}_{2}$. Therefore, the addition of rutile $\mathrm{TiO}_{2} \mathrm{NPs}$ not only enhanced the dispersion of the constituents but also improved the physical and electrochemical properties of the GPE. Karlsson et al. [75] studied polymer kinetics using quasi-elastic neutron scattering experiments to observe the effect of the filler on the crystallinity and structural changes in the polymer. The results showed that the improvement in ionic conductivity was because of the filler rather than the enhanced polymer dynamics based on the presence of a 5-nm-thick immobilized polymer layer around the filler particles. Kwak et al. [76] prepared a viscous $\mathrm{P}(\mathrm{EO}-\mathrm{EC}) / \mathrm{LiCF}_{3} \mathrm{SO}_{3} / \mathrm{TiO}_{2}$ polymer electrolyte mixture with a porous $\mathrm{P}(\mathrm{VdF}-\mathrm{HFP}) / \mathrm{P}(\mathrm{EO}-\mathrm{EC}) / \mathrm{TiO}_{2}$ membrane. The $\mathrm{TiO}_{2}$ content used was 0.0 , $0.5,1.0,1.5,2.0,5.0$, and $10.0 \mathrm{wt} \%$ in the polymer electrolyte and $0.0,10.0,20.0,30.0$, and $40.0 \mathrm{wt} \%$ in the porous membrane with a blend composition of $6: 4 \mathrm{P}(\mathrm{VdF}-\mathrm{HFP})$ to $\mathrm{P}(\mathrm{EO}-\mathrm{EC})$. The stress and tensile modulus values showed an increase for the membrane up to 2.0 and $41.0 \mathrm{MPa}$, respectively, using $30 \mathrm{wt} \% \mathrm{TiO}_{2}$, and a decrease up to 1.2 and $34.5 \mathrm{MPa}$, respectively, when adding $40 \mathrm{wt} \% \mathrm{TiO}_{2}$. These results indicated that the presence of high concentrations of $\mathrm{TiO}_{2}$ up to $20 \mathrm{wt} \%$ improved the mechanical properties of the membrane owing to the interaction between the NPs and the host polymer. In addition, an increase in ionic conductivity was observed up to $4.7 \times 10^{-2} \mathrm{mS} \mathrm{cm}^{-1}$ at $25^{\circ} \mathrm{C}$ for the GPEs containing $1.5 \mathrm{wt} \% \mathrm{TiO}_{2}$ owing to the interaction between the oxide groups of the polymer and hydroxyl groups of the $\mathrm{TiO}_{2}$ filler.

Hwang et al. [77] reported that the electrolytic conductance of GPEs was increased when reducing the particle size of the $\mathrm{TiO}_{2}$. The ionic conductivity of a GPE containing $\mathrm{TiO}_{2} \mathrm{NPs}$ was higher than that of a GPE without $\mathrm{TiO}_{2}$ at $30{ }^{\circ} \mathrm{C}$. Agnihotry et al. [78] examined the effects of different concentrations of nanosized $\mathrm{TiO}_{2}$ in a PMMA-based GPE. This study demonstrated that the ionic conductivity was enhanced when using an optimum $\mathrm{TiO}_{2}$ loading ( $\left.2 \mathrm{wt} \%\right)$ in the GPE. Byung et al. [79] synthesized a GPE by blending poly(acrylonitrile)-poly(ethylene glycol diacrylate) (PAN-PEGDA) with Li-salt and $\mathrm{TiO}_{2}$ NPs. The high surface area of inorganic fillers can improve the interfacial resistance and ionic conductivity of Li metal owing to an increase in chemical stability and possible retention of organic solvents in the micropores; this assists in the regulation of possible side reactions associated with $\mathrm{Li}$ metal. In addition, nanosized inorganic fillers were evenly dispersed and increased the mechanical stability of the polymer matrix. Walkowial et al. [80] and Kurc et al. [81,82] modified the surface of a new hybrid $\mathrm{TiO}_{2} / \mathrm{SiO}_{2}$ filler for GPEs. The original hybrid fillers were modified by grafting functional groups, such as methacryloxy or vinyl groups, on the surface of the fillers. The surface modification chemistry of the filler seemed to be another factor affecting the overall performance of the GPE in terms of solvent absorption, specific conductivity, and intercalation of lithium on graphite. As shown in the SEM images (Figure 5a), the hybrid $\mathrm{TiO}_{2} / \mathrm{SiO}_{2}$ spherical NPs are homogeneously dispersed. Figure $5 \mathrm{~b}$ shows that the hybrid $\mathrm{TiO}_{2}-\mathrm{SiO}_{2}$ predominantly contains rutile $\mathrm{TiO}_{2}$. Figure $5 \mathrm{c}$ indicates that the mean pore diameter of the $\mathrm{TiO}_{2}-\mathrm{SiO}_{2}$ hybrid is $3.8 \mathrm{~nm}$, which represents the mesoporous components, and the surface area is $12.5 \mathrm{~m}^{2} / \mathrm{g}$, which suggests an intermediate surface activity level. Hybrid $\mathrm{TiO}_{2} / \mathrm{SiO}_{2}$ 
powder with a moderate degree of surface functionalization was considered as a potential candidate for GPE applications in LIBs. The SEM image of the GPE without functionalized fillers typically exhibits a porous structure (Figure $5 d$ ).
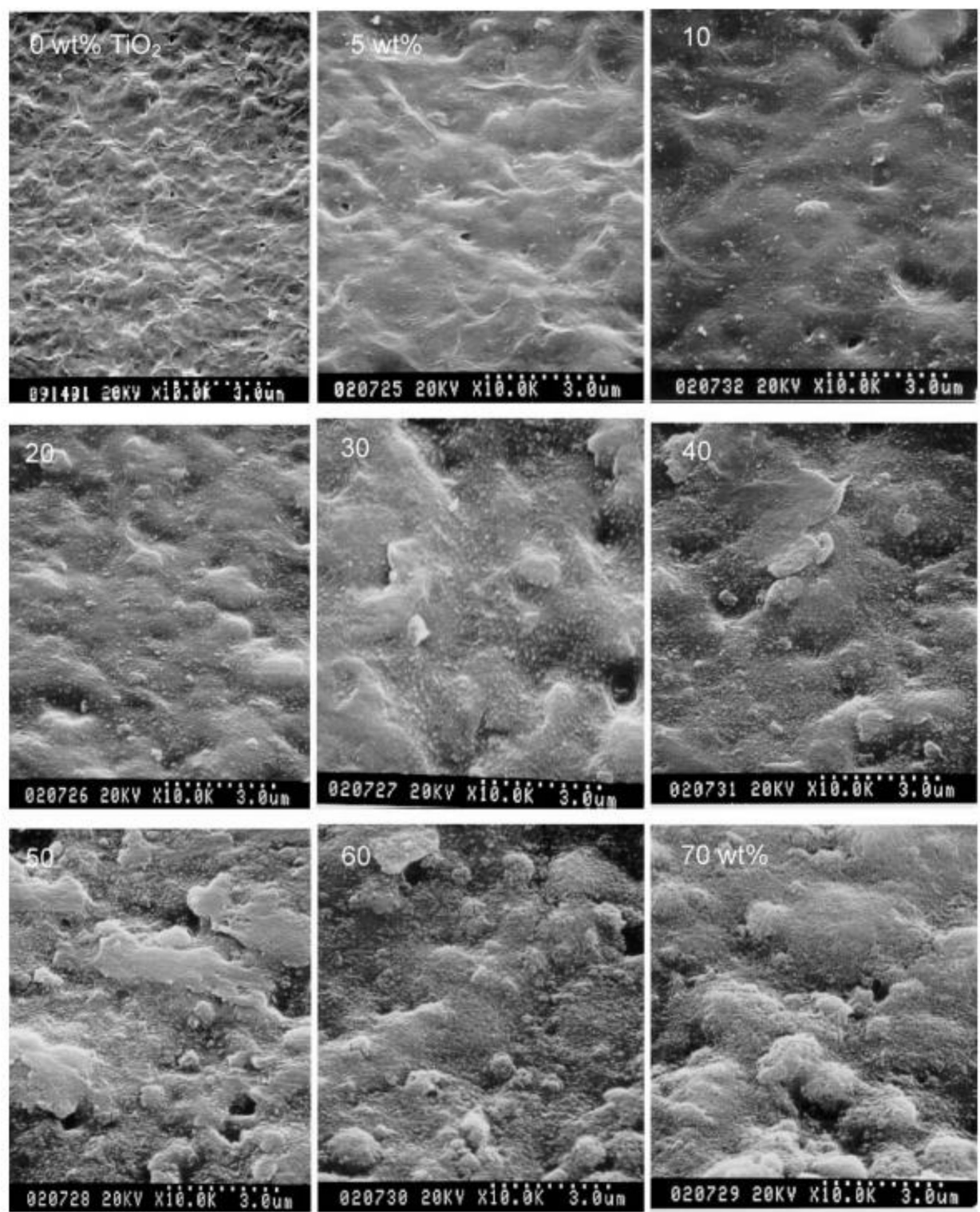

Figure 4. Surface morphology of P poly(vinylidene fluoride-co-hexafluoropropylene) (PVDF-HFP) with varying $\mathrm{TiO}_{2}$ (rutile) contents from the upper left to the lower right panel. Reprinted with permission from Kim et al. [74]. Copyright 2003 Elsevier B.V.

An experimental investigation by Yahya et al. was performed on proton-conducting GPE nanocomposites based on $\mathrm{TiO}_{2} \mathrm{NP}$-dispersed cellulose acetate (CA) [83]. The increase in the ionic conductivity of the GPE nanocomposite could be explained by the addition of $\mathrm{TiO}_{2}$, which increased the total solution/solvent dielectric constant. The dielectric constant of $\mathrm{TiO}_{2}$ was higher than that of $\mathrm{N}, \mathrm{N}$-dimethylformamide (DMF), leading to a reduced Coulombic interaction between the ion aggregates and dissociation of ions from the salt resulting in free $\mathrm{NH}_{4}{ }^{+}$ions. The GPE prepared by adding $\mathrm{NH}_{4} \mathrm{BF}_{4}$ and $\mathrm{TiO}_{2}$ to $\mathrm{CA}$ was considered a promising material for proton batteries. 

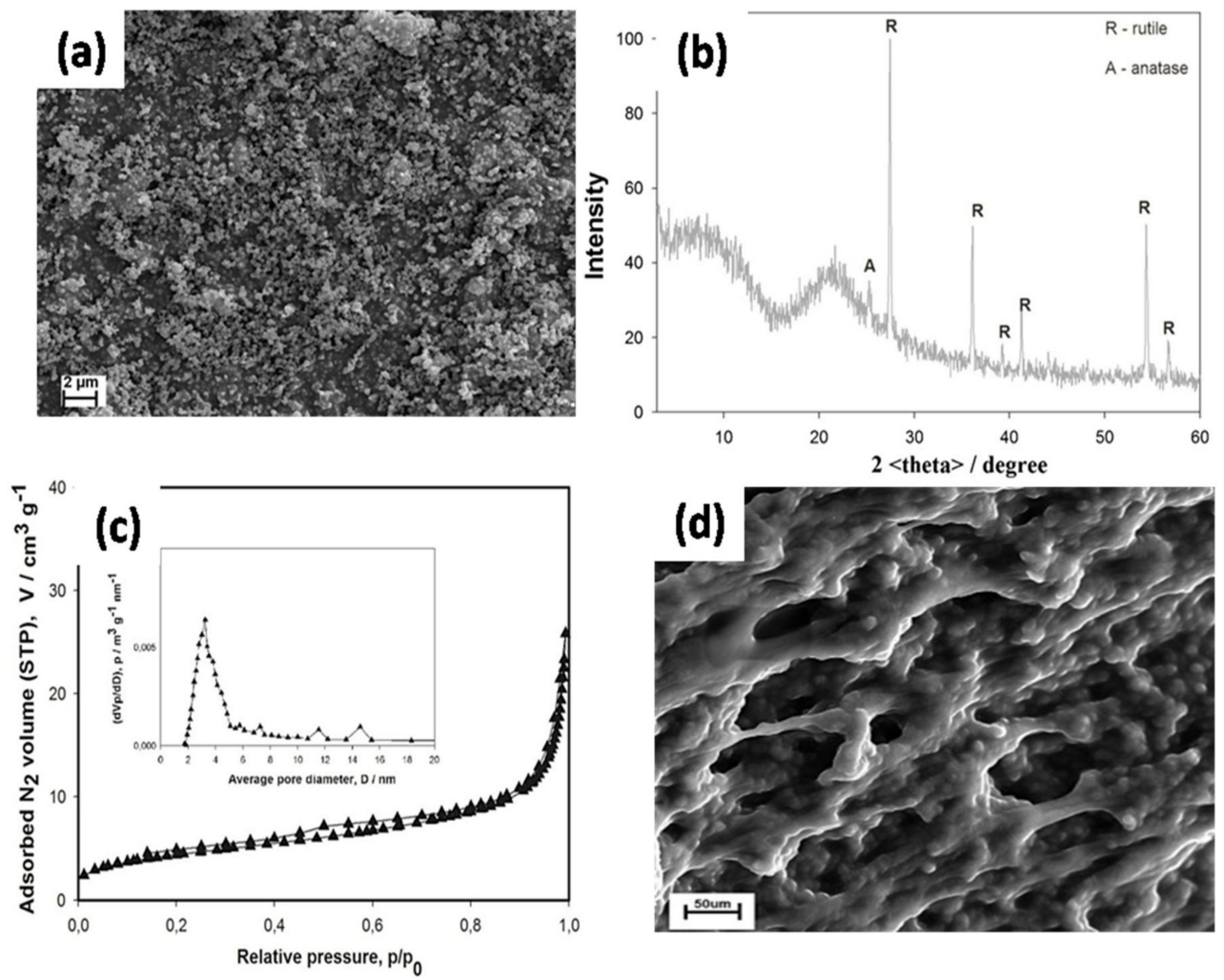

Figure 5. (a) SEM image of the $\mathrm{TiO}_{2}-\mathrm{SiO}_{2}$ hybrid composite, (b) wide angle X-ray spectroscopy of the $\mathrm{TiO}_{2}-\mathrm{SiO}_{2}$ hybrid composite, (c) nitrogen adsorption/desorption isotherm and pore size of the $\mathrm{TiO}_{2}-\mathrm{SiO}_{2}$ hybrid composite, and (d) SEM image of the surface of the membrane containing the $\mathrm{TiO}_{2}-\mathrm{SiO}_{2}$ hybrid composite. Reprinted with permission from Kurc et al. [81]. Copyright 2014 Elsevier Ltd.

Cao et al. [84] demonstrated improvement in the GPE by incorporating $\mathrm{TiO}_{2}$ in PVDF/PMMA via electrospinning for practical applications in LIBs. The GPE containing $3 \mathrm{wt} \% \mathrm{TiO}_{2}$ showed a highest electrolytic conductance of $3.9 \times 10^{-1} \mathrm{mS} \mathrm{cm}^{-1}$ with an electrochemical stability up to $5.1 \mathrm{~V}$ vs. $\mathrm{Li}^{+} / \mathrm{Li}$ at room temperature. The increase in electrolytic conductance with the addition of $\mathrm{TiO}_{2}$ particles was due to better dispersion through a Lewis acid-base interaction between the polar groups of the electrolytes and the filler and a decrease in the crystallinity of the polymer. Hong Chen et al. [85] investigated the role of nano- $\mathrm{TiO}_{2}$ dispersibility in a GPE based on a PVDF-HFP polymer for LIBs (schematic is shown in Figure 6a). Figure 6b shows the dispersion of the nanoparticles (pristine, commercial, and modified $\mathrm{TiO}_{2}$ ) in DMF. The morphology of nano- $\mathrm{TiO}_{2}-\mathrm{PMMA}$ doped PVDF-HFP membrane exhibits a smoother surface with fewer pores compared to the pristine PVDF-HFP membrane and nano- $\mathrm{TiO}_{2}$ doped PVDF-HFP membrane. Interestingly, the highly dispersed $\mathrm{TiO}_{2}-\mathrm{PMMA}$ hybrid membrane has a rougher surface, and the pore size is more uniform (Figure $6 \mathrm{c}$ ). The effect of $\mathrm{TiO}_{2}$ dispersion on the $\mathrm{C}$-rate discharge performance is shown in Figure 6d. The addition of nanosized $\mathrm{TiO}_{2}$ to the PVDF-HFP-based GPE significantly improved the discharge capacity of the cells. In addition, the highly dispersed nano- $\mathrm{TiO}_{2}-\mathrm{PMMA}$ doped GPE showed the highest discharge capacity compared to the other electrolytes. This study demonstrated that the dispersion of nanosized $\mathrm{TiO}_{2}$ is an important factor that influences the performance of the PVDF-HFPbased polymer electrolyte. Sankaranarayanan et al. [86] explained the effect of $\mathrm{TiO}_{2}$ on the electrochemical performance based on the distribution and aggregation of the fillers, Lewis acid-base interactions, and polymer segment-ion coupling. The addition of $\mathrm{TiO}_{2}$ to the GPE nanocomposite promoted Lewis acid-base interactions, thereby facilitating the dissolution of $\mathrm{LiClO}_{4}$ salts and increasing the amount of free $\mathrm{Li}^{+}$ions. Bozkurt et al. [87] produced polymer electrolyte nanocomposites based on borate ester graft copolymer PVA, poly(ethylene glycol) methyl ether (PEGME)), nano- $\mathrm{TiO}_{2}$, and trifluoromethane sulfonate $\left(\mathrm{CF}_{3} \mathrm{SO}_{3} \mathrm{Li}\right)$. The conduction pathway for ion transport was improved by the 
boron-containing PVA backbone and flexible side chains. This study suggested that the presence of inorganic fillers resulted in an increase in ionic conductivity, $\mathrm{Li}^{+}$ion transfer, interfacial stability between the electrode and electrolyte, and the mechanical strength of the GPEs. Chen et al. [88] showed that after adding $\mathrm{TiO}_{2} \mathrm{NPs}$, the PVDF-HFP/PMMA/ $/ \mathrm{TiO}_{2}$ membrane exhibited enhanced thermal stability and electrolytic conductance. Based on the images of the GPE membrane, its thermal stability was significantly improved after the addition of $\mathrm{TiO}_{2} \mathrm{NPs}$ (Figure $7 \mathrm{a}, \mathrm{b}$ ). In particular, the GPE containing $5 \mathrm{wt} \% \mathrm{TiO}_{2} \mathrm{NPs}$ showed homogeneously interconnected pores which resulted in an excellent performance (Figure 7c,d). The EIS analysis of GPE containing varying concentrations of $\mathrm{TiO}_{2}$, shown in Figure $7 c$, shows that after the introduction of $\mathrm{TiO}_{2}$, the bulk resistance $\left(\mathrm{R}_{\mathrm{b}}\right)$ of the GPEs significantly decreases for the sample containing the lowest $\mathrm{TiO}_{2}$ content of $5 \mathrm{wt} \%$. The initial discharge capacities were $143.6,180.5,188.1$, and $163.6 \mathrm{mAh} \mathrm{g}^{-1}$ for the different $\mathrm{TiO}_{2}$ contents $(0,2,5$, and $7 \mathrm{wt} \%)$, respectively. After 50 cycles, the capacity decreased to $114,154.3$, 173.2 , and $139.9 \mathrm{mAh} \mathrm{g}^{-1}$, with a capacity retention of $79.4 \%, 85.5 \%, 92.1 \%$, and $85.5 \%$, respectively (Figure 7d). This study showed that the incorporation of $\mathrm{TiO}_{2} \mathrm{NPs}$ to the GPE improved its electrochemical stability and ionic conductivity in LIBs. Yamolenko et al. [89] extended this study on the effect of NPs to a polyester-diacrylate (PEDAC)-based network polymer electrolyte. The mechanical strength of the GPE was enhanced after improving the distribution of the NPs in the polymer electrolyte by ultrasonic treatment compared to simple mechanical stirring.

(a)

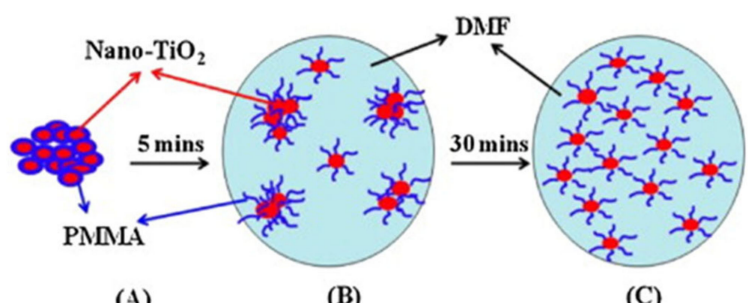

(A) (b)

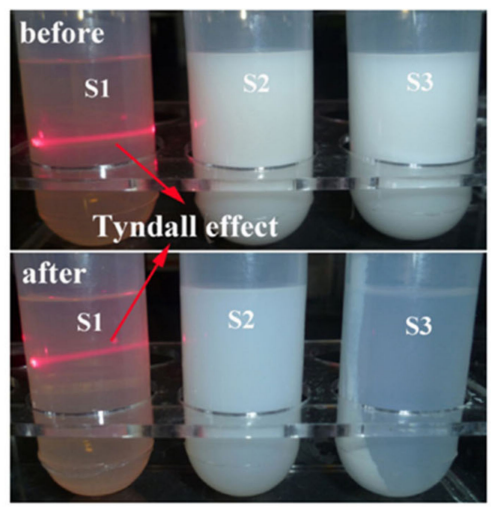

(c)
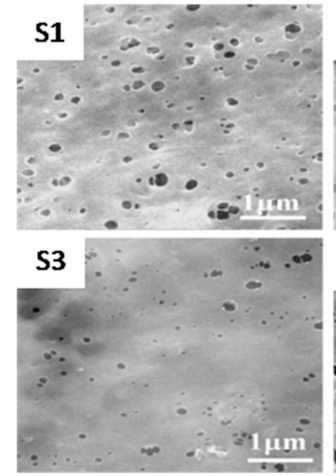

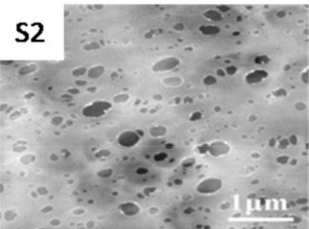

S4

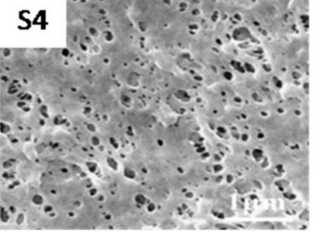

(d)

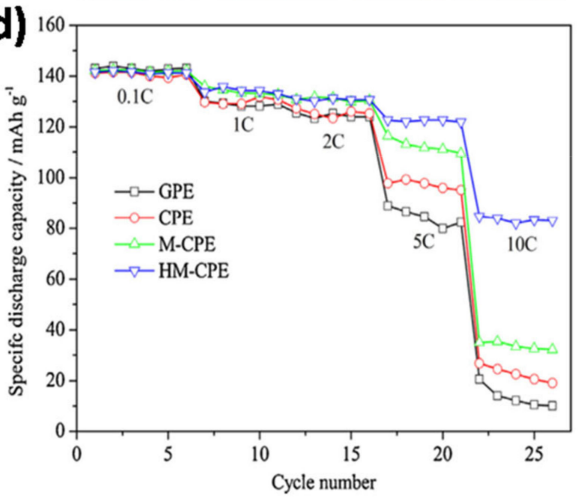

Figure 6. (a) Schematic of nano- $\mathrm{TiO}_{2}$ - poly(methyl methacrylate) (PMMA) in N,N-dimethylformamide (DMF) (A: mixture of nano- $\mathrm{TiO}_{2}$ and PMMA, B: tethered PMMA on Nano-TiO, C: self-assembly of PMMA-tethered Nano-TiO ${ }_{2}$ ) and (b) photographs of the dispersed NPs in DMF before (top panel) and after (bottom panel) 10 min centrifugation at 10,000 rpm. The same $\mathrm{TiO}_{2}$ content $\left(5 \mathrm{wt} \%\right.$ ) was used in each sample: (S1) highly dispersed nano- $\mathrm{TiO}_{2}-\mathrm{PMMA}$, (S2) nano- $\mathrm{TiO} 2-\mathrm{PMMA}$, and (S3) pristine nano-TiO 2. (c) SEM images of the GPEs: (S1) pristine PVDF-HFP ("GPE"), (S2) nano-TiO 2 /PVDF-HFP ("CPE"), (S3) nano- $\mathrm{TiO}_{2}-\mathrm{PMMA} / \mathrm{PVDF}-\mathrm{HFP}$ ("M-CPE"), and (S4) highly dispersed nano- $\mathrm{TiO}_{2}-\mathrm{PMMA} / \mathrm{PVDF}-\mathrm{HFP}$ ("HM-CPE"). (d) The rate capabilities of the different electrolytes shown in (c). Reprinted with permission from Chen et al. [85]. Copyright 2013 Elsevier Ltd. 

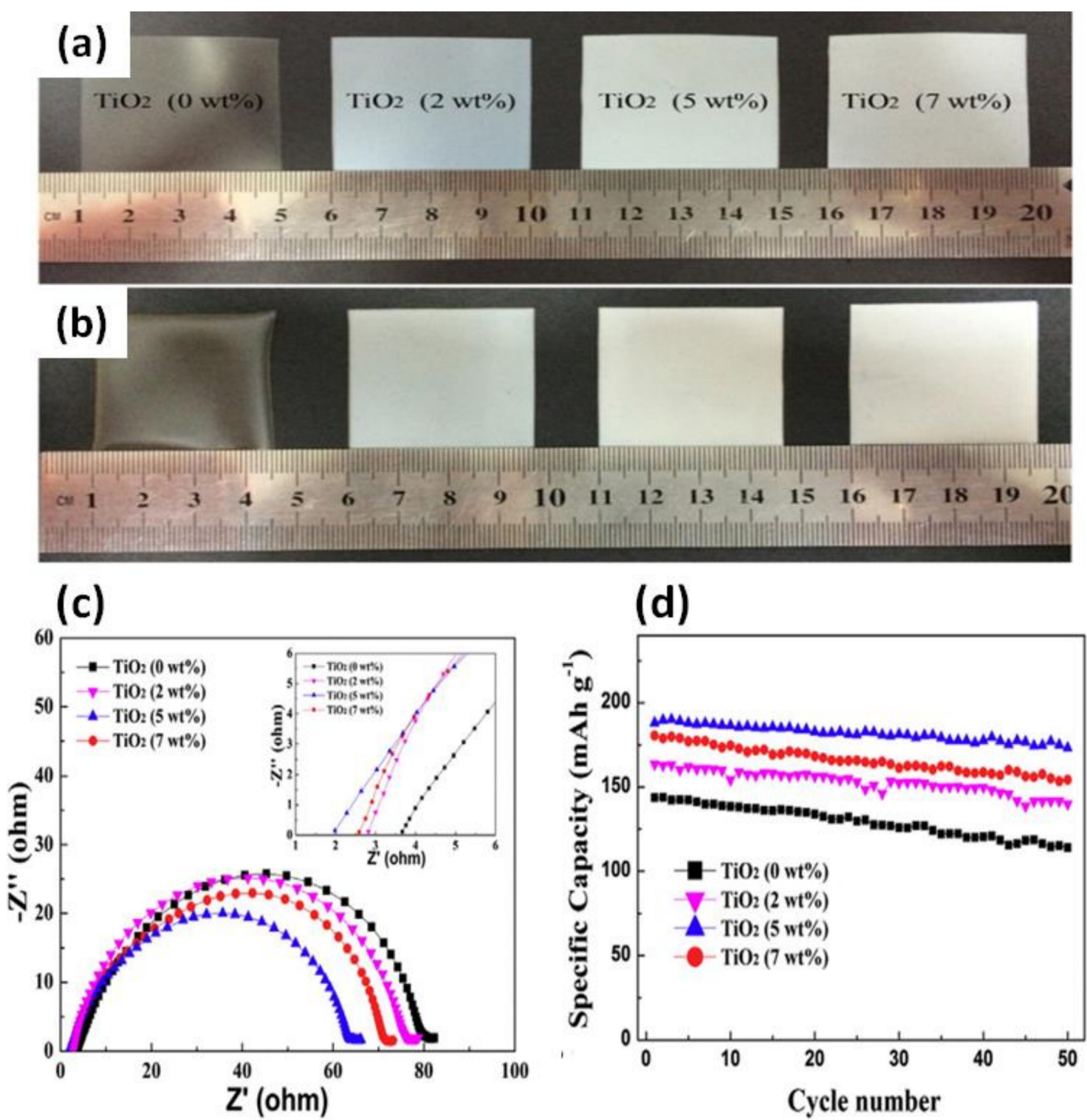

Figure 7. Thermal behavior of the GPE membranes (a) before and (b) after storing at $130{ }^{\circ} \mathrm{C}$ for $1 \mathrm{~h}$, (c) EIS results of the GPE membrane containing varying contents of $\mathrm{TiO}_{2}$, and (d) cyclic performance of the $\mathrm{LiCoO}_{2} / \mathrm{Li}$ cells using the GPE at 0.2 C. Reprinted with permission from Chen et al. [88]. Copyright 2015 Elsevier B.V.

Teng et al. [90] reported a GPE prepared by combining poly(acrylonitrile-co-vinyl acetate) (PAV) with PMMA and $\mathrm{TiO}_{2}$ NPs, i.e., $\mathrm{PAVM}_{\mathrm{TiO}}$ (Figure 8). This study introduced a new concept concerning the association of oxide NPs with the space-charge regimes around the polymer's functional groups to induce 3D conduction pathways for $\mathrm{Li}^{+}$ions in GPEs applied in LIBs (Figure 8a-c). Based on the impedance spectra shown in Figure 8d, the high-frequency semicircle represents the movement of charge carriers through the SEI layer, middle-frequency semicircle shows charge-transfer resistance, and sloping line is related to the Warburg impedance. The results revealed the superiority of GPE-PAVM:TiO in enhancing $\mathrm{Li}^{+}$ion transport. Figure 8e presents the discharge capacities of the full-cell batteries at a high rate of $20 \mathrm{C}$. The cell with the GPE-PAVM:TiO ${ }_{2}$ electrolyte delivered discharge capacities of 152 and $84 \mathrm{mAh} \mathrm{g}^{-1}$ at 0.1 and $20 \mathrm{C}$, respectively, thus outperforming the cell with the SLE electrolyte with capacities of 146 and $40 \mathrm{mAh} \mathrm{g}^{-1}$, respectively. The $\mathrm{Li}^{+}$ ion transport efficiency in the bulk solution as well as at the electrode-electrolyte interface was enhanced through the $3 \mathrm{D}$ percolation pathway by immobilizing the $\mathrm{PF}_{6}{ }^{-}$anions in the oxide NP framework. Sakunthala et al. performed a comparative study between single- 
crystalline $\mathrm{TiO}_{2}$ nanorods and submicronsized $\mathrm{TiO}_{2}$ fillers in PVDF-HFP/EC/LiClO 4 . The $\mathrm{Li}^{+}$ion transfer and tensile strength of the membrane containing $5 \mathrm{wt} \% \mathrm{TiO}_{2}$ nanorods were higher than those of the membrane containing $5 \mathrm{wt} \%$ submicronsized $\mathrm{TiO}_{2}$. This can be explained by the improved interaction of the rod-shaped morphology of the singlecrystalline $\mathrm{TiO}_{2}$ filler with the polymer/salt/plasticizer matrix in the GPE [91].
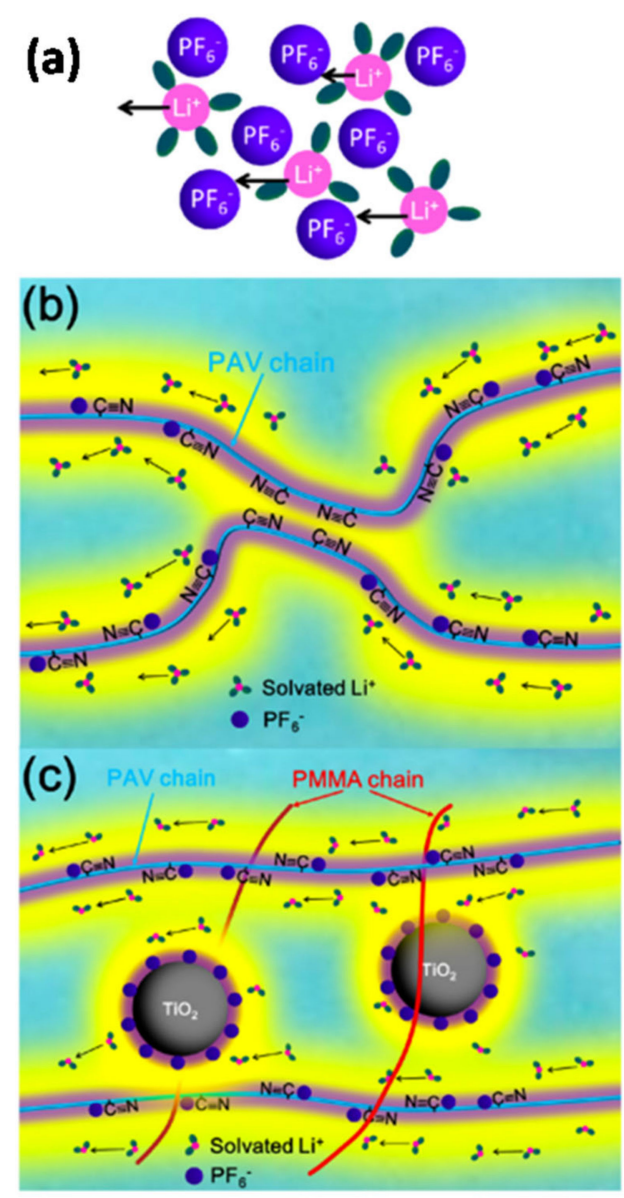
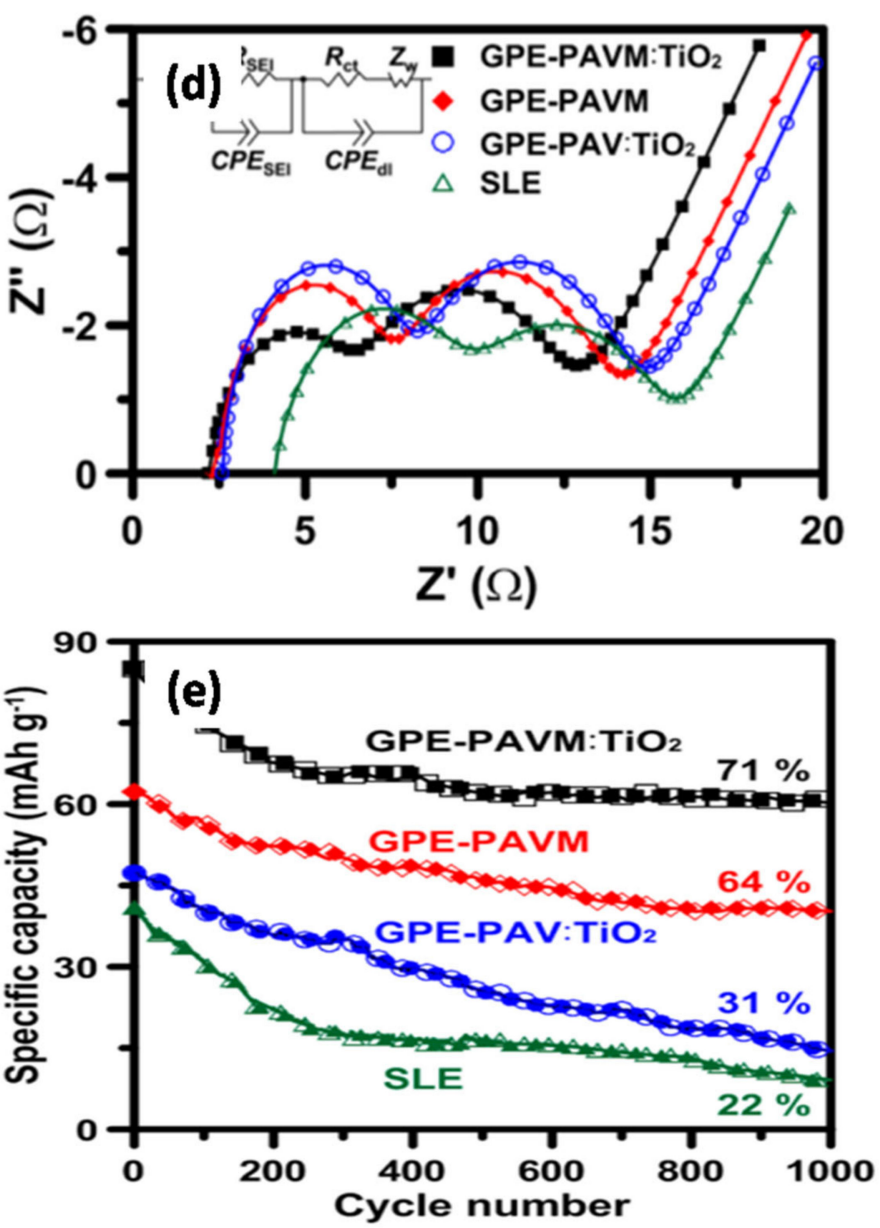

Figure 8. (a) Separator-supported LE (SLE): limitation in ionic dissociation. (b) GPE- poly(acrylonitrile-co-vinyl acetate) (PAV): a space-charge layer of $\mathrm{Li}^{+}$ions is formed due to the $\mathrm{PF}_{6}{ }^{-}$anion absorbed by the nitrile functional groups on the PAV chain. (c) GPE-PAVM: $\mathrm{TiO}_{2}$ : the 3D percolation pathway is formed by the space-charged layers surrounding the $\mathrm{TiO}_{2}$ NPs and PAV chain. (d) Nyquist plots of the full cell (graphite-GPE-LFP) and (e) discharge capacity of the full cell at a 20 C-rate over a voltage range of 2.0-3.8 V. Reprinted with permission from Teng et al. [90]. Copyright 2016 American Chemical Society.

Sivakumar et al. [92] fabricated a GPE containing a PVC-PEMA blend using hydrothermally derived $\mathrm{TiO}_{2}$ NPs as an inorganic filler. The influence of the filler NPs on the surface morphology, thermal stability, and electrochemical properties were studied. The addition of $\mathrm{TiO}_{2} \mathrm{NPs}$ reduced the crystallinity of the polymer and enhanced the $\mathrm{Li}^{+}$ion transport pathways. Similarly, Singh et al. [93] modified the structural properties of PEMA-based plasticized polymer electrolytes by incorporating $\mathrm{TiO}_{2} \mathrm{NPs}$. The addition of $\mathrm{TiO}_{2} \mathrm{NPs}_{\text {in }}$ the plasticized polymer electrolyte suppressed the crystallinity and enhanced the amorphous nature. Hence, the addition of $\mathrm{TiO}_{2} \mathrm{NPs}$ could be a novel approach to enhance the electrolytic conductance in GPEs. The ionic conductivity and temperatures of some significant GPEs containing $\mathrm{TiO}_{2}$ fillers are listed in Table 1. 
Table 1. List of GPEs with $\mathrm{TiO}_{2}$ filler with their conductivity and temperature.

\begin{tabular}{|c|c|c|c|c|c|}
\hline Polymer & Salt/Plasticizers & Solvent & Conductivity $\left(\mathrm{mS} \mathrm{cm}^{-1}\right)$ & Temperature $\left({ }^{\circ} \mathrm{C}\right)$ & Reference \\
\hline PEO & $\mathrm{LiClO}_{4}$ & $\mathrm{ACN}$ & - & 90 & [73] \\
\hline PEO & $\mathrm{LiBF}_{4}$ & $\mathrm{ACN}$ & $7 \times 10^{-4}$ & 30 & [67] \\
\hline PVDF-HFP & $\mathrm{LiPF}_{6}-\mathrm{EC} / \mathrm{DMC}$ & Acetone & $10^{0}$ & 25 & [74] \\
\hline PEG & $\mathrm{LiClO}_{4}$ & Dicloro-methane & - & 120 & [75] \\
\hline $\mathrm{P}(\mathrm{VdF}-\mathrm{HFP}) / \mathrm{P}(\mathrm{EO}-\mathrm{EC})$ & $\mathrm{LiCF}_{3} \mathrm{SO}_{3}$ & Acetone & $4.7 \times 10^{0}$ & 25 & [76] \\
\hline PEO & $\mathrm{LiClO}_{4}$ & THF & $1.03 \times 10^{-2}$ & 30 & [77] \\
\hline $\mathrm{P}(\mathrm{VdF}-\mathrm{HFP}) / \mathrm{P}(\mathrm{EO}-\mathrm{EC})$ & $\mathrm{LiCF}_{3} \mathrm{SO}_{3}$ & Acetone & $5.1 \times 10^{-2}$ & 25 & {$[78]$} \\
\hline PAN/PEGDA & $\begin{array}{c}\mathrm{LiPF}_{6} / \mathrm{LiCF}_{3} \mathrm{SO}_{3}- \\
\mathrm{EC} / \mathrm{DMC}\end{array}$ & - & $3.8 \times 10^{0}$ & 30 & [79] \\
\hline PVDF-HFP & $\mathrm{LiPF}_{6}-\mathrm{EC} / \mathrm{DMC}$ & Acetone + DBP & $8.5 \times 10^{-1}$ & 25 & [80] \\
\hline PAN & $\mathrm{LiPF}_{6}-\mathrm{TMS}$ & DMF & $9.8 \times 10^{-1}$ & 25 & [81] \\
\hline Cellulose acetate (CA) & $\mathrm{NH}_{4} \mathrm{BF}_{4}$ & DMF & $1.37 \times 10^{1}$ & 30 & [83] \\
\hline PVDF/PMMA & $\mathrm{LiClO}_{4}-\mathrm{EC} / \mathrm{PC}$ & $\mathrm{DMF}+$ acetone & $3.9 \times 10^{0}$ & 30 & {$[84]$} \\
\hline PEO-PVC & $\mathrm{LiClO}_{4}$ & Cyclohexanone & $8.33 \times 10^{-4}$ & - & [86] \\
\hline PVA/PEGME & $\mathrm{LiCF}_{3} \mathrm{SO}_{3}$ & DMSO & $1.58 \times 10^{-1}$ & 30 & [87] \\
\hline PVDF-HFP/PMMA & $\mathrm{LiPF}_{6}-\mathrm{EC} / \mathrm{DMC}$ & $\mathrm{DMF}+$ Acetone & $2.49 \times 10^{0}$ & 30 & [88] \\
\hline Polyester diacrylate & $\mathrm{LiClO}_{4}-\mathrm{EC}$ & Benzoyl peroxide & $1.8 \times 10^{0}$ & 20 & [89] \\
\hline PAN/PVA & $\mathrm{LiPF}_{6}-\mathrm{EC} / \mathrm{DMC} / \mathrm{DEC}$ & Dimethylacet-amide & $4.5 \times 10^{0}$ & 30 & [90] \\
\hline PVDF-HFP & $\mathrm{LiClO}_{4}-\mathrm{EC}$ & Acetone & $1.11 \times 10^{1}$ & 30 & [91] \\
\hline PVC/PEMA & $\mathrm{LiClO}_{4}-\mathrm{EC} / \mathrm{DMC}$ & THF & $0.5 \times 10^{1}$ & 30 & [92] \\
\hline PEMA & NaI-EC & THF & $2.42 \times 10^{-1}$ & 30 & [93] \\
\hline
\end{tabular}

\subsection{Aluminum Oxide $\left(\mathrm{Al}_{2} \mathrm{O}_{3}\right)$}

Li et al. [94] prepared a GPE by combining porous P(VDF-co-HFP) with alumina $\left(\mathrm{Al}_{2} \mathrm{O}_{3}\right)$ NPs as the filler. An increase in the $\mathrm{Al}_{2} \mathrm{O}_{3} \mathrm{NP}$ content reduced the level of crystallization in the polymer, thereby increasing the amorphous phase of the membrane. Piotrowska et al. [95] described the effect of oxide fillers on the properties of GPEs with a PVDF-HFP polymer matrix. Modification of the PVDF-HFP membranes with $\mathrm{Al}_{2} \mathrm{O}_{3} \mathrm{NPs}$ led to a decrease in the liquid phase uptake ability owing to the reduction of accessible pore spaces. Egshira et al. [96] assessed the availability of the alumina filler in an imidazoliumbased gel electrolyte. The $\mathrm{Al}_{2} \mathrm{O}_{3}$ filler enhanced $\mathrm{Li}^{+}$ion mobility by providing alternative pathways for $\mathrm{Li}^{+}$ion movement and changing the interaction between the $\mathrm{Li}^{+}$ions and the EO chain. Rai et al. [97] prepared nano- $\mathrm{Al}_{2} \mathrm{O}_{3}$-filled PVA composite gel electrolytes. As shown in Figure 9a, the PVA membrane exhibits a porous structure, while the addition of $2 \mathrm{wt} \% \mathrm{Al}_{2} \mathrm{O}_{3} \mathrm{NPs}$ reduces the porosity of the PVA composite electrolyte as the $\mathrm{Al}_{2} \mathrm{O}_{3}$ NPs are trapped among the chains in the pores (Figure $9 \mathrm{~b}$ ). Upon the addition of $6 \mathrm{wt} \%$ $\mathrm{Al}_{2} \mathrm{O}_{3}$ NPs (Figure 9c), the PVA chains are fully covered with $\mathrm{Al}_{2} \mathrm{O}_{3}$ NPs. This indicates complete dispersion of the $\mathrm{Al}_{2} \mathrm{O}_{3}$ nanofiller in the electrolyte film. Upon further addition of $\mathrm{Al}_{2} \mathrm{O}_{3} \mathrm{NPs}(10 \mathrm{wt} \%$ ), the grain sizes and shapes become irregular resulting in a partially crystalline structure containing $\mathrm{Al}_{2} \mathrm{O}_{3}$ NPs and PVA electrolyte (Figure 9d). An increase in the $\mathrm{Al}_{2} \mathrm{O}_{3} \mathrm{NP}$ content increased the amorphous phase of pristine PVA. The $\mathrm{Li}^{+}$ion transfer capacity of the GPE reached its maximum with the addition of $6 \mathrm{wt} \% \mathrm{Al}_{2} \mathrm{O}_{3} \mathrm{NPs}$.

A novel GPE was prepared by combining a poly(methyl methacrylate-acrylonitrileethyl acrylate) (P(MMA-AN-EA)-based polymer electrolyte with nano-SiO 2 and $\mathrm{Al}_{2} \mathrm{O}_{3}$ as inorganic fillers [98]. The maximum electrolytic conductance of the GPE was achieved when $5 \mathrm{wt} \%$ nano- $\mathrm{SiO}_{2}$ and nano- $\mathrm{Al}_{2} \mathrm{O}_{3}$ were used. This study showed the different roles of the inorganic fillers: $\mathrm{SiO}_{2}$ contributed to the enhanced ion conduction due to strong Lewis acid-base interactions, whereas $\mathrm{Al}_{2} \mathrm{O}_{3}$ improved the structural and thermal stability of the GPE owing to its high stiffness. Wen et al. [99] synthesized a novel GPE with a trilayer structure consisting of polyvinyl formal (PVFM)-4,4-diphenyl-methane diisocyanate (MDI) covered by a PVA- $\mathrm{Al}_{2} \mathrm{O}_{3}$ solution on both sides to achieve synergistic effects for each layer (Figure 10a). The morphology of the $\mathrm{Al}_{2} \mathrm{O}_{3} / \mathrm{PVFM} / \mathrm{Al}_{2} \mathrm{O}_{3}$ trilayer membrane was determined by FESEM (Figure 10b-e). The thicknesses of the layers were 45.42, 54.27, and $65.77 \mu \mathrm{m}$, respectively (Figure 10b). The morphology of the PVFM membrane exhibits sponge-like pores, which are expected to enhance the transport of $\mathrm{Li}^{+}$ions (Figure 10c). The porous structure of the inorganic particulate films did in fact increase $\mathrm{Li}^{+}$ion transfer 
(Figure 10d). The surface morphology of the PVFM membrane shows evenly distributed pores, as shown in Figure 10e. This study indicated that the inorganic layers enhanced the thermal integrity and mechanical properties of the membrane. This multilayer polymer membrane could be a potential material for application in LIBs.
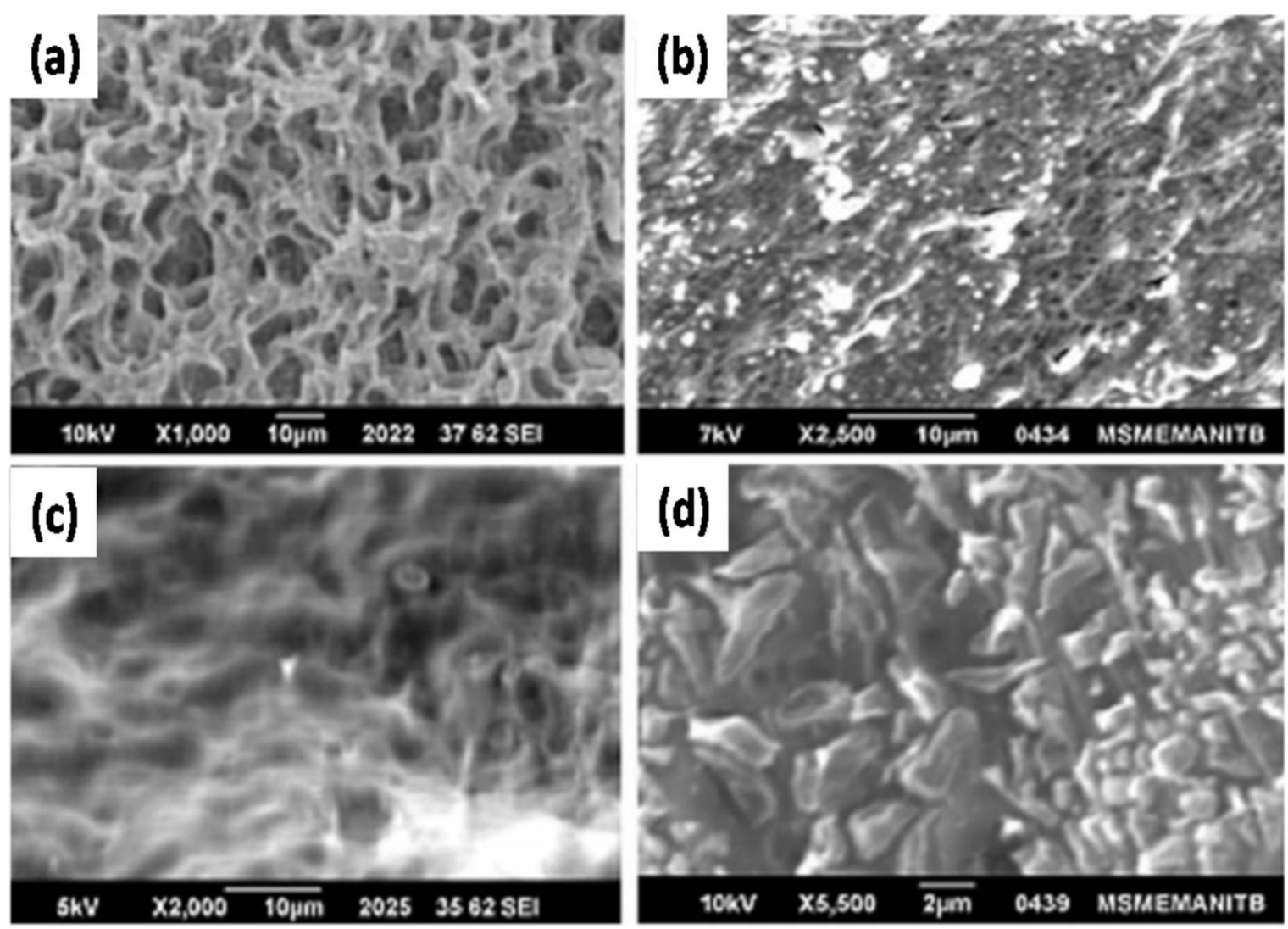

Figure 9. SEM images of the (a) PVA: $\mathrm{NH}_{4} \mathrm{SCN} / \mathrm{DMSO}$ GPE containing (b) 2, (c) 6, and (d) $10 \mathrm{wt} \% \mathrm{Al}_{2} \mathrm{O}_{3} \mathrm{NPs}_{\text {. }}$ Reprinted with permission from Rat et al. [97]. Copyright 2012 Indian Academy of Sciences.

Kim et al. [100] prepared a GPE containing a PVDF-HFP fibrous matrix with $\mathrm{Al}_{2} \mathrm{O}_{3}$ as the inorganic filler by electrospinning. The morphologies of polymer fibrous matrices exhibiting different diameters are shown in Figure 11a-d. The surface morphology of the pure polymer is rougher than that of the $\mathrm{Al}_{2} \mathrm{O}_{3}$-composite polymers and exhibits an average diameter of $2.3 \mu \mathrm{m}$ (Figure 11a,b) compared to $1.2 \mu \mathrm{m}$ for the $\mathrm{Al}_{2} \mathrm{O}_{3}$-composite polymer matrix (Figure 11c,d). The presence of inorganic fillers in the fibrous polymer matrices prevented polymer shrinkage and agglomeration, which was beneficial for the formation of homogeneous pores. Figure 11e shows that the discharge capacities of the NMC and LTO half cells of the GPE- $\mathrm{Al}_{2} \mathrm{O}_{3}$ composite are 189.6 and $166.3 \mathrm{mAh} \mathrm{g}^{-1}$, respectively, which are higher than those of the GPE without $\mathrm{Al}_{2} \mathrm{O}_{3}$ (168.2 and $146.8 \mathrm{mAh} \mathrm{g}^{-1}$, respectively). The presence of $\mathrm{Al}_{2} \mathrm{O}_{3}$ NPs increased the porosity and absorption of free ions, thereby enhancing the electrolytic conductance and electrochemical stability compared to a pure GPE. The $\mathrm{Al}_{2} \mathrm{O}_{3}$-composite GPE also showed a better discharge capacity retention of $\sim 96 \%$ (initial and final specific capacities of 166.3 and $160.2 \mathrm{mAh} \mathrm{g}^{-1}$, respectively) (Figure 11f). Jain et al. [101] presented efficient conduction pathways constructed in PVdF-based GPEs with $\mathrm{Al}_{2} \mathrm{O}_{3}$ and boron nitride (BN) ceramic nano/microparticles. The high dielectric constants of $\mathrm{Al}_{2} \mathrm{O}_{3}$ and $\mathrm{BN}$ facilitated anion capture in the GPE and the transfer of $\mathrm{Li}^{+}$ without coordination to the anions. 

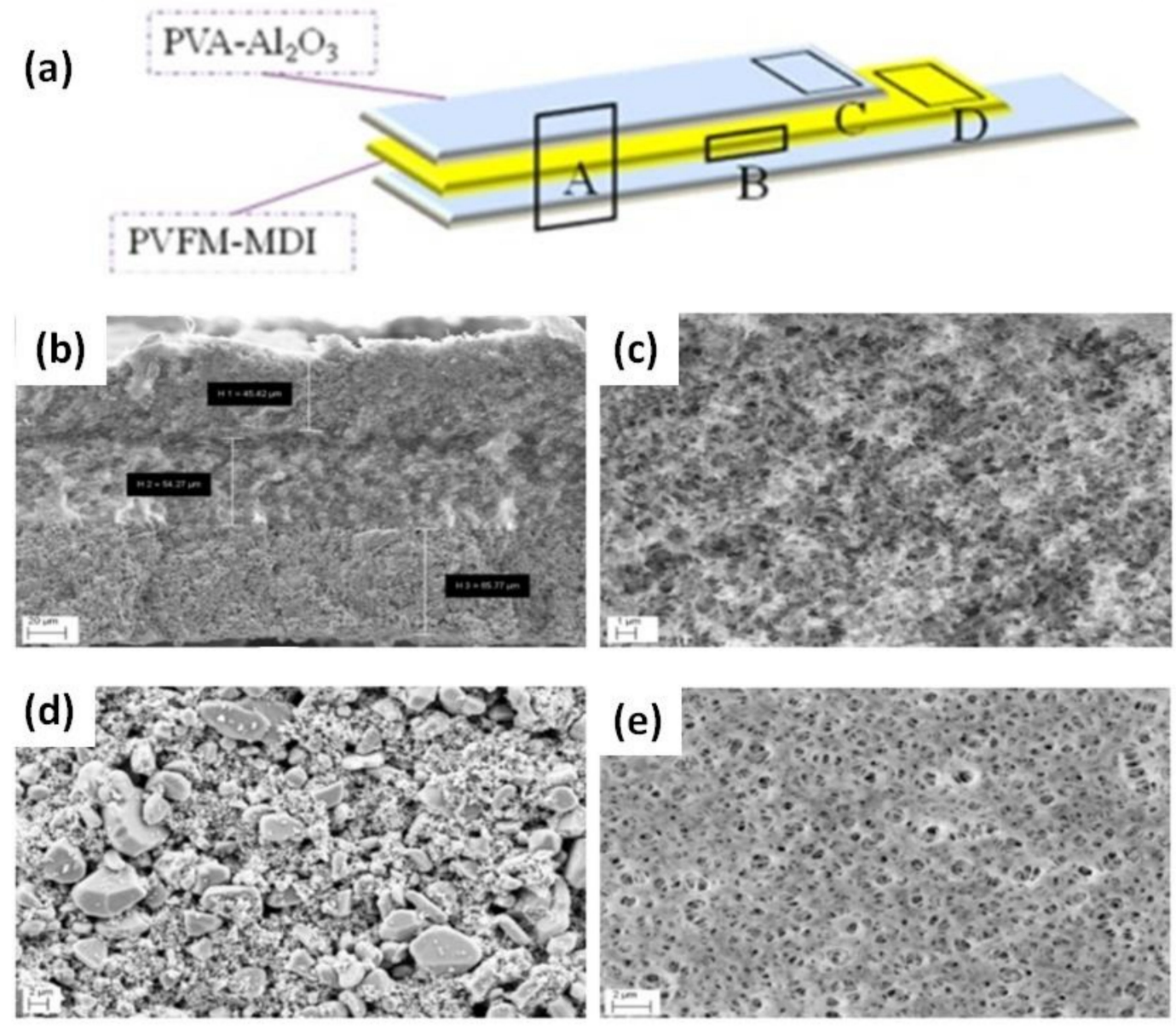

Figure 10. (a) Schematic of the membrane $\left(\mathrm{Al}_{2} \mathrm{O}_{3} / \mathrm{PVFM} / \mathrm{Al}_{2} \mathrm{O}_{3}\right)$. SEM images of the trilayer membrane; (b) cross-sectional image of the trilayer membrane; (c) cross-sectional image of the PVFM membrane; (d) the surface morphology of the $\mathrm{Al}_{2} \mathrm{O}_{3}$ coating layer; and (e) the surface morphology of the PVFM-based membrane. Reprinted with permission from Wen et al. [99]. Copyright 2007 Scientific Research Publishing Inc.
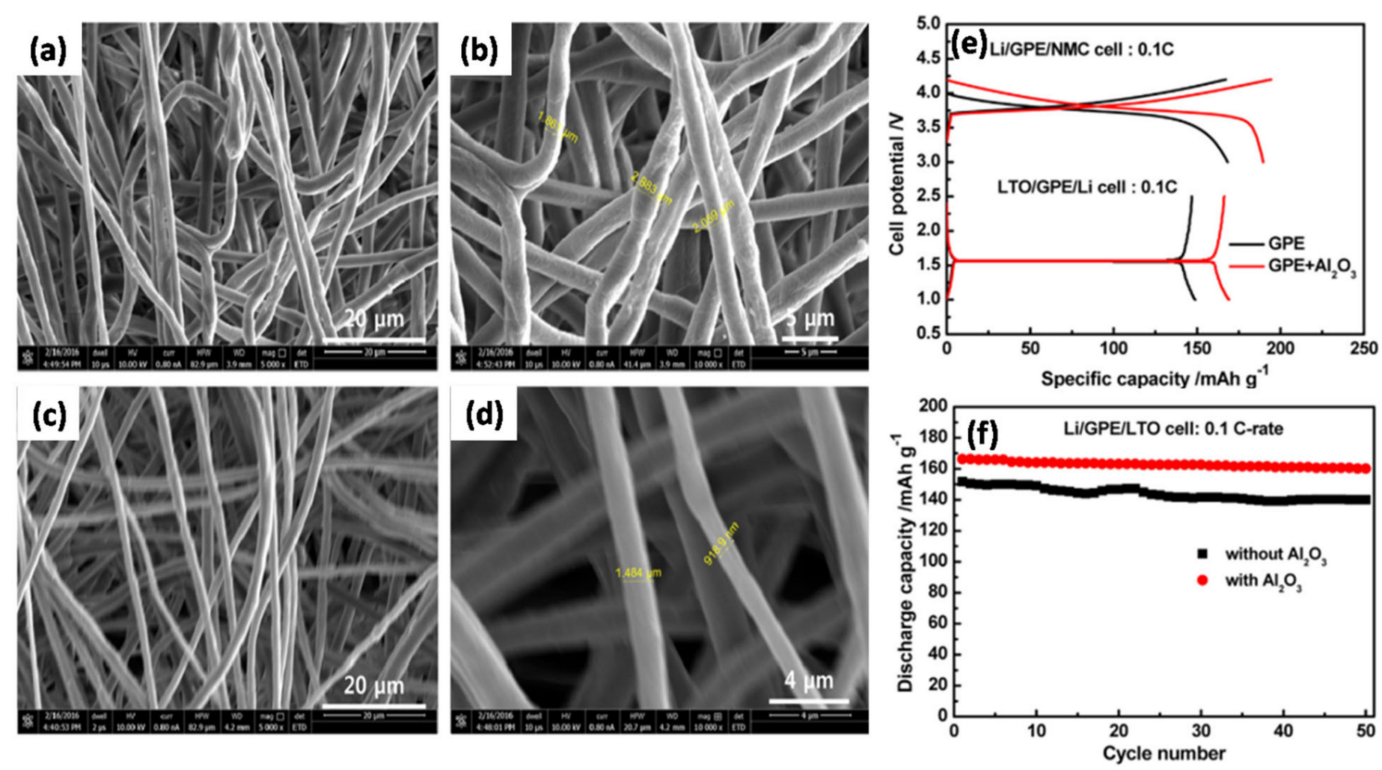

Figure 11. Morphology of (a,b) pristine GPE and (c,d) $\mathrm{Al}_{2} \mathrm{O}_{3}-\mathrm{GPE}$ membrane. (e) Initial charge-discharge curves of the $\mathrm{Li}_{4} \mathrm{Ti}_{5} \mathrm{O}_{12}$ (LTO) and $\mathrm{LiNi}_{1 / 3} \mathrm{Mn}_{1 / 3} \mathrm{Co}_{1 / 3} \mathrm{O}_{2}$ (NMC) half cells and (f) the cyclic performance of the GPE membrane. Reprinted with permission from Kim et al. [100]. Copyright 2017 Elsevier Ltd. 
Delgado-Rosero et al. [102] synthesized a GPE containing PEO and sodium trifluoroacetate $\left(\mathrm{CF}_{3} \mathrm{COONa}\right)$ with different contents of $\mathrm{Al}_{2} \mathrm{O}_{3}$. The addition of inorganic fillers increased the amorphous phase portion surrounding the filler of the $(\mathrm{PEO})_{10} \mathrm{CF}_{3} \mathrm{COONa}+$ $\mathrm{x} w \mathrm{t} \% \mathrm{Al}_{2} \mathrm{O}_{3}$ composite, thereby improving $\mathrm{Na}^{+}$ion transport through the pathways of the amorphous phase. Maragani et al. [103] reported a GPE containing a combination of PAN and sodium fluoride (NaF) with $\mathrm{Al}_{2} \mathrm{O}_{3}$ nanofibers formed through a solution casting technique. With an increase in the $\mathrm{Al}_{2} \mathrm{O}_{3}$ nanofiber content, the amorphous phase of the GPE increased, resulting in an improvement in ion conduction. Yang et al. [104] designed a novel GPE with uniformly cross-linked $\beta-\mathrm{Al}_{2} \mathrm{O}_{3}$ nanowires that compactly covered a $\mathrm{P}(\mathrm{VDF}-\mathrm{co}-\mathrm{HFP})$-GPE through strong molecular interactions (Figure 12a-c). In this innovative structure, the LEs were immobilized through bonding between the cross-linked $\mathrm{Al}_{2} \mathrm{O}_{3}$ nanowires and PVDF-HFP (ANs-GPE), thereby creating uniform and continuous $\mathrm{Na}^{+}$ion transport channels along the $\mathrm{Al}_{2} \mathrm{O}_{3}$ nanowires (Figure 12a-c). This innovative structure can significantly improve the density and homogeneity of the $\mathrm{Na}^{+}$ion transport channel, resulting in superior electrochemical performance (Figure 12d-f). Mishra et al. [105] studied the effect of $\mathrm{Al}_{2} \mathrm{O}_{3} \mathrm{NP}$ dispersion on a PVdF-HFP/PMMA blend-based nanocomposite GPE system. The electrolytic conductance changed significantly depending on the $\mathrm{Al}_{2} \mathrm{O}_{3}$ concentration in the PVdF-HFP/PMMA membrane. The maximum electrolytic conductance achieved was $\sim 1.5 \times 10^{0} \mathrm{mS} \mathrm{cm}^{-1}$ when $6 \mathrm{wt} \% \mathrm{Al}_{2} \mathrm{O}_{3} \mathrm{NPs}$ were added to the GPE. The ionic conductivities and temperatures of the GPEs containing $\mathrm{Al}_{2} \mathrm{O}_{3}$ fillers are summarized in Table 2.
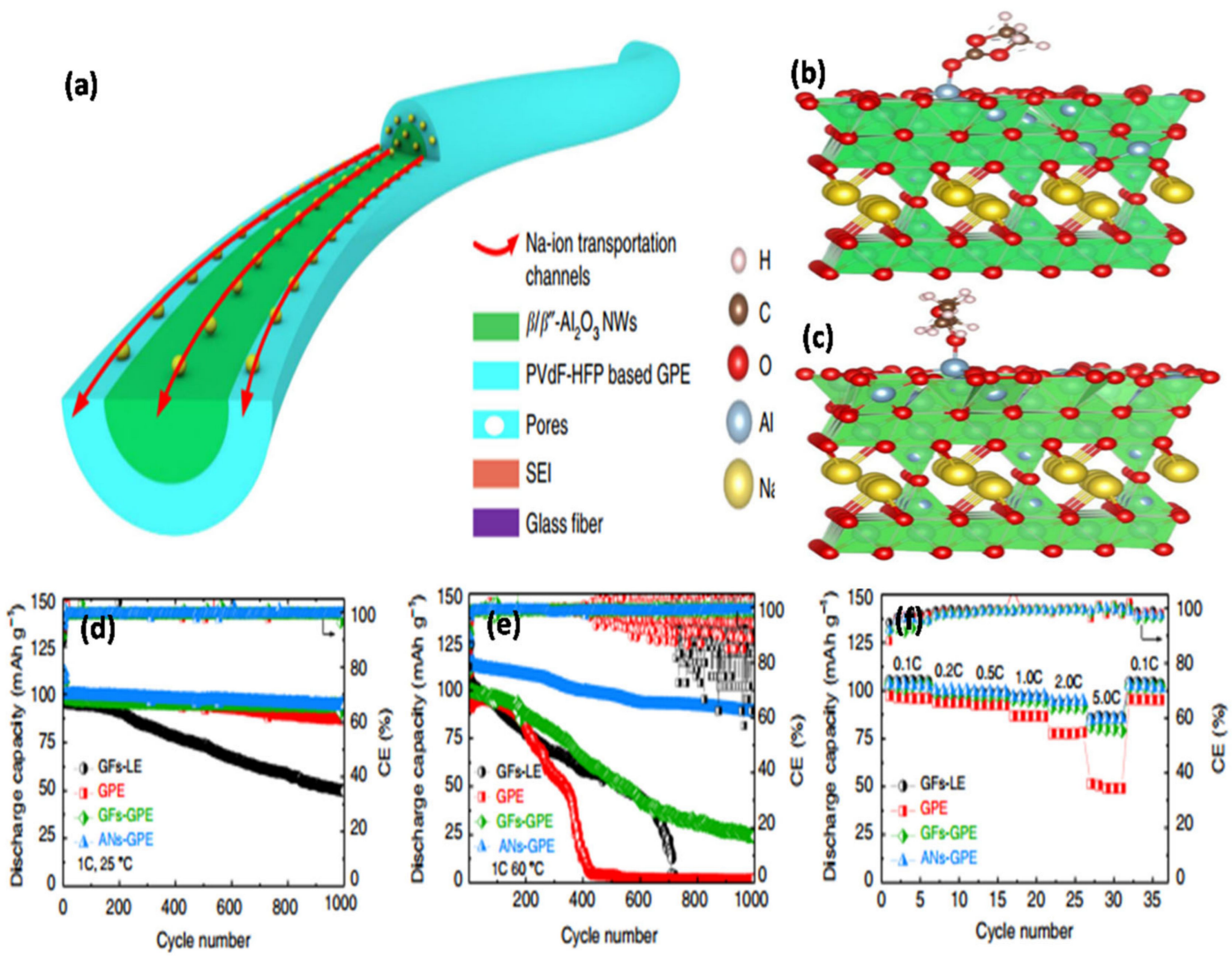

Figure 12. (a) Schematic of Na-ion transportation in the $\mathrm{Al}_{2} \mathrm{O}_{3}$ nanowire (AN)-GPE. (b,c) Adsorption of ethylene carbonate (EC) and diethylene carbonate (DEC) on the $\beta-\mathrm{Al}_{2} \mathrm{O}_{3}(003)$. (d,e) Cyclic performance of the $\mathrm{Na}_{3} \mathrm{~V}_{2}\left(\mathrm{PO}_{4}\right)_{3}(\mathrm{NVP}) / \mathrm{Na}$ cells using a glass fiber (GF)-LE, GPE, GFs-GPE, and ANs-GPE at $1 \mathrm{C}$ under 25 and $60^{\circ} \mathrm{C}$, respectively. (f) Rate performance of the NVP/Na cells using the different GPEs. Reprinted with permission from Yang et al. [104]. Copyright 2019 Springer Nature. 
Table 2. List of GPEs with $\mathrm{Al}_{2} \mathrm{O}_{3}$ filler with their conductivity and temperature.

\begin{tabular}{|c|c|c|c|c|c|}
\hline Polymer & Salt/Plasticizers & Solvent & Conductivity $\left(\mathrm{mS} \mathrm{cm}^{-1}\right)$ & Temperature $\left({ }^{\circ} \mathrm{C}\right)$ & Reference \\
\hline PVDF-HFP & $\mathrm{LiPF}_{6}-\mathrm{EC} / \mathrm{DMC}$ DBP & NMP & $1.95 \times 10^{-0}$ & 25 & [94] \\
\hline PVDF-HFP & $\mathrm{LiPF}_{6}-\mathrm{PC} / \mathrm{DBP}$ & Acetone & - & $20-70$ & [95] \\
\hline PEO/PMA & LiTFSI-EC/EMITFSI & - & $10^{-1}$ & 25 & [96] \\
\hline PVA & $\mathrm{NH}_{4} \mathrm{SCN}$ & DMSO & $5.81 \times 10^{1}$ & 30 & [97] \\
\hline P(MMA-AN-EA) & $\mathrm{LiPF}_{6}-\mathrm{EC} / \mathrm{DMC}$ & DMF & $2.2 \times 10^{0}$ & 30 & [98] \\
\hline PVFM & $\mathrm{LiPF}_{6}-\mathrm{EC} / \mathrm{DMC}$ & NMP & $4.13 \times 10^{-1}$ & 25 & [99] \\
\hline PVDF-HFP & $\mathrm{LiPF}_{6}-\mathrm{EC} / \mathrm{DMC}$ & Acetone-NMP & $4.1 \times 10^{0}$ & 25 & [100] \\
\hline PVDF & $\mathrm{LiPF}_{6}-\mathrm{EC} / \mathrm{PC}$ & NMP & - & - & [101] \\
\hline $\mathrm{PEO}$ & $\mathrm{CF}_{3} \mathrm{COONa}$ & $\mathrm{ACN}$ & - & - & \\
\hline PAN & NaF-EC & DMF & $4.82 \times 10^{0}$ & 30 & [103] \\
\hline PVDF-HFP & $\mathrm{NaClO}_{4}-\mathrm{EC} / \mathrm{DEC}$ & Acetone + ethanol & $7.13 \times 10^{-1}$ & 25 & [104] \\
\hline PVdF-HFP/PMMA & $\mathrm{NaCF}_{3} \mathrm{SO}_{3}-\mathrm{EC} / \mathrm{PC}$ & $\mathrm{THF}+$ Acetone & $1.5 \times 10^{0}$ & 25 & [105] \\
\hline
\end{tabular}

\subsection{Silicon Dioxide $\left(\mathrm{SiO}_{2}\right)$}

Wieczorek et al. [106] designed a novel model GPE using a combination of amorphous poly(ethylene oxide) dimethyl ether (PEODME) and $\mathrm{LiClO}_{4}$ with fumed nano-silica. The presence of nanosized fumed silica in the GPE was promising because of the reduction in ion association. Wu et al. [107] prepared a hybrid polymer electrolyte film consisting of PMMA, $\mathrm{LiClO}_{4}$, propylene carbonate (PC), and $\mathrm{SiO}_{2}$ filler using a solvent casting technique. The conductivity was not positively correlated with the increased concentration of $\mathrm{SiO}_{2}$ owing to the aggregation of $\mathrm{SiO}_{2}$, which led to the formation of crystal-like particles on the surface of the membrane. Kim et al. [108] reported novel homogeneous spherical core-shell structured $\mathrm{SiO}_{2}\left(\mathrm{Li}^{+}\right) \mathrm{NP}$ fillers that were applied as functional fillers in GPEs (Figure 13). $\mathrm{SiO}_{2}\left(\mathrm{Li}^{+}\right)$was synthesized by dispersing $\mathrm{Li}^{+}$ions in the core-shell structure of the $\mathrm{SiO}_{2}$ particles (Figure 13a). Figure 13b shows the charge-discharge curves of the GPE containing $20 \mathrm{wt} \% \mathrm{SiO}_{2}\left(\mathrm{Li}^{+}\right)$. The first discharge capacity with $\mathrm{LiCoO}_{2}$ in the cathode was $153 \mathrm{mAh} \mathrm{g}^{-1}$. The GPEs containing the novel filler exhibited unique $\mathrm{Li}^{+}$ion transport and mechanical strength. Consequently, the battery exhibited low internal resistance, high capacity, and a stable cyclic performance. In addition, the capacity retention was enhanced by increasing the $\mathrm{SiO}_{2}\left(\mathrm{Li}^{+}\right)$content in the GPEs up to $20 \mathrm{wt} \%$ (Figure 13c). The addition of $\mathrm{SiO}_{2}\left(\mathrm{Li}^{+}\right)$particles resulted in the retention of more LEs in the GPE, thereby improving the electrochemical performance during cycling.

Li et al. [109] obtained similar results and proposed that the addition of $\mathrm{SiO}_{2}\left(\mathrm{Li}^{+}\right)$ increases the amorphous phase and porosity of the polymer film, thus improving the adsorption and gelation of the LE. From the surface morphology of the membranes, as shown in Figure 14, it was established that as the content of $\mathrm{SiO}_{2}\left(\mathrm{Li}^{+}\right)$increases, the pore size of the film also increases, resulting in a high uptake of liquid electrolyte. The electrolytic conductance of the GPE was improved because of the large number of $\mathrm{Li}^{+}$ions in $\mathrm{SiO}_{2}\left(\mathrm{Li}^{+}\right)$. However, the GPE became very fragile when the $\mathrm{SiO}_{2}\left(\mathrm{Li}^{+}\right)$content reached $10 \mathrm{wt} \%$. Manisankar et al. [110] synthesized superhydrophobic $\mathrm{PVDF}-\mathrm{SiO}_{2}$ films with different $\mathrm{SiO}_{2}$ contents by electrospinning. When the $\mathrm{SiO}_{2}$ content increased, the surface roughness of the membrane also increased, but the average diameter of the nanofibers was not affected. Kim et al. [111] synthesized a secure and flexible electrolyte through the combination of mesoporous $\mathrm{SiO}_{2} \mathrm{NPs}$ containing methacrylate groups and fibrous PAN membrane (Figure 15a,b). The initial discharge capacity delivered was $157.9 \mathrm{mAh} \mathrm{g}^{-1}$ after 300 cycles with a capacity retention of $88.0 \%$. In addition, the GPE containing the mesoporous $\mathrm{SiO}_{2}$ particles exhibits better $\mathrm{Li}^{+}$ion transfer than the GPE containing non-porous $\mathrm{SiO}_{2}$ particles (Figure $15 c, d$ ). This study emphasized the role of $\mathrm{SiO}_{2}$ mesoporous NPs compared with non-porous $\mathrm{SiO}_{2} \mathrm{NPs}$ when attempting to achieve good electrochemical properties in terms of discharge capacity, capacity retention, rate capability, and cycling stability. GPEs containing a combination of $\mathrm{PEO} / \mathrm{LiClO}_{4}$ complex and 1,3 dioxolane (DIOX)/tetraethyleneglycol dimethylether (TEGDME) as plasticizer with a $\mathrm{SiO}_{2}$ filler has also been synthesized [112]. An increase in $\mathrm{SiO}_{2}$ filler content and plasticizer reduced the degree of crystallization of the polymer membrane, thus increasing the ionic conductivity. 

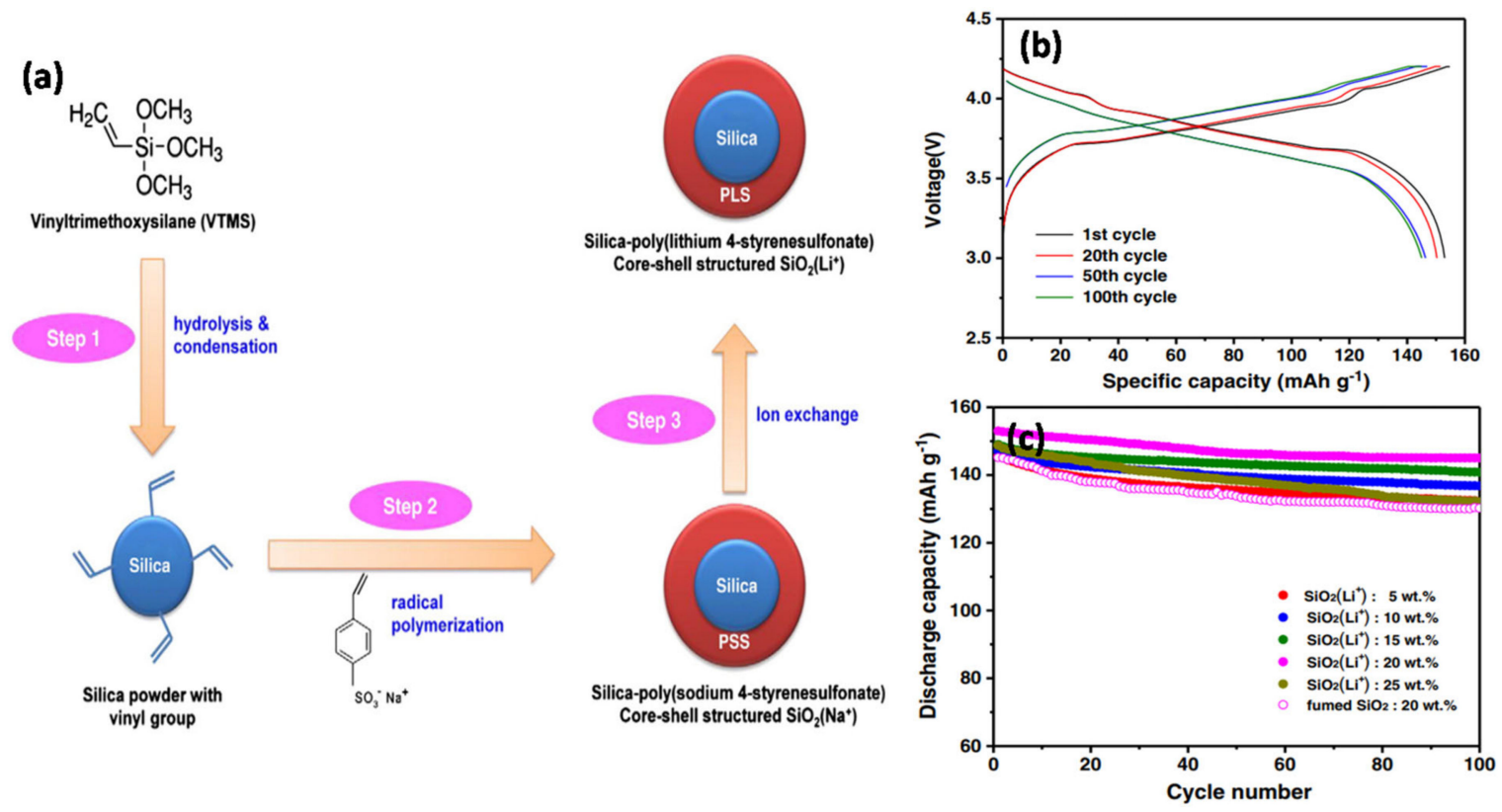

Figure 13. (a) Reaction scheme for the synthesis of the $\mathrm{SiO}_{2}\left(\mathrm{Li}^{+}\right)$particles. (b) Charge-discharge curves of the GPE containing 20 wt. $\% \mathrm{SiO}_{2}\left(\mathrm{Li}^{+}\right)$particles. (c) Discharge capacities of the GPE containing different contents of $\mathrm{SiO}_{2}\left(\mathrm{Li}^{+}\right)$particles. Reprinted with permission from Kim et al. [108]. Copyright 2012 Elsevier B.V.
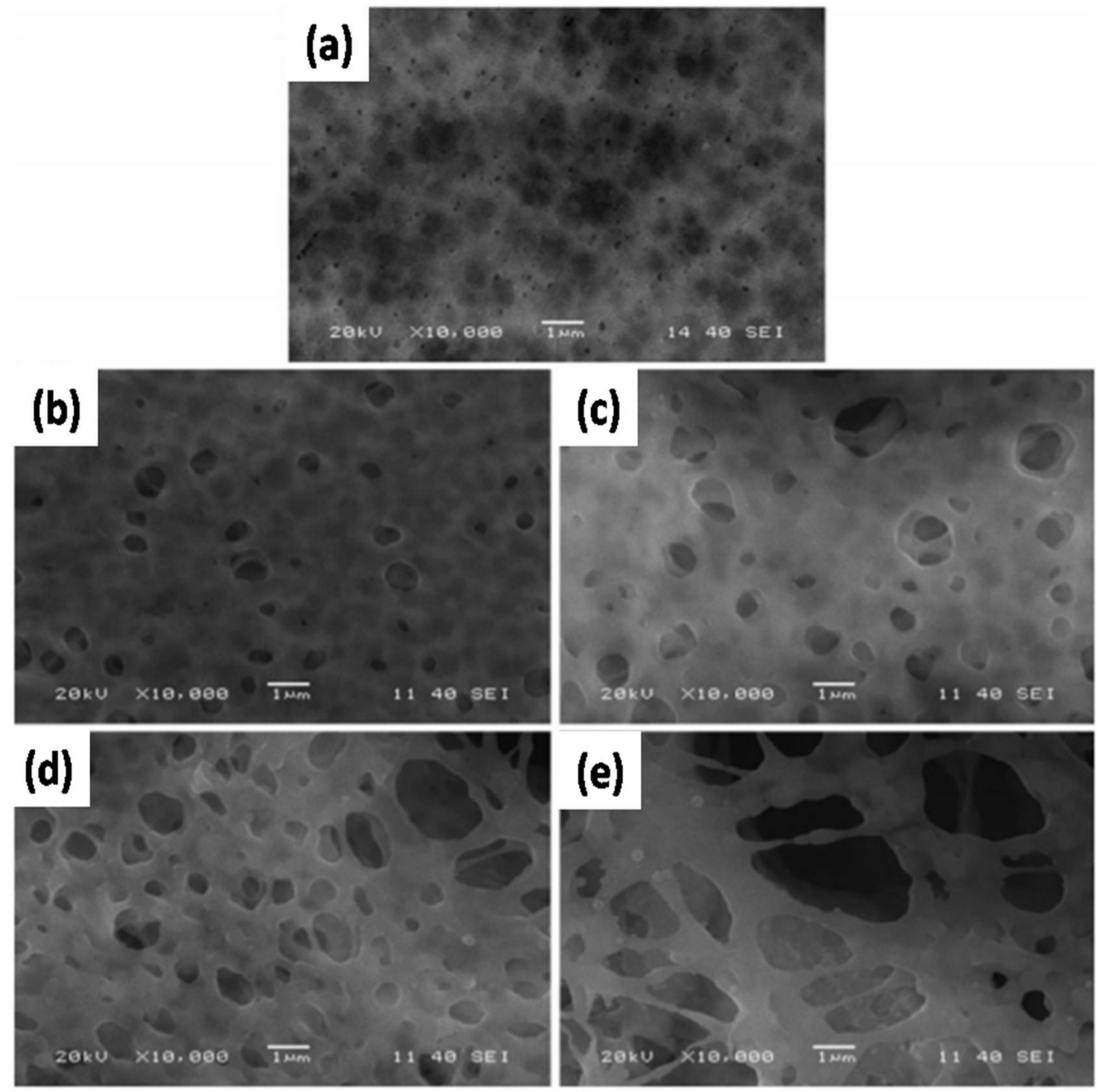

Figure 14. SEM images of the GPE membrane: (a) pristine PVDF, (b) PVDF-1\% SiO $2\left(\mathrm{Li}^{+}\right),(\mathbf{c}) \mathrm{PVDF}-2 \% \mathrm{SiO}_{2}\left(\mathrm{Li}^{+}\right),(\mathbf{d}) \mathrm{PVDF}-5 \%$ $\mathrm{SiO}_{2}\left(\mathrm{Li}^{+}\right)$, and (e) PVDF-10\% $\mathrm{SiO}_{2}\left(\mathrm{Li}^{+}\right)$. Reprinted with permission from Li et al. [109]. Copyright 2013 Springer Nature. 

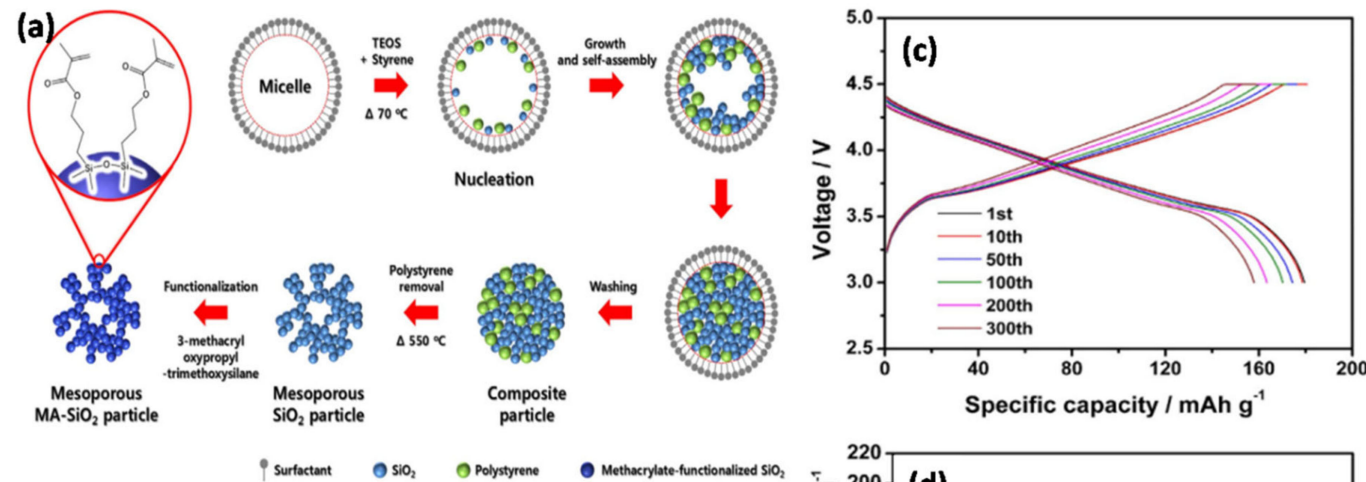

(b)
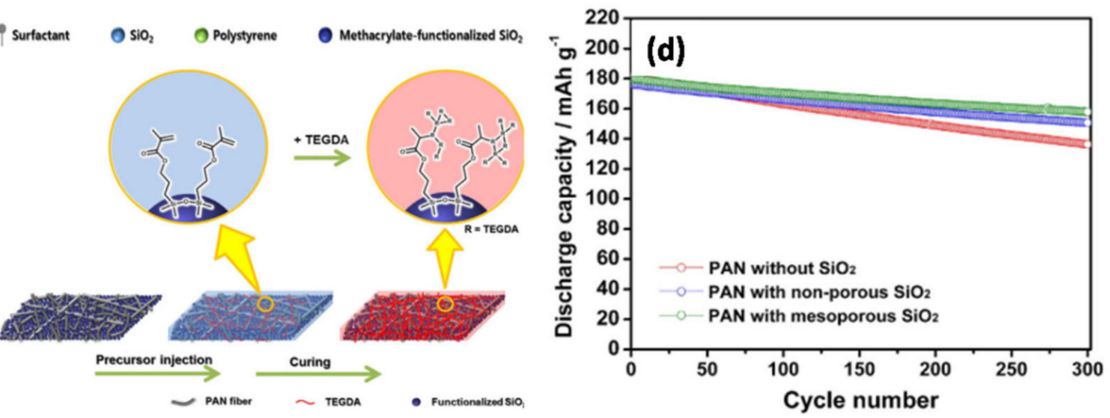

Figure 15. Reaction schemes for the synthesis of (a) mesoporous $\mathrm{MA}-\mathrm{SiO}_{2}$ particles and (b) cross-linked composite GPE. (c) Charge-discharge curves of the cell and (d) cyclic performance with different electrolytes at $25^{\circ} \mathrm{C}$. Reprinted with permission from Kim et al. [111]. Copyright 2016 Springer Nature.

Wu et al. [22] studied the influence of $\mathrm{SiO}_{2} \mathrm{NP}$ content on PVdF-HFP/IL membranes in terms of their ion conduction and discharge capacity in LIBs. The crystallization phase of the membrane was reduced due to the dispersion of $\mathrm{SiO}_{2} \mathrm{NPs}$, which hindered the structural stability of the polymer but improved ion transport because of their interaction with the amorphous phase of the host polymer. The $\mathrm{SiO}_{2} \mathrm{NPs}$ acted as multifunctional inorganic fillers with good interfacial stability, which increased the ion conduction and $\mathrm{Li}^{+}$ ion transfer number for the poly(propylene carbonate)-based GPE in Li-S batteries [113].

$\mathrm{Hu}$ et al. [114] studied a GPE containing dispersed $\mathrm{SiO}_{2} \mathrm{NPs}$ in a PEO matrix. Uniformly dispersed $\mathrm{SiO}_{2} \mathrm{NPs}$ were obtained in the polymer matrix owing to the high miscibility of all the precursors. The synthesized GPE nanocomposite membrane significantly improved the electrochemical performance, which suggests a promising strategy for the development of safer and more flexible Li-metal batteries. The ionic conductivities and temperatures of the significant GPEs containing $\mathrm{SiO}_{2}$ fillers are listed in Table 3.

Table 3. List of GPEs with $\mathrm{SiO}_{2}$ filler with their conductivity and temperature.

\begin{tabular}{|c|c|c|c|c|c|}
\hline Polymer & Salt/Plasticizers & Solvent & Conductivity $\left(\mathrm{mS} \mathrm{cm}^{-1}\right)$ & Temperature $\left({ }^{\circ} \mathrm{C}\right)$ & Reference \\
\hline $\mathrm{PEO}$ & $\mathrm{LiClO}_{4}$ & DMF & $3 \times 10^{-3}$ & 30 & [106] \\
\hline PMMA & $\mathrm{LiClO}_{4}-\mathrm{PC}$ & DMF & $5.64 \times 10^{-2}$ & 80 & [107] \\
\hline PVdF-HFP & $\mathrm{LiPF}_{6}-\mathrm{EC} / \mathrm{DEC} / \mathrm{DBP}$ & Acetone & - & - & [108] \\
\hline PVDF & $\mathrm{LiPF}_{6}-\mathrm{EC} / \mathrm{DEC} / \mathrm{DBP}$ & DMF & $3.87 \times 10^{1}$ & 30 & [109] \\
\hline PVDF & LiPF6-EC/DMC & DMF & $7.73 \times 10^{-4}$ & 30 & [110] \\
\hline PAN & - & DMF & $1.8 \times 10^{-3}$ & 25 & [111] \\
\hline PEO & $\mathrm{LiCLO}_{4}$-DIOX/TGDME & $\mathrm{ACN}$ & $10^{-4}$ & 25 & [112] \\
\hline PVdF-HFP & LiTFSI-SDS & - & $1.22 \times 10^{-3}$ & 25 & [22] \\
\hline PPC & $\mathrm{LiTFSI}+\mathrm{LiNO}_{3}$ & DMAC & $1.64 \times 10^{-4}$ & 23 & [113] \\
\hline $\mathrm{PEO}$ & $\mathrm{LiClO}_{4}$ & $\mathrm{ACN}$ & $1.1 \times 10^{-4}$ & 30 & [114] \\
\hline
\end{tabular}

\subsection{Zirconium Dioxide $\left(\mathrm{ZrO}_{2}\right)$}

Vickraman et al. [115] studied a novel GPE containing lithium bis(oxalato)borate (LiBOB) as the $\mathrm{Li}$ salt and PVdF-PVC as the polymer matrix with varying contents of $\mathrm{ZrO}_{2}$. The high ionic mobility of the GPE is related to the large amorphous phase of the polymer 
host and its large free volumes that enhanced $\mathrm{Li}^{+}$ion transfer. Suthanthiraraj et al. [116] investigated the effect of $\mathrm{ZrO}_{2} \mathrm{NPs}$ in a new PPG-silver triflate $\left(\mathrm{AgCF}_{3} \mathrm{SO}_{3}\right)$ system in terms of the improvement to ion transport and electrochemical behavior. This study showed that structural modification of the polymer matrix by the addition of $\mathrm{ZrO}_{2} \mathrm{NPs}$ increased the ionic mobility and physicochemical properties of the GPE. Sivakumar et al. [117] reported the effect of the different concentrations of dispersed $\mathrm{ZrO}_{2}$ from the perspective of its enhanced ionic conductivity. The ionic conductivity increased upon the introduction of $\mathrm{ZrO}_{2}$ in the bare gel polymer system up to a loading of $6 \mathrm{wt} \%$. However, a further increase in the $\mathrm{ZrO}_{2}$ content reduced the conductivity because of the larger crystalline region present in the matrix, which hindered the ionic mobility. Similar results were observed by Sivakumar et al. [118] demonstrating that the introduction of $\mathrm{ZrO}_{2}$ into a PVDF-HFP(PC+DEC)- $\mathrm{LiClO}_{4}$ system significantly improved the electrolytic conductance of the GPE. The addition of $\mathrm{ZrO}_{2}$ NPs restricted the reorganization of the polymer chain structure, thereby increasing the amorphous phase of the polymer and improving the electrolytic conductance. Chen et al. [119] synthesized a novel GPE by in situ immobilization of ionic liquids (ILs) and nanoporous $\mathrm{ZrO}_{2}$ in a polymer matrix. This study showed that the $\mathrm{ZrO}_{2}$ skeleton cooperates with $\mathrm{Li}$ salts, resulting in improved dissociation of the $\mathrm{Li}$ salts and $\mathrm{Li}^{+}$ ion transfer. Therefore, a discharge capacity of $135.9 \mathrm{mAh} \mathrm{g}^{-1}$ was obtained after 200 cycles at $30^{\circ} \mathrm{C}$. In addition, the cell operated well in the temperature range of -10 to $90{ }^{\circ} \mathrm{C}$. The good contact and stable interface between the Li-metal electrode and GPE can be attributed to its effective electrochemical performance in Li-metal batteries.

Xiao et al. [120] synthesized a novel GPE by combining synthesized PMMA-Z $\mathrm{rO}_{2}$ (sPZ) hybrid particles with a P(VDF-HFP) polymer matrix. The morphology of the GPE membrane containing homogeneously interconnected micropores is shown in Figure 16a. As shown in Figure 16b, the cell delivers $126.4 \mathrm{mAh} \mathrm{g}^{-1}$ at $2.0 \mathrm{C}$ after 150 cycles, corresponding to a capacity retention of $85.2 \%$ at $0.1 \mathrm{C}$. The cell containing a graphite electrode delivers $288.5 \mathrm{mAh} \mathrm{g}^{-1}$ at $0.5 \mathrm{C}$ after 80 cycles (Figure 16c). The modified $\mathrm{ZrO}_{2}$ significantly enhanced the properties of the GPE in terms of mechanical strength, ion conduction, and thermal stability.
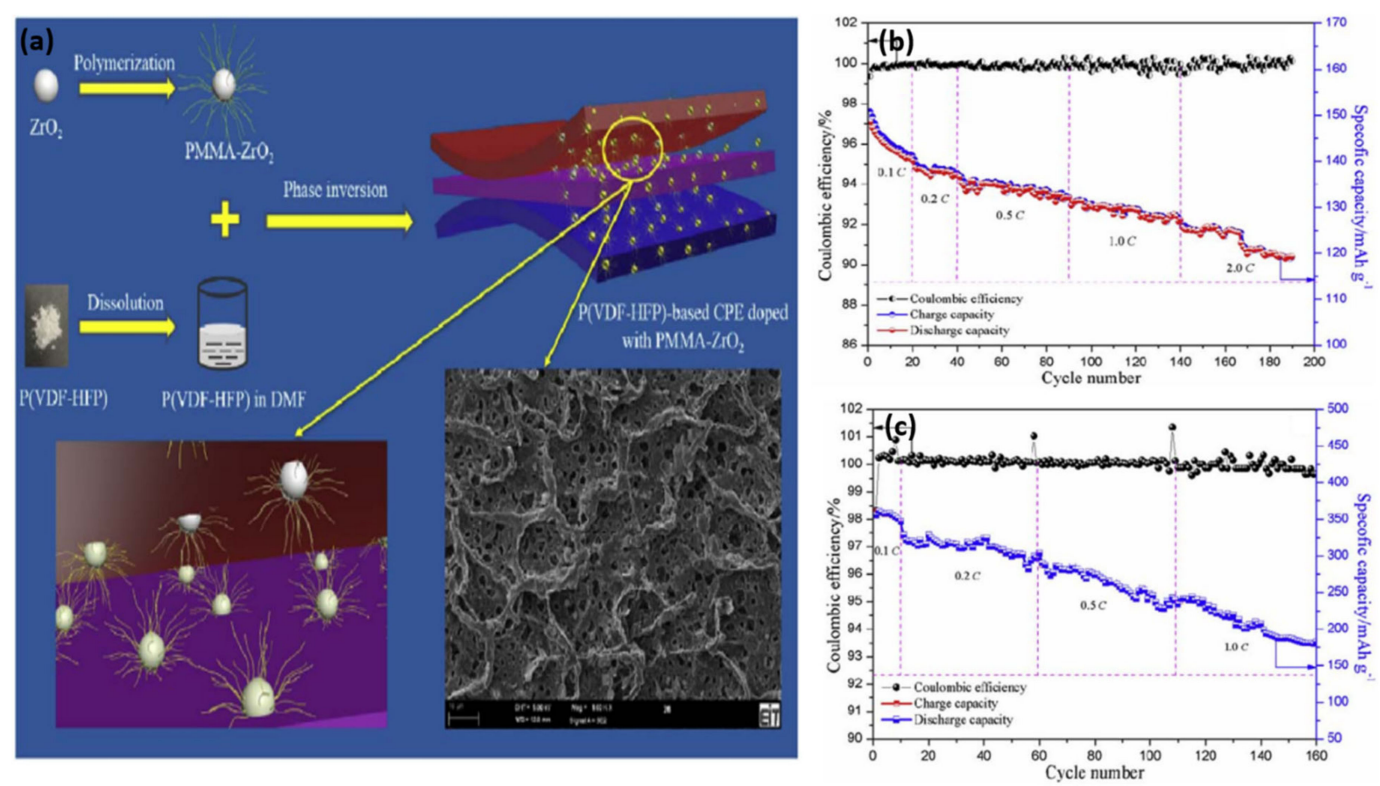

Figure 16. (a) Schematic of the GPE-sPZ hybrid particles. (b,c) Cyclic performance and Coulombic efficiency of the Li/CPEsPZ/ $\mathrm{LiCoO}_{2}$ and $\mathrm{Li} / \mathrm{CPE}-\mathrm{sPZ} /$ graphite coin cells at different C-rates at room temperature. Reprinted with permission from Xiao et al [120]. Copyright 2018 Elsevier B.V.

Khoon et al. [121] obtained similar results and proposed that the $\mathrm{ZrO}_{2}$-based GPE has the potential to be applied in lithium polymer batteries owing to the improved $\mathrm{Li}^{+}$ion transfer. The incorporation of $\mathrm{ZrO}_{2}$ NPs into the polymer-salt system resulted in a higher 
electrolytic conductance than that for the GPE without $\mathrm{ZrO}_{2}$ NPs. Prasanna et al. [122] prepared a nanocomposite GPE comprising a solution of zinc trifluoromethanesulfonate in a 1-ethyl-3-methylimidazolium bis(trifluoromethylsulfonyl)imide IL entrapped in a PVC/PEMA blend and dispersed $\mathrm{ZrO}_{2}$ nanofillers via a solution casting method. The GPE film showed the highest ionic conductivity of $3.63 \times 10^{-1} \mathrm{mS} \mathrm{cm}^{-1}$ at room temperature when $3 \mathrm{wt} \% \mathrm{ZrO}_{2}$ nanofiller was added. A list of significant GPEs containing $\mathrm{ZrO}_{2}$ fillers is provided in Table 4 with their ionic conductivities and temperatures.

Table 4. List of GPEs with $\mathrm{ZrO}_{2}$ filler with their conductivity and temperature.

\begin{tabular}{|c|c|c|c|c|c|}
\hline Polymer & Salt/Plasticizers & Solvent & Conductivity $\left(\mathrm{mS} \mathrm{cm}^{-1}\right)$ & Temperature $\left({ }^{\circ} \mathrm{C}\right)$ & Reference \\
\hline $\mathrm{PVDF} / \mathrm{PVC}$ & LiBOB-EC/DEC & THF & $1.53 \times 10^{0}$ & 70 & [115] \\
\hline PPG & $\mathrm{AgCF}_{3} \mathrm{SO}_{3}$ & THF & $2.9 \times 10^{0}$ & 30 & [116] \\
\hline PVdF-HFP & LiTFSI-PC & THF & $4.46 \times 10^{0}$ & 30 & [117] \\
\hline PS/PMMA & $\mathrm{LiClO}_{4}$ & - & $2.2 \times 10^{0}$ & 30 & [118] \\
\hline PVDF-HFP & $\mathrm{LiPF}_{6}-\mathrm{EC} / \mathrm{DMC} / \mathrm{EMC}$ & DMF & $3.6 \times 10^{0}$ & 30 & [120] \\
\hline PVDF-HFP/MG49 & $\mathrm{LiBF}_{4}$ & $\mathrm{THF}$ & $3.39 \times 10^{0}$ & 30 & [121] \\
\hline PVC/PEMA & $\mathrm{Zn}(\mathrm{OTf})_{2}$ & DMF & $3.63 \times 10^{-1}$ & 30 & [122] \\
\hline
\end{tabular}

\subsection{Cerium Oxide $\left(\mathrm{CeO}_{2}\right)$}

Rajendran et al. [123] reported a GPE system containing PEO-PMMA- $\mathrm{LiClO}_{4}$ DMP with varying $\mathrm{CeO}_{2}$ contents. The maximum ionic conductivity achieved was $2.07 \times 10^{-1} \mathrm{mS} \mathrm{cm}^{-1}$ when $10 \mathrm{wt} \% \mathrm{CeO}_{2}$ was added to the GPE. Vijayakumar et al. [124] prepared a new GPE membrane containing a PVDF-HFP-based polymer electrolyte and micro/nanosized $\mathrm{CeO}_{2}$ using a phase inversion technique. The highest ionic conductivity achieved was $2.47 \times 10^{0} \mathrm{mS} \mathrm{cm}^{-1}$ at room temperature in the presence of $8 \mathrm{wt} \% \mathrm{CeO}_{2}$. The addition of $\mathrm{CeO}_{2}$ NPs to the GPE reduced the interfacial resistance and enabled a wider electrochemical window and good cycling performance. Vijayakumar et al. [125] reported similar results in which the incorporation of $\mathrm{CeO}_{2}$ reduced the ion coupling and increased the charge carrier number, thereby improving the ionic conductivity. However, an excess of $\mathrm{CeO}_{2}$ led to an increased dilution effect, which resulted in a continuous decrease in the electrolytic conductance. Kumar et al. [126] designed a new class of nanocomposite polymer electrolytes to elucidate the origin and nature of the interactions between the surface of the $\mathrm{CeO}_{2}$ filler NPs in the polymer chain and the migrating ionic species. The study showed an enhanced percolation network among the $\mathrm{CeO}_{2}$ particles due to the increased ionic dynamics and surface interactions, which led to an increase in the electrolytic conductance. The surface interactions of the filler played an important role in increasing the charge carrier number and mobility, resulting in the highest ion conductivity of $5.2 \times 10^{-1} \mathrm{mS} \mathrm{cm}^{-1}$ being achieved at room temperature. Polu et al. [127] synthesized a GPE based on PEG-Mg $\left(\mathrm{CH}_{3} \mathrm{COO}\right)_{2}$ as the polymer matrix and $\mathrm{CeO}_{2} \mathrm{NPs}$ as the inorganic filler. The maximum ionic conductivity achieved was $3.40 \times 10^{-3} \mathrm{mS} \mathrm{cm}^{-1}$ when $15 \mathrm{wt} \%$ $\mathrm{CeO}_{2}$ was added to the GPE system. This study indicated that the addition of a certain concentration of filler increased the ionic conductivity, but further addition resulted in a decrease in conductivity. A list of GPEs containing $\mathrm{CeO}_{2}$ fillers is presented in Table 5 along with their ionic conductivities and temperatures.

Table 5. List of GPEs with $\mathrm{CeO}_{2}$ filler with their conductivity and temperature.

\begin{tabular}{cccccc}
\hline Polymer & Salt/Plasticizers & Solvent & Conductivity $\left(\mathbf{m S ~ c m} \mathbf{~ c m}^{-1}\right)$ & Temperature $\left({ }^{\circ} \mathbf{C}\right)$ & Reference \\
\hline PMMA/PEO & $\mathrm{LiClO}_{4}$-DMP & THF & $20.65 \times 10^{-2}$ & 30 & {$[123]$} \\
PVDF-HFP & $\mathrm{LiClO}_{4}$-EC/DMC & NMP & $2.47 \times 10^{0}$ & 30 & {$[124]$} \\
PVDF-HFP & $\mathrm{LiClO}_{4}-\mathrm{EC} / \mathrm{DMC}$ & $\mathrm{NMP}$ & $3.84 \times 10^{0}$ & 30 & {$[125]$} \\
PPG & $\mathrm{AgCF}_{3} \mathrm{SO}_{3}$ & - & $5.2 \times 10^{-1}$ & 30 & {$[126]$} \\
PEG & $\mathrm{Mg}\left(\mathrm{CH}_{3} \mathrm{COO}\right)_{2}$ & Distilled water & $3.4 \times 10^{-3}$ & 25 & {$[127]$} \\
\hline
\end{tabular}




\subsection{Barium Titanate $\left(\mathrm{BaTiO}_{3}\right)$}

Kim et al. [128] studied the effect of $\mathrm{BaTiO}_{3}$ nanosized filler content in composite polymer electrolytes (CPEs). The optimum content of $15 \mathrm{wt} \% \mathrm{BaTiO}_{3}$ showed reduced crystallinity of the CPEs and high ion conduction with a wide electrochemical window and good thermal stability. The results indicated that the addition of $\mathrm{BaTiO}_{3}$ filler affects the electrochemical properties and the crystallinity of the CPEs. Sivakumar et al. [129] synthesized a GPE by dispersing hydrothermally derived $\mathrm{BaTiO}_{3}$ NPs in PVC-PEMA$\mathrm{EC} / \mathrm{DMC}-\mathrm{LiClO}_{4}$. The use of $\mathrm{BaTiO}_{3} \mathrm{NPs}$ as fillers increased the electrolytic conductance owing to the improvement in the polymer fractions and the amorphous phase of the GPE. The presence of dispersed $\mathrm{BaTiO}_{3} \mathrm{NPs}$ in the GPE prevented the growth of a passive layer on the surface of the Li-metal anode. Manimuthu et al. [130] discussed the influence of different ratios of $\mathrm{BaTiO}_{3}$ NPs on the PEO/PVDF-HFP-based polymer electrolyte. The presence of a $\mathrm{BaTiO}_{3}$ filler with high polarity reduced the crystallinity of the polymer because of the cooperation between the polymer chain and the filler surface, which increased the ion conduction of the GPE membrane. Table 6 lists $\mathrm{BaTiO}_{3}$ filler-based GPEs with their ionic conductivities and temperatures.

Table 6. List of GPEs with $\mathrm{BaTiO}_{3}$ filler with their conductivity and temperature.

\begin{tabular}{cccccc}
\hline Polymer & Salt/Plasticizers & Solvent & Conductivity $\left(\mathbf{m S ~} \mathbf{~ c m}^{-1}\right)$ & Temperature $\left({ }^{\circ} \mathbf{C}\right)$ & Reference \\
\hline PEO-PVDF & $\mathrm{LiClO}_{4}$-PC & ACN & $1.2 \times 10^{-1}$ & 30 & {$[128]$} \\
PVC-PEMA & $\mathrm{LiClO}_{4}$-EC/DMC & THF & $0.61 \times 10^{1}$ & 30 & {$[129]$} \\
PEO/PVDF-HFP & $\mathrm{LiClO}_{4}$-PC & Acetone & $6 \times 10^{0}$ & 30 & {$[130]$} \\
\hline
\end{tabular}

\section{Mechanism of $\mathrm{Li}^{+}$Transport on the Interface between the Inorganic Filler and Polymer Matrix in GPEs}

As GPEs combine the advantages of LEs and SPEs in terms of electrolytic conductance and mechanical stability, they are considered to have more potential for practical applications in LIBs and non-LIBs [13]. During the charge-discharge process, a solid electrolyte interface (SEI) is still formed, similar to LEs, through a reaction between the plasticizers and electrode surface in GPEs. The electrochemical behavior and internal resistance allow the measurement of the ionic conductivity of the GPE at various charge-discharge rates [131]. Generally, LEs have high electrolytic conductance in the range of $10^{-0}$ to $10^{1} \mathrm{mS} \mathrm{cm}^{-1}$; thus, to evaluate the efficient usage of the GPE, its ionic conductivity should be higher than that of LEs $\left(>10^{-1} \mathrm{mS} \mathrm{cm}^{-1}\right)$ [42,132]. In gel-type polymer electrolytes, polymers are used as host matrices to trap the liquid constituent [133]. In this case, $\mathrm{Li}^{+}$ion transfer is not affected by the segmental polymer chain motion but through the swollen gelled phase or liquid phase. In addition, the solvents used for GPEs should have a high dielectric constant and low viscosity. In SPE, polymer chains conduct local segmental motion continuously, leading to the formation of the free volume. Under the effect of the electric field, the lithium ions diffuse to a new coordinating position along the polymer chain or move from chain to chain through these free volumes. In the presence of ceramics, the diffusion of $\mathrm{Li}^{+}$ion is enhanced because the ceramics increase the free volume of the polymer chain. Thus, the mechanism of reduction in the polymer crystallinity is not dependent on the chemical nature of the filler, but on the size, volume fraction, and shape of ceramic filler [134]. Because of the different particle sizes, the optimal content of ceramic fillers to achieve optimum diffusion of $\mathrm{Li}^{+}$ion is different. Inert ceramic oxide fillers such as $\mathrm{TiO}_{2}, \mathrm{SiO}_{2}$ are often used with only a few percent (ceramic-in-polymer) to achieve optimum ionic conductivity. However, as the inert filler content increases, it decreases the mechanical strength of the polymer membrane. In contrast, active fillers, such as LLZO, LAGP, etc., have high ionic conductivity and can participate in $\mathrm{Li}^{+}$ion transport, thus when the active filler content increases, the conductivity can be increased accordingly. Therefore, depending on the properties and content of the active filler and polymer, the optimal content to achieve maximum electrical conductivity is different [57]. The dissociation of the salt is facilitated 
by a high dielectric constant, while a low viscosity increases the ionic mobility in the electrolyte, resulting in a high electrolytic conductance [135]. In addition, the functional groups of the polymer matrix should be able to dissolve the Li salt to form the polymer-salt system. This requires that the lattice energy of the salt be relatively low, but the dielectric constant of the polymer matrix is relatively high. More importantly, the properties of the lithium salt will affect the performance of lithium polymer batteries. Because of its high ion conductivity, good electrochemical stability, and corrosion resistance for aluminum current collector, $\mathrm{LiPF}_{6}$ is mainly used in commercial LIBs. However, the halogen-based lithium salts have some disadvantages: $\mathrm{LiClO}_{4}$ is potentially explosive when exposed to an organic substance; $\mathrm{LiAsF}_{6}$ contains toxic As; $\mathrm{LiBF}_{6}$ and $\mathrm{LiPF}_{4}$ are easily decomposed into $\mathrm{HF}$, which is toxic and corrosive in the moist atmosphere. Organic lithium salts, such as $\mathrm{LiCF}_{3} \mathrm{SO}_{3}$, $\mathrm{LiTf}$, etc., are highly resistant to oxidation, thermally stable, and non-toxic, but they have poor ionic conductivity. LiTFSI is the best choice for Li salt in LIBs with high solubility in common solvents, but they are corrosive to aluminum current collectors. Therefore, the search for reliable new lithium salts has remained at the center of research in recent years [136]. Typically, electrolytic conductance is related to the elementary electric charge and ion mobility. The electrolytic conductance of GPEs is mainly dominated by the properties of the trapped liquid electrolyte in the micropores of the membrane; thus, the interconnected micropores of the membrane are the main factor affecting the mobile ions. In contrast, for a homogeneous membrane or a membrane without micropores, the $\mathrm{Li}^{+}$ion mobility is primarily determined by the swollen gelled phase. In addition, an incomplete drying during the SPE preparation leads to the presence of moisture and solvent that results in the decomposition reaction of polymer. The standard drying process for the preparation of SPE membrane with a high content of Li salt (polymer-in-salt) will trap a large amount of solvent due to the strong interaction between solvent and ion species, which leads to the high ionic conductivity. The presence of trace water up to a few ppm remained after drying under vacuum was sufficient to trigger the depolymerization process. This process can have a strong impact on the electrochemical performance. Therefore, it is necessary to remove water to avoid the depolymerization of the polymer [137]. The possible mechanism of ion transport is as follows: (i) $\mathrm{Li}^{+}$ions are located in the porous structure of the polymer; (ii) through dispersion of the inorganic filler, the porous structure of the polymer is maintained, which assists in the absorption of the LE in the GPE, resulting in alleviation of the leakage problem and an enhanced safety of the applied device; and (iii) $\mathrm{Li}^{+}$ions migrate from one coordination site to a new site through the liquid phase or gelled phase (porous structure) via the effect of the inorganic fillers.

A new concept has been recently proposed by Chen et al. [138] who explained the electrolytic conductance is highly affected by the layers of chemical water (immobile ice layer) adsorbed on $\mathrm{OH}$-terminated $\mathrm{SiO}_{2}$ surface. They proposed the immobilization of 1-butyl-1-methylpyrrolidinium-bis TFSI (BMP TFSI) IL molecules extends the formation of ice layer on the $\mathrm{SiO}_{2}$ surface (Figure 17). In symmetric $\mathrm{O}=\mathrm{S}=\mathrm{O}$ groups on the TFSI anion, one oxygen can interact with a hydroxyl group on silica surface while other oxygen atom interacts with BMP cation groups. The TFSI anion in LiTFSI also has two groups of $\mathrm{O}=\mathrm{S}=\mathrm{O}$, ensuring dense adsorption of the TFSI monolayer. However, the molecular interaction between the BMP cation and TFSI (LiTFSI) anion is different because TFSI has free rotation and no polarization from the underlying surface. The TFSI molecules must compensate for the positive bipolar charge due to the formation of $\mathrm{H}$ bonds between the $\mathrm{O}$ group of the TFSI anion and the $\mathrm{OH}$ group of the ice layer. This loosens the bond between the $\mathrm{Li}^{+}$cation and the TFSI anion. In this way, the concentration of free $\mathrm{Li}^{+}$increases at this interface, resulting in higher ionic conductivity. 


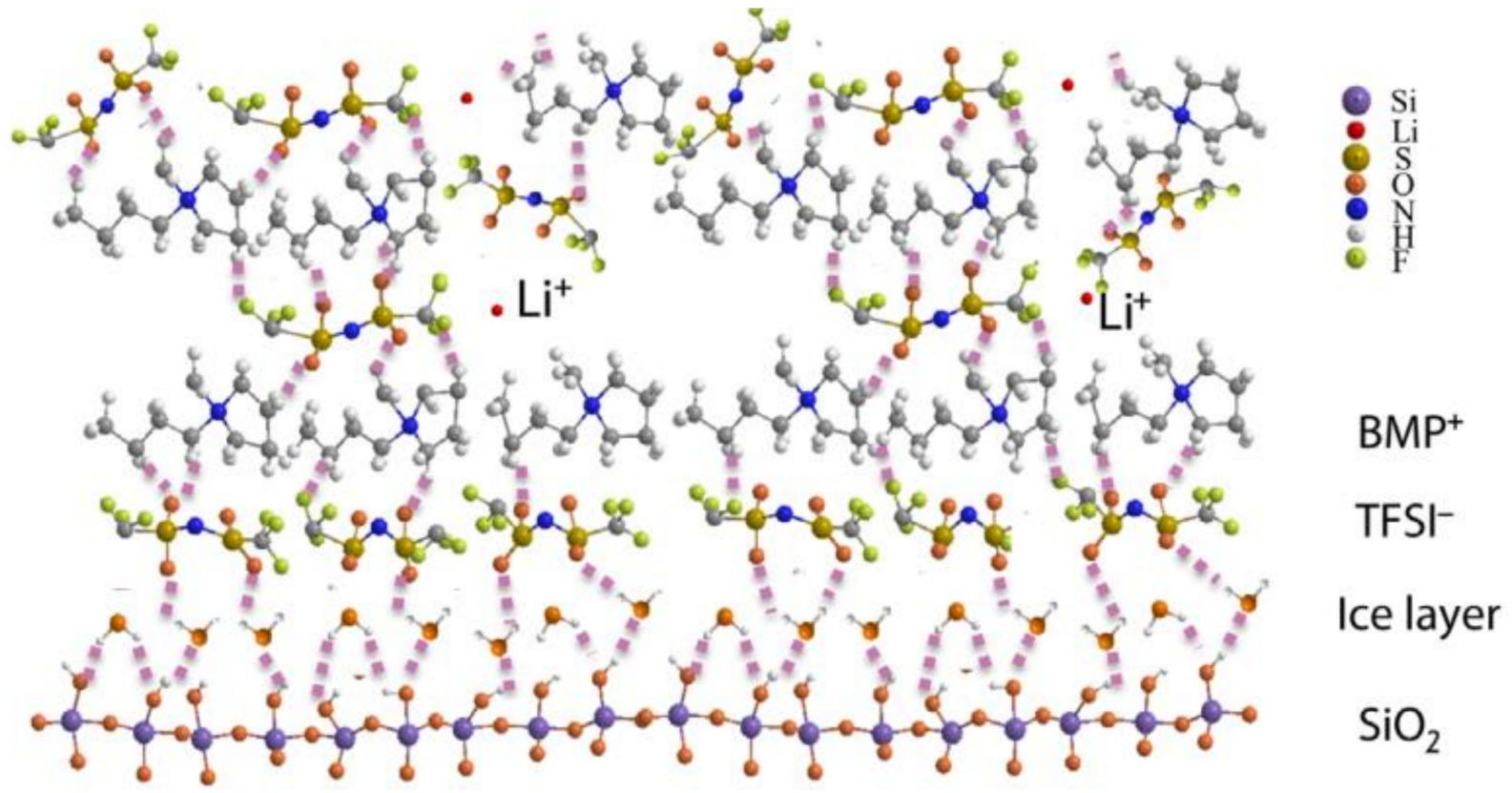

Figure 17. The model of the electrolytic conductance on the inorganic filler $\left(\mathrm{SiO}_{2}\right)$ interfaces through the layers of immobile ice layer absorbed on OH-terminated silica surface. Reprinted with permission from Chen et al. [138]. 2020 Creative Commons Attribution-Noncommercial liscense.

In addition to the $\mathrm{Li}^{+}$ions transport mechanism, the interaction of lithium dendrite with the polymer and filler also needs to be considered. The dendrite growth during chargedischarge cycling hinders the utilization of GPE in LIBs, causing detrimental effects related to the safety and electrochemical performance of the battery, although its effect is lower than that of LE $[139,140]$. The inclusion of inorganic filler into GPE can suppress the formation of lithium dendrite through enhancement of the mechanical properties of the polymer matrix, trapping the $\mathrm{LE}$ resulting in a uniform $\mathrm{Li}^{+}$ions flow at the $\mathrm{Li}$ metal-electrolyte interface [141]. Liu et al. studied the growth of $\mathrm{Li}$ dendrite through the addition of $\mathrm{SiO}_{2} \mathrm{NPs}$ (nano- $\mathrm{SiO}_{2}$ and acid-modified nano-SiO $\mathrm{S}_{2}$ filler) into PEO-LiTFSI system at current densities of 0.1 and $0.5 \mathrm{~mA} \mathrm{~cm}^{-2}$ [142]. The study showed that the interfacial resistance of cells is significantly reduced when introducing $\mathrm{SiO}_{2} \mathrm{NPs}$. However, more importantly, the acidmodified nano- $\mathrm{SiO}_{2}$ filler was the most effective to reduce the interfacial resistance. The acid modification on the nano- $\mathrm{SiO}_{2}$ surface immobilized the PEO chains and promoted the movement of $\mathrm{Li}^{+}$ions. In addition, the Lewis acid-base interaction between the hydroxyl groups of the trace water in polymer electrolyte and the surface of acid-modified nano-SiO prevented the reaction of the traces water with Li metal, thereby hindering the growth of lithium dendrite. The interaction of Li dendrite with polymer and inorganic filler was also observed by Liu et al. [143]. In this study, they prepared a multi-functional GPE by combining ultraviolet (UV)-cured ethoxylated trimethylolpropane triacrylate (ETPTA) macromer with $\mathrm{PEO}$ and $\mathrm{Al}_{2} \mathrm{O}_{3} \mathrm{NPs}$ as an inorganic filler. The uniform dispersion and high-density of $\mathrm{Al}_{2} \mathrm{O}_{3}$ NPs in GPE acted as a filler to stabilize the electrode interface as well as a protective agent to prevent the lithium dendrite growth, thus promoting good cycle stability (Figure 18a). From SEM images (Figure 18b-d), $\mathrm{LiFePO}_{4} / \mathrm{GPE} / \mathrm{Li}$ cell showed large dendrites on the surface of lithium anode after 20 cycles at $0.5 \mathrm{C}$ compared with the smooth surface of pristine lithium anode before cycling. In contrast, in the presence of $\mathrm{Al}_{2} \mathrm{O}_{3} \mathrm{NPs}$, no dendrites were observed on the surface of lithium anode in $\mathrm{LiFePO}_{4} / \mathrm{Al}_{2} \mathrm{O}_{3}$ $\mathrm{GPE} / \mathrm{Li}$ cell. The addition of inorganic filler can suppress the lithium dendrite growth, which in turn greatly improves the safety of LIBs. Besides, the presence of polymer can prevent direct contact of the electrode and LE. 


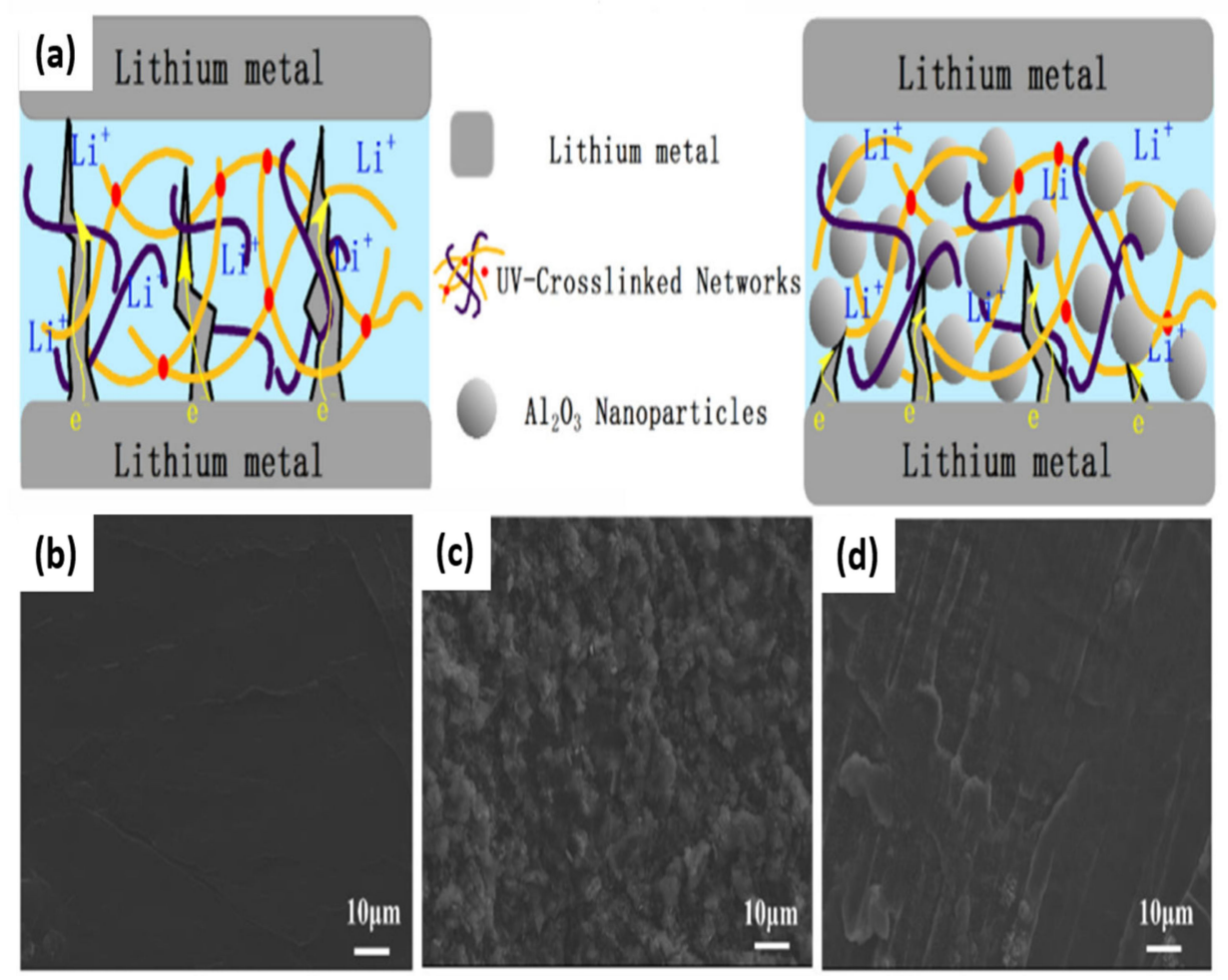

Figure 18. (a) Schematic illustrations the prevent of lithium dendrite growth by $\mathrm{Al}_{2} \mathrm{O}_{3}-\mathrm{GPE}$ electrolyte; (b) pristine of lithium anode before cycling in LFP/GPE/Li cell; (c) lithium anode in $\mathrm{LFP} / \mathrm{GPE} / \mathrm{Li}$ cell after 200 cycles at $0.5 \mathrm{C}$; (d) lithium anode in LFP/ $\mathrm{Al}_{2} \mathrm{O}_{3}-\mathrm{GPE} / \mathrm{Li}$ cell after 200 cycles at 0.5 C. Reprinted with permission from Liu et al. [143]. Copyright 2018. The Chinese Ceramic Society. Production and hosting by Elsevier B.V.

For SPE, the dendrite formation in the Li metal anode causes a short circuit of the battery, in which the polymer decomposition is the main failure mechanism of this battery [144]. Golozar et al. studied the mechanism of these dendrite formation [145]. The presence of carbon increases the hardness of the dendrite and facilitates their penetration into the SPE, thereby causing a short circuit of the battery. $\mathrm{Li}_{\mathrm{x}} \mathrm{C}_{\mathrm{x}}$ is formed through the reduction of SPE throughout the cycle, which produces carbon-rich species. In addition, the decomposition of LiTFSI at grain boundaries has also been observed [146]. The dissolution of the lithium metal into the polyether begins at the grain boundary and continues after many cycles leading to the depletion of lithium. $\mathrm{Li}_{3} \mathrm{~N}$ initially formed becomes insoluble in the next cycles and further decomposition of salt leads to the formation of $\mathrm{Li}_{2} \mathrm{~S}$, $\mathrm{LiC}_{\mathrm{x}} \mathrm{F}_{\mathrm{y}}, \mathrm{Li}_{\mathrm{x}} \mathrm{CNF}_{3}$, and $\mathrm{Li}_{\mathrm{y}} \mathrm{SO}_{\mathrm{x}}$, where $\mathrm{LiF}$ acts as a protective layer for the lithium from further dissolution.

\section{Synthesis Methods for Inorganic Gel Polymer Electrolytes}

\subsection{GPEs Based on Physical Preparation Methods}

GPE can be separated into two categories, physical and chemical gels, based on their preparation method. In physical gels, LEs are confined to the polymer matrix without significant polymer-solvent bonding. The GPE can be prepared from a dry polymer membrane that undergoes swelling by a liquid electrolyte containing Li salts and plasticizers. The general synthesis methods include conventional solution casting, phase inversion, and electrospinning.

In the solution cast method, the solvent should be able to dissolve both the Li salt and polymer matrix without water molecules absorbed from environment [42]. Forsyth et al. [147] demonstrated a purpose-designed Teflon mold method for the preparation of GPEs which combines an IL electrolyte (consisting of $3.8 \mathrm{~m}$ LIFSI in trimethyl(isobutyl)phosphonium bis(fluorosulfonyl)imide $\left(\mathrm{P}_{111 i 4} \mathrm{FSI}\right)$ ), poly(diallyldimethylammonium) bis(trifluorometha- 
nesulfony)imide (PDADMA TFSI), and $\mathrm{Al}_{2} \mathrm{O}_{3}$ NP inorganic filler. The $\mathrm{P}_{1114} \mathrm{FSI}$ showed a wide electrochemical window, and the high concentration of Li salt could significantly enhance the lithium stripping and plating. On the other hand, the introduction of $\mathrm{Al}_{2} \mathrm{O}_{3}$ increased the mechanical stability, which allowed more IL to interact with the GPE. The optimized composition of GPE with $5 \mathrm{wt} \% \mathrm{Al}_{2} \mathrm{O}_{3} \mathrm{NPs}$ and $50 \%$ of IL showed the highest ionic conductivity of $0.28 \times 10^{0} \mathrm{mS} \mathrm{cm}{ }^{-1}$ and enhanced the $\mathrm{Li}^{+}$ion transport. The solution cast method is a commonly used traditional method due to its ease of fabrication. The obtained GPEs generally show increased electrolytic conductance and good interfacial properties between electrode and electrolyte as well as the good electrochemical performance of the full cell polymer batteries.

Phase inversion method is also commonly used to fabricate highly porous polymeric film through a de-mixing procedure in which an initial homogeneous polymer solution is changed from a liquid state to a solid-state [148]. Liu et al. [149] integrated non-woven fabrics of PVDF-PAN-SiO ${ }_{2}$-based GPE membrane using a Loeb-Sourirajan (L-S) inverted phase method (i.e., the dry-wet phase inversion technique to prepare cellulose acetate membrane for seawater desalination) to obtain a polymer membrane with uniform pore size. The chemical reaction that occurred between two salts $\left(\mathrm{NaHCO}_{3}\right.$ and $\left.\mathrm{CH}_{3} \mathrm{COOH}\right)$ during the membrane preparation process promotes the formation of porous and interconnected structures in GPE. The GPE membrane showed the highest ionic conductivity of $3.32 \times 10^{0} \mathrm{mS} \mathrm{cm}^{-1}$ with enhanced the mechanical strength and electrolyte uptake. The combination of L-S inverted phase and chemical reaction process was suitable to prepare polymer matrices in GPE. The facile electrolytic conductance and stable interfacial property between electrode and electrolyte in this GPE resulted in an excellent performance in LIBs.

Electrospinning is another common method to produce polymer fibers with a diameter ranging from tens of nanometers to tens of micrometers through the electrostatic repulsion of the polymer solution [150,151]. A novel PVDF-HFP-based GPE with nanostructured IL and $\mathrm{SiO}_{2}$ NP-tethered 1 methyl-1-propulpiperidinium bis(trifluoromethanesulfonyl) imide $\left(\mathrm{SiO}_{2}\right.$ PPTFSI) was prepared by electrospinning process [152]. The obtained GPE showed good mechanical stability, an increase in the electrolytic conductance as well as $\mathrm{Li}^{+}$ion transfer. More importantly, the assembled cell showed an initial discharge capacity of $119 \mathrm{mAh} \mathrm{g}^{-1}$ and a capacity retention of $92.1 \%$ after 460 cycles at $1 \mathrm{C}$. The use of a nanostructured IL and modified $\mathrm{SiO}_{2}$ presented a potential candidate to improve the cyclic performance and the safety of LIBs. Although the electrospinning method is a cost-effective and simple manufacturing process, the difficulty in controlling the pore structure and the time-consuming process are significant drawbacks that need to be considered.

Generally, physical methods are used to cross-link polymer chains through weak physical interactions in GPEs. Owing to the weak interaction between the constituents, safety issues remain a concern as the polymer matrix can easily swell or dissolve in the LE at high temperatures, which leads to solvent leakage and reduced electrochemical performance. Poor thermal stability is another limitation when applying GPEs synthesized through physical methods to practical applications [131].

\subsection{GPEs Based on Chemical Preparation Methods}

The chemical methods used to prepare GPEs are also called "in situ synthesis" methods. In chemical gels, the crosslinking agent and functional groups of the polymers form a chemical bond. The precursor solution is prepared by dissolving the crosslinking agent and monomers in a LE in a specific ratio. Subsequently, the GPE is synthesized by polymerization of the monomer, forming a cross-linked network, and the LE is uniformly immobilized in the nanopores. Polyester is the most commonly used material for GPEs owing to the facile interaction between the lithium-ion and ethylene oxide (EO) units. Generally, polyether is formed when using precursors containing methacrylate groups on the surface [153]. Sato et al. [154] designed novel three-dimensional hybrid silica particles (PSiPs) with concentrated polymer brushes (CPB) with trace amount of IL. Initially, the surface of monodisperse silica particle ( $\mathrm{SiP})$ was changed by a mixture of ethanol/water/ (2- 
bromo-2methyl) propionyloxyhexyltriethoxysilane (BHE) to form a new type of colloidal crystal. Then, by surface-initiated living radical polymerization (LRP) process, the PSiPs were successfully synthesized by grafting well-defined polymers on the surface to form the CPB-modified particles. The GPE with CPB-modified SiP provided an advanced ion conduction channel with an orderly and clearly defined structure. A newly designed GPE gave the chance for bipolar LIB device with a good electrochemical performance and made it possible to apply in practical use. Guo et al. [155] fabricated ionic liquid GPEs (ILGPEs) supported by active filler LAGP or inactive filler $\mathrm{SiO}_{2}$ for enhanced ionic conductivity and electrochemical performance. As for inorganic fillers, the optimized content of nano- $\mathrm{SiO}_{2}$ could decrease the crystalline phase of the host polymer as well as promote the Li-ion transport. Nevertheless, when the concentration of $\mathrm{SiO}_{2}$ exceeded the optimal value, the fillers impeded the effective migration of $\mathrm{Li}^{+}$ion into the ILGPE. However, in the case of LAGP filler, it not only reduced the crystallinity but also improved the electrolytic conductance of the host polymer even when the concentration was greatly increased because LAGP is also the source of $\mathrm{Li}^{+}$ion. The IL-GPE with $10 \mathrm{wt} \%$ LAGP showed high thermal stability and no flammability, which suggests it can be a promising electrolyte for the highly safe energy storage devices. Ma et al. [156] improved the ionic conductivity of GPE by LATP ceramic particles, which were dispersed in polymerized ionic liquids (PILs) as a polymer matrix, and LiTFSi as a source of $\mathrm{Li}^{+}$ion. The PIL was synthesized using 1-vinyl-3-ethylimidazolium TFSI as a monomer and nonwoven polyethylene terephthalate (PET) as a polymer in GPE. The optimized content of LATP (10 wt \%) exhibited good rate performance and capacity retention of $97 \%$ after 250 cycles at $60{ }^{\circ} \mathrm{C}$, indicating that PIL-LiTFSI-LATP can yield superior cyclic performance at the high temperature. Wang et al. [157] incorporated two-dimensional (2D) silica NP into PIL to optimize the transport properties of GPE. The desired transport properties were due to the bonding of the grafted PIL and mesoporous structure of 2D silica nano filler with abundant, shorter, and continuous ion transport pathways. In addition, the 2D nanofiller could effectively control the ion transport trajectory through the surface contact orientations, thus leading to higher ion conductivity than the GPEs added with zero-dimensional (0D) or one-dimensional (1D) nanofiller. The assembled cell showed a discharge capacity of $135.8 \mathrm{mAh} \mathrm{g}^{-1}$ after 30 cycles at $60^{\circ} \mathrm{C}$, suggesting that their capacity and capacity retention are superior to cells using unmodified PIL/IL PE $\left(50.0 \mathrm{mAh} \mathrm{g}^{-1}\right)$. The ionotropic gelation method is a technique used to prepare micro-and nanoparticles, which are synthesized by adding anion polyelectrolyte solution with drop-by-drop manner to an acidic chitosan solution. Chitosan is ionotropically gelated to be proton conductive membranes, creating proton conductor sites in a single step. In contrast, the pre-formed chitosan in the solution is not highly conductive because of the limited $\mathrm{Li}^{+}$diffusion through the polymer matrix $[158,159]$. Kim et al. prepared a multifunctional binder network by combining chitosan and reduced graphene oxide (rGO) to enhance the electrochemical performance of Li-sulfur batteries [160]. A homogeneous network formed by the reaction of chitosan with GO in an aqueous solution enhanced the redox system by trapping lithium polysulfides, reinforced the mechanical properties, and promoted ion/electron movement. This multifunctional network binder can be used for high-performance Li-S batteries. Zhao et al. used chitosan crosslinked with a carboxylic acid or acrylic acid molecules to form a compatible binder for both silicon and graphite [161]. The crosslinked chitosan lattice can effectively regulate the large volume change of silicon particles throughout the cycles. In this sense, chitosan network can be used as an effective binder in LIBs.

\section{Promising Applications of GPEs in Various Battery Systems}

The ionic conductivity enhancement and host polymer structure modification realized by the addition of inorganic fillers in GPE can be applied to improve the electrochemical performance of various battery systems. 


\subsection{Lithium-Ion Batteries}

Because GPEs are highly resistant to electrochemical oxidation compared to LEs, GPEs are selected as potential electrolytes for practical applications in LIBs. Many studies have used inorganic fillers such as $\mathrm{SiO}_{2}, \mathrm{TiO}_{2}, \mathrm{Al}_{2} \mathrm{O}_{3}$, etc., to enhance the mechanical strength and improve the ionic conductivity of GPE in LIBs. Lewis acid-base interaction between a surface group of filler and ions appeared to be responsible for this role. Some new inorganic fillers that have been recently introduced in LIBs are aluminum oxyhydroxide $\left(\mathrm{AlO}(\mathrm{OH})_{\mathrm{n}}\right)$, graphene oxide (GO), clays, etc., which are expected to modify the structure of polymer matrix and thus enhance the $\mathrm{Li}^{+}$ion transport. Stephen et al. [162] prepared a multifunctional GPE by combining a PVdF-HFP as a polymer matrix, lithium bis perfluorosulfonyl imide $\left(\mathrm{LiN}\left(\mathrm{CF}_{3} \mathrm{SO}_{2}\right)_{2}\right)$ as a lithium salt, and $\mathrm{AlO}(\mathrm{OH})_{\mathrm{n}}$ as an inorganic filler. The introduction of $\mathrm{AlO}(\mathrm{OH})_{\mathrm{n}}$ not only increases the amorphous domain and acts as "solid plasticizer" to promote the $\mathrm{Li}^{+}$ion transfer but also provides a good interfacial property towards Li-metal anode. The full cell with GPE membrane exhibited first discharge capacity of $127 \mathrm{mAh} \mathrm{g}^{-1}$ with a capacity retention of $98.4 \%$ after 20 cycles at $70{ }^{\circ} \mathrm{C}$. Aravindan et al. [163] continued to employ $\mathrm{AlO}(\mathrm{OH})_{\mathrm{n}}$ as an inert filler in PVdF-HFP and indicated that the introduction of $10 \% \mathrm{AlO}(\mathrm{OH})_{\mathrm{n}}$ in GPE membrane enhanced the ionic conductivity due to the interaction of Lewis acid-base between $\mathrm{F}$ atoms in PVdF-HFP and $\mathrm{OH}^{-}$groups in filler. This interaction increased the amorphous domain by preventing reorganization of polymer chains, thus leading to the enhancement of the electrolyte uptake at ambient temperature condition. In addition, the study showed high cyclic stability with a capacity retention of $97.8 \%$ after 10 cycles. The advantages of using $\mathrm{AlO}(\mathrm{OH})_{\mathrm{n}}$ over conventional inorganic fillers, such as $\mathrm{TiO}_{2}, \mathrm{SiO}_{2}, \mathrm{Al}_{2} \mathrm{O}_{3}$, etc., are mainly because of its ability to promote more dissociation of lithium salt, which leads to the enhanced number of charged carriers, ionic conductivity, and electrochemical performance. Chen et al. [164] prepared a high-performance battery using a PVDF-HFP-based GPE co-doped with PEO and GO via weak hydrogen bond interaction. The GPE showed a 3D porous network with superior ionic conductivity up to $2.1 \times 10^{0} \mathrm{mS} \mathrm{cm}^{-1}$ and excellent cycling stability with a capacity retention of $92 \%$ after 2000 cycles at 5 C. The good electrochemical performance was due to the abundant oxygen-functional groups in GO sheets that interact with the copolymer (PVDF-HFP and PEO polymer) to form an amorphous phase and porous structure, which is beneficial for both $\mathrm{Li}^{+}$and $\mathrm{PF}_{6}{ }^{-}$intercalation/deintercalation kinetics. Zhao et al. [165] used GO as a filler to synthesize the homogeneous GPE for enhancing the electrochemical properties of the cell. The presence of GO enhanced the contact between the GPE and electrodes and formed a more stable SEI layer, leading to the enhancement of electrolytic conductance and the $\mathrm{Li}^{+}$ion transfer of GPE. Thus, the discharge capacity and cyclic performance of battery were effectively improved. Liu et al. [166] designed a GPE by incorporating graphene fillers in the presence of PVDF as a host polymer, and $\mathrm{LiPF}_{6}$ as a source of $\mathrm{Li}^{+}$ions. This study demonstrated the decrease in crystallinity of porous PVDF due to the homogeneously dispersed graphene in host polymer, resulting in the increased GPE electrolytic conductance from $1.85 \times 10^{0} \mathrm{mS} \mathrm{cm}^{-1}$ in pure PVDF to $3.61 \times 10^{0} \mathrm{mS} \mathrm{cm}^{-1}$ in the presence of $0.002 \mathrm{wt} \%$ graphene, and enhanced cyclic performance of the cell. Chen et al. [167] studied a GPE that consists of PAVM as a host polymer, $\mathrm{LiPF}_{6}$ as a source of $\mathrm{Li}^{+}$ion, and $\mathrm{GO}$ quantum dots (GOQD) as an inorganic filler. The GOQD hinders the formation of ion-solvent clusters and immobilizes anions; as a result, the assembled $\mathrm{LiFePO}_{4} / \mathrm{GPE} / \mathrm{Li}$ cell showed a good performance at high rates (up to $20 \mathrm{C}$ ) and exhibited capacity retention of $100 \%$ after 500 cycles. From these results, it can be expected that layered GO can significantly change the properties of the host polymer even with a very low content due to its highly oxidizing and hydrophilic nature. Compared with conventional ceramic nanofillers, GO has some advantages because of its tunable surface functionalities, high compatibility, and excellent dispersion with the polymer network. Dyartanti et al. [168] prepared a PVDF-PVP-based GPE containing an montmorillonite (MMT) nano-clay as a filler. The addition of MMT clay showed an increased porosity of host polymer and enhanced the uptake of LE, leading to an increased ionic conductivity of $5.61 \times 10^{0} \mathrm{mS} \mathrm{cm}^{-1}$. The full cell showed good 
cyclic stability with a capacity retention of $97.7 \%$ after 48 cycles. The use of clay as an inorganic layered filler is beneficial because of its unique characteristics of the length scale (channel width = $16 \AA$ ), high cation exchange capacity, suitable interlayer charge, and a substantial specific surface area $\left(\sim 31.82 \mathrm{~m}^{2} \mathrm{~g}^{-1}\right)$. Table 7 summarizes the electrochemical performance of LIBs with inorganic fillers added in GPEs.

Table 7. Lists of GPEs and their electrochemical performance in lithium-ion batteries (LIBs).

\begin{tabular}{|c|c|c|c|c|c|c|}
\hline Polymer & Salt/Plasticizers/Fillers & $\begin{array}{l}\text { Specific Capacity } \\
\left(\mathrm{mA} \mathrm{h} \mathrm{g}^{-1}\right)\end{array}$ & $\begin{array}{c}\text { Capacity } \\
\text { Retention (\%) }\end{array}$ & $\begin{array}{l}\text { Long-Term } \\
\text { Cycling }\end{array}$ & Current Density & Reference \\
\hline PAN/PEGDA & $\begin{array}{c}\mathrm{LiPF}_{6}-\mathrm{LiCF}_{3} \mathrm{SO}_{3} / \mathrm{EC}- \\
\mathrm{DMC} / \mathrm{TiO}_{2}\end{array}$ & 138.0 & - & 50 & $0.2 \mathrm{C}$ & [79] \\
\hline PAN & $\mathrm{LiPF}_{6} / \mathrm{TMS} / \mathrm{TiO}_{2}$ & 345.0 & - & 20 & $0.2 \mathrm{C}$ & [81] \\
\hline PAN & $\mathrm{LiPF}_{6} / \mathrm{TMS} / \mathrm{TiO}_{2}-\mathrm{SiO}_{2}$ & 182.0 & 75.8 & 100 & $0.2 \mathrm{C}$ & [82] \\
\hline PVDF-HFP & $\mathrm{LiPF}_{6} / \mathrm{TiO}_{2}$ & 122.0 & 92.4 & 100 & $0.5 \mathrm{C}$ & [85] \\
\hline PVDF-HFP/PMMA & $\mathrm{LiPF}_{6 /}$ EC-DMC/TiO ${ }_{2}$ & 173.2 & 92.1 & 50 & $0.2 \mathrm{C}$ & [88] \\
\hline PAN/PVA & $\begin{array}{c}\mathrm{LiPF}_{6 /} \text { EC-DMC- } \\
\mathrm{DEC} / \mathrm{TiO}_{2}\end{array}$ & 60.0 & 71.0 & 1000 & $20 \mathrm{C}$ & [90] \\
\hline P(MMA-AN-EA) & $\mathrm{LiPF}_{6} / \mathrm{EC}-\mathrm{DMC} / \mathrm{Al}_{2} \mathrm{O}_{3}$ & 132.0 & 94.8 & 100 & $0.2 \mathrm{C}$ & [98] \\
\hline PVFM & $\mathrm{LiPF}_{6 /} \mathrm{EC}-\mathrm{DMC} / \mathrm{Al}_{2} \mathrm{O}_{3}$ & 140.3 & 88.6 & 15 & $0.2 \mathrm{C}$ & [99] \\
\hline PVDF-HFP & $\mathrm{LiPF}_{6} / \mathrm{EC}-\mathrm{DMC} / \mathrm{Al}_{2} \mathrm{O}_{3}$ & 160.2 & 96.0 & 50 & $0.1 \mathrm{C}$ & [100] \\
\hline PVDF-HFP & $\begin{array}{c}\mathrm{LiPF}_{6 /} \text { EC-DEC- } \\
\mathrm{DBP} / \mathrm{SiO}_{2}\end{array}$ & 149.0 & 97.4 & 100 & $0.5 \mathrm{C}$ & [108] \\
\hline PAN & $\mathrm{SiO}_{2}$ & 157.9 & 88.0 & 300 & $0.5 \mathrm{C}$ & [111] \\
\hline PPC & LiTFSI-LiNO $3 / \mathrm{SiO}_{2}$ & 597.0 & 85.0 & 500 & $0.1 \mathrm{C}$ & [113] \\
\hline PEO & $\mathrm{LiClO}_{4} / \mathrm{SiO}_{2}$ & 123.5 & 70.0 & 90 & $0.2 \mathrm{C}$ & [114] \\
\hline PVDF-HFP & $\begin{array}{c}\mathrm{LiPF}_{6 /} \mathrm{EC}-\mathrm{DMC}- \\
\mathrm{EMC} / \mathrm{ZrO}_{2}\end{array}$ & 126.4 & 85.2 & 150 & $2 \mathrm{C}$ & [120] \\
\hline PVDF-HFP & $\mathrm{LiClO}_{4} / \mathrm{EC}-\mathrm{DMC} / \mathrm{CeO}_{2}$ & 105.8 & 86.0 & 30 & $0.5 \mathrm{C}$ & [124] \\
\hline PVDF-HFP & $\mathrm{LiClO}_{4} / \mathrm{EC}-\mathrm{DMC} / \mathrm{CeO}_{2}$ & 116.4 & 81.6 & 50 & $0.5 \mathrm{C}$ & [125] \\
\hline PEO/PVDF-HFP & $\mathrm{LiClO}_{4} / \mathrm{PC} / \mathrm{BaTiO}_{3}$ & 123.0 & - & 100 & $0.3 \mathrm{C}$ & [130] \\
\hline PVDF-HFP & $\mathrm{LiN}\left(\mathrm{CF}_{3} \mathrm{SO}_{2}\right)_{2} / \mathrm{AlO}(\mathrm{OH})_{\mathrm{n}}$ & 125.0 & 98.4 & 20 & $0.1 \mathrm{C}$ & [162] \\
\hline PVDF-HFP & $\mathrm{LiBOB} / \mathrm{AlO}(\mathrm{OH})_{\mathrm{n}}$ & 157.0 & 97.8 & 10 & $0.1 \mathrm{C}$ & [163] \\
\hline P(VDF-HFP)-co-PEO & $\mathrm{LiPF}_{6} / \mathrm{GO}$ & 103.0 & 92.0 & 2000 & $5 \mathrm{C}$ & [164] \\
\hline PVDF-HFP & LiTFSI/GO & 120.0 & 94.4 & 100 & $0.2 \mathrm{C}$ & [165] \\
\hline PVDF & $\mathrm{LiPF}_{6} /$ Graphene & 144.0 & 96.6 & 100 & $2.0 \mathrm{C}$ & [166] \\
\hline PAVM & $\mathrm{LiPF}_{6} / \mathrm{GOQD}$ & - & 100 & 500 & $5 \mathrm{C}$ & [167] \\
\hline P(OPal-MMA) & $\mathrm{LiClO}_{4} /$ Clay & 146.4 & - & 50 & $0.5 \mathrm{C}$ & [168] \\
\hline
\end{tabular}

\subsection{Sodium-Ion Batteries}

Because of their versatility, flexibility, and thermodynamic stability, SPEs have been selected as one of the most promising candidates for high safety sodium-ion batteries (SIBs). However, the low ion mobility in SPEs at room temperature hinders their practical application in SIBs. The addition of inorganic fillers to GPEs is an effective method to improve the ion conduction of electrolytes. Conventional fillers, such as $\mathrm{SiO}_{2}, \mathrm{TiO}_{2}, \mathrm{Al}_{2} \mathrm{O}_{3}$, and $\mathrm{BaTiO}_{3}$, etc., have been used to synthesize composite solid polymer electrolytes for sodium batteries [169-171]. Hwang et al. [172] fabricated a GPE containing a PEO-based polymer electrolyte, $\mathrm{NaClO}_{4}$, and nanosized $\mathrm{TiO}_{2}$ using a solution casting technique. The GPE, with a EO:Na ratio of 20:1 (w:w) and $5 \mathrm{wt} \% \mathrm{TiO}_{2}$, showed the highest ionic conductivity of $\sim 2.62 \times 10^{-1} \mathrm{mS} \mathrm{cm}^{-1}$ at $60^{\circ} \mathrm{C}$ and enhanced the stability of cyclic performance of the cell. This result can be explained by the positive effect of the $\mathrm{TiO}_{2}$ filler, which reduced the crystallinity of the polymer, thus enabling faster ionic transport. Zhang et al. [173] prepared a novel GPE based on PMMA, PEG, $\mathrm{NaClO}_{4}$, and $\alpha-\mathrm{Al}_{2} \mathrm{O}_{3}$ which contained acidic surface sites. High electrolytic conductance $\left(1.46 \times 10^{-1} \mathrm{mS} \mathrm{cm}^{-1}\right.$ at $\left.70{ }^{\circ} \mathrm{C}\right)$, wide electrochemical stability window ( $4.5 \mathrm{~V}$ vs. $\left.\mathrm{Na}^{+} / \mathrm{Na}\right)$, and good mechanical stability were achieved by the GPE. The reversible capacity reached $85 \mathrm{mAh} \mathrm{g}^{-1}$, corresponding to a capacity retention of $94.1 \%$, even after 350 cycles, when coupled with a $\mathrm{Na}_{3} \mathrm{~V}_{2}\left(\mathrm{PO}_{4}\right)_{3}$ cathode. Kumar et al. [174] investigated a GPE containing $\mathrm{SiO}_{2}$ NPs dispersed in PVDF-HFP. This membrane was transparent, flexible, and free-standing, which makes it suitable for flexible SIBs. The material showed a high electrolytic conductance of $4.1 \times 10^{0} \mathrm{mS} \mathrm{cm}^{-1}$ at ambient temperature and good thermal stability owing to the formation of space-charge layers between the $\mathrm{SiO}_{2}$ 
particles and the gel region. Liu et al. [175] synthesized a PVDF-HFP/PMMA-based GPE membrane containing a suitable number of $\beta-\mathrm{Al}_{2} \mathrm{O}_{3} \mathrm{NPs}$. The incorporation of PMMA into PVDF-HFP-based film improved the ionic conductivity due to the amorphous properties of PMMA which can promote the uptake of the LE and enhance the interaction of carbonylcarbonate groups in MMA monomer and electrolyte, respectively. The GPE membrane showed a high electrolytic conductance of $2.39 \times 10^{0} \mathrm{mS} \mathrm{cm}^{-1}$ and enhanced the electrochemical stability window up to $5.04 \mathrm{~V}$. Besides, the full cell exhibited good electrochemical performance with the first discharge capacity of $94.1 \mathrm{mAh} \mathrm{g}^{-1}$ and capacity retention of $85 \%$ after 300 cycles at $0.5 \mathrm{C}$. Wang et al. [176] employed a sodium ion conductive $\mathrm{Na}_{3} \mathrm{Zr}_{2} \mathrm{Si}_{2} \mathrm{PO}_{12}$ (NZSPO) in modified PVDF-HFP/PMMA/polyurethane (TPU)-based GPE to enhance the properties of membrane. The introduction of filler increased the amorphous phase and boosted the porosity of GPE membranes, leading to the increase in LE uptake. Besides, the NZSPO itself was the active filler; thus, it could provide pathways of ions at the interface between the filler and GPE. The GPE film showed ionic conductivity of $2.83 \times 10^{0} \mathrm{mS} \mathrm{cm}^{-1}$ and a wide electrochemical window of $5.16 \mathrm{~V}$. The full cell exhibited the first discharge capacity of $92.7 \mathrm{mAh} \mathrm{g}^{-1}$ with capacity retention of $99.2 \%$ after 100 cycles at $0.5 \mathrm{C}$. Yi et al. [177] prepared a PMMA-based GPE by introducing $\mathrm{Na}_{3} \mathrm{Zr}_{2} \mathrm{Si}_{2} \mathrm{PO}_{12}$ and PVDF-HFP to boost the interfacial adhesion between electrode and electrolyte. The GPE membrane showed a high electrolytic conductance of $2.78 \times 10^{0} \mathrm{mS} \mathrm{cm}^{-1}$ and a wide electrochemical window of $4.9 \mathrm{~V}$. More importantly, the assembled full cell with GPE exhibited the first discharge capacity of $96 \mathrm{mAh} \mathrm{g}^{-1}$ with excellent cyclability during 600 cycles.

Recently, inorganic NPs have also been employed to further enhance the electrochemical properties of PEO/Na-salts/ILs in GPEs. Song et al. [178] developed a hybrid GPE consisting of $\mathrm{PEO}-\mathrm{NaClO}_{4}-\mathrm{SiO}_{2}$ and 1-ethyl-3-methylimidazolium bis(fuorosulfonyl)imide (Emim FSI) for sodium batteries. This GPE demonstrated an integrated structure by redox processes and interactions among the Emim FSI, silicon, and PEO. The GPE showed a high electrolytic conductance of $1.3 \times 10^{0} \mathrm{mS} \mathrm{cm}^{-1}$ at ambient temperature and stable voltage window of $4.2 \mathrm{~V}$ vs. Na/ $\mathrm{Na}^{+}$, which is sufficient for most cathode materials in SIBs. These results indicated that the introduction of nanosized inorganic fillers is a good strategy to enhance the electrochemical performance of polymer electrolytes. Table 8 presents the electrochemical performance of SIBs with GPEs containing inorganic fillers.

Table 8. Lists of GPEs and their electrochemical performance in SIBs.

\begin{tabular}{|c|c|c|c|c|c|c|}
\hline Polymer & Salt/Plasticizers/Fillers & $\begin{array}{l}\text { Specific Capacity } \\
\left(\mathrm{mA} h \mathrm{~g}^{-1}\right)\end{array}$ & $\begin{array}{c}\text { Capacity } \\
\text { Retention (\%) }\end{array}$ & $\begin{array}{l}\text { Long-Term } \\
\text { Cycling }\end{array}$ & Current Density & Reference \\
\hline PVDF-HFP & $\mathrm{NaClO}_{4} / \mathrm{EC}-\mathrm{DEC} / \mathrm{Al}_{2} \mathrm{O}_{3}$ & 120.0 & 95.3 & 1000 & $1 \mathrm{C}$ & [104] \\
\hline PVDF-HFP/PMMA & $\begin{array}{c}\mathrm{NaCF}_{3} \mathrm{SO}_{3} \mathrm{EC}- \\
\mathrm{PC} / \mathrm{Al}_{2} \mathrm{O}_{3}\end{array}$ & 360.0 & 90.0 & 10 & - & [105] \\
\hline PEO & $\mathrm{NaClO}_{4} / \mathrm{TiO}_{2}$ & 45.0 & 91.5 & 25 & $0.1 \mathrm{C}$ & [172] \\
\hline PMMA-PEG & $\mathrm{NaClO}_{4} / \mathrm{Al}_{2} \mathrm{O}_{3}$ & 85.0 & 94.1 & 350 & $0.5 \mathrm{C}$ & [173] \\
\hline PVDF-HFP & $\mathrm{NaCF}_{3} \mathrm{SO}_{3} / \mathrm{SiO}_{2}$ & 21.0 & 15.0 & 8 & - & [174] \\
\hline PVDF-HFP/PMMA & $\mathrm{NaClO}_{4} / \beta-\mathrm{Al}_{2} \mathrm{O}_{3}$ & 80.0 & 85.0 & 300 & $0.5 \mathrm{C}$ & [175] \\
\hline $\begin{array}{c}\text { PVDF- } \\
\mathrm{HFP} / \mathrm{PMMA} / \mathrm{TPU}\end{array}$ & $\mathrm{NaClO}_{4} / \mathrm{NZSPO}$ & 92.0 & 99.2 & 100 & $0.5 \mathrm{C}$ & [176] \\
\hline PVDF-HFP/PMMA & $\mathrm{NaPF}_{6} / \mathrm{NZSPO}$ & 96.0 & - & 600 & $1 \mathrm{C}$ & [177] \\
\hline $\mathrm{PEO}$ & $\mathrm{NaClO}_{4} / \mathrm{SiO}_{2}$ & 46.2 & 51.0 & 100 & $0.5 \mathrm{C}$ & [178] \\
\hline
\end{tabular}

\subsection{Magnesium-Ion Batteries}

Magnesium (Mg) is the eighth most abundant element in the Earth's crust, the third most abundant element in seawater, and is geographically widespread [179]. Compared with Li-metal anodes, it is less likely that $\mathrm{Mg}$ dendrites would grow as they thermodynamically prefer three dimensional crystal growth rather than one-dimensional growth [180]. Nevertheless, the presence of dendrite $\mathrm{Mg}$ has been reported in several LEs and remains the hurdle to overcome with $\mathrm{Mg}$ metal anodes. $\mathrm{Mg}$ metal interacts more strongly with counter ions or polymer matrices than lithium metal and requires a higher under/overpotential for $\mathrm{Mg}$ electrode position/dissolution. Therefore, it is necessary to develop new $\mathrm{Mg}$ polymer 
electrolytes [181]. Kim et al. [182] prepared $\mathrm{Mg}^{2+}$ ion-conducting polymer electrolytes containing $\mathrm{P}(\mathrm{VdF}-\mathrm{co}-\mathrm{HFP}), \mathrm{Mg}\left(\mathrm{ClO}_{4}\right)_{2}-\mathrm{EC} / \mathrm{PC}$, and $\mathrm{SiO}_{2}$ filler. This GPE achieved an electrolytic conductance of $3.2 \times 10^{0} \mathrm{mS} \mathrm{cm}^{-1}$ at room temperature. Hashmi et al. [183] investigated a novel GPE nanocomposite based on PVdF-HFP containing dispersed $\mathrm{MgO}$ NPs. The maximum electrolytic conductance was $8 \times 10^{0} \mathrm{mS} \mathrm{cm}^{-1}$ at room temperature when $3 \mathrm{wt} \% \mathrm{MgO}$ was introduced. The assembled $\mathrm{V}_{2} \mathrm{O}_{5} / \mathrm{GPE} / \mathrm{Mg}$ battery showed the low first discharge capacity of $58 \mathrm{mAh} \mathrm{g}^{-1}$ and poor cycling performance with capacity retention of $38 \%$ after 10 cycles, which are attributed to high interfacial resistance between $\mathrm{Mg}$ and GPE. Pandey et al. [184] studied the effect of $\mathrm{MgO}$ and $\mathrm{SiO}_{2}$ particle sizes in a PVDF-HFP-based polymer electrolyte. High conductivities of $1 \times 10^{1} \mathrm{mS} \mathrm{cm}^{-1}$ for $3 \mathrm{wt} \%$ and $9 \times 10^{0} \mathrm{mS} \mathrm{cm}^{-1}$ for $15 \mathrm{wt} \% \mathrm{SiO}_{2}$ were obtained for the $\mathrm{SiO}_{2}$ dispersed gel electrolyte. The presence of $\mathrm{MgO}$ formed space-charge regions that facilitated the $\mathrm{Mg}^{2+}$ ion motion, thereby enhancing the electrolytic conductance. Hashmi et al. [185] investigated the effect of $\mathrm{SiO}_{2}$ NPs in a PVDF-HFP-based polymer electrolyte. The highest electrolytic conductance achieved was $1.1 \times 10^{1} \mathrm{mS} \mathrm{cm}^{-1}$ at $25^{\circ} \mathrm{C}$ when $3 \mathrm{wt} \% \mathrm{SiO}_{2} \mathrm{NPs}$ were added. The assembled full cell with GPE exhibited a first discharge capacity of $175 \mathrm{mAh} \mathrm{g}^{-1}$ with poor cyclability after 10 cycles. They also studied the effect of microsized $\mathrm{MgO}$ particle dispersion in a PVDF-HFP-based magnesium-ion $\left(\mathrm{Mg}^{2+}\right)$ conducting GPE [186]. The maximum ionic conductivity reached $6 \times 10^{0} \mathrm{mS} \mathrm{cm}^{-1}$ at room temperature with the incorporation of $10 \mathrm{wt} \% \mathrm{MgO}$ particles. Hashmi et al. [187] reported a novel GPE membrane containing PVDF-HFP as the polymer matrix, $\mathrm{Mg}$ trifluoromethanesulfonate (Mg-triflate or $\mathrm{Mg}(\mathrm{Tf})_{2}$ ) in a mixture of EC and $\mathrm{PC}$ as the $\mathrm{Mg}$ salt and nanosized passive $\mathrm{Al}_{2} \mathrm{O}_{3}$ filler or active filler $\mathrm{Mg}$ aluminate $\left(\mathrm{MgAl}_{2} \mathrm{O}_{4}\right)$. The presence of the filler increased the porosity of the membrane, thereby increasing the electrolytic conductance of the GPE film. The highest ionic conductivities achieved were $3.3 \times 10^{0}$ and $4.0 \times 10^{0} \mathrm{mS} \mathrm{cm}^{-1}$ when adding $30 \mathrm{wt} \%$ $\mathrm{Al}_{2} \mathrm{O}_{3}$ and $20 \mathrm{wt} \% \mathrm{MgAl}_{2} \mathrm{O}_{4}$ fillers, respectively. To achieve the impressive improvement of electrochemical performance with the inorganic fillers-added GPE, it is thought that high impedance at the interface between $\mathrm{Mg}$ metal and GPE needs to be resolved, which requires the finding of suitable electrode materials. Table 9 shows the list of electrochemical performance of MIBs with inorganic filler-added GPEs.

Table 9. Lists of GPEs and their electrochemical performance in MIBs.

\begin{tabular}{|c|c|c|c|c|c|c|}
\hline Polymer & Salt/Plasticizers/Fillers & $\begin{array}{l}\text { Specific Capacity } \\
\left(\mathrm{mA} h \mathrm{~g}^{-1}\right)\end{array}$ & $\begin{array}{c}\text { Capacity } \\
\text { Retention (\%) }\end{array}$ & $\begin{array}{l}\text { Long-Term } \\
\text { Cycling }\end{array}$ & Current Density & Reference \\
\hline PVDF-HFP & $\mathrm{Mg}\left(\mathrm{ClO}_{4}\right)_{2} / \mathrm{EC}-\mathrm{PC} / \mathrm{SiO}_{2}$ & 24.0 & 41.4 & 11 & - & [182] \\
\hline PVDF-HFP & $\mathrm{Mg}\left(\mathrm{ClO}_{4}\right)_{2} / \mathrm{EC}-\mathrm{PC} / \mathrm{SiO}_{2}$ & 175.0 & 79.5 & 10 & $0.1 \mathrm{C}$ & [185] \\
\hline PVDF-HFP & $\mathrm{Mg}\left(\mathrm{ClO}_{4}\right)_{2} / \mathrm{EC}-\mathrm{PC} / \mathrm{MgO}$ & 175.0 & 67.31 & 10 & - & [186] \\
\hline
\end{tabular}

\subsection{Zinc-Ion Batteries}

Because of the favorable features of $\mathrm{Zn}$ metal, such as low cost, low toxicity, and high natural abundance, $\mathrm{Zn}$ has received intensive attention as an anode material in $\mathrm{Zn}$ rechargeable batteries. Hashmi et al. [188] prepared a GPE containing PVDF-HFP as the host polymer, a solution of EC-PC- $\mathrm{Zn}(\mathrm{Tf})_{2}$, and nanosized $\mathrm{ZnO}$ filler particles. The GPE exhibited good thermal stability and good electrochemical performance achieving an electrolytic conductance of $>10^{0} \mathrm{mS} \mathrm{cm}^{-1}$. LE immobilization and dispersion of the $\mathrm{ZnO}$ NPs in the GPE led to appropriate changes in the PVDF-HFP and filler-polymer interactions. Suthanthirarai et al. [189] prepared new GPE using a solution casting technique and evaluated the transport mechanism of a $\mathrm{Zn}^{2+}$-conducting polymer electrolyte system. The highest electrolytic conductance was $3.4 \times 10^{-3} \mathrm{mS} \mathrm{cm}^{-1}$ at room temperature when $5 \mathrm{wt} \% \mathrm{TiO}_{2} \mathrm{NPs}$ were added. The presence of $\mathrm{TiO}_{2} \mathrm{NPs}$ formed a space-charged region, which significantly enhanced the movement of the $\mathrm{Zn}^{2+}$ ions, thereby increasing the ionic conductivity. From good thermal stability and enhanced ionic conductivity achieved by adding inorganic fillers in GPEs, the choice of appropriate inorganic filler in GPE can be seen as a potential approach for the high-performance ZIBs. 


\section{Conclusions and Perspectives}

The incorporation of inorganic fillers into the polymer/salt system has been demonstrated as a promising strategy to enhance the electrochemical performance of GPEs in the last few decades. The introduction of inorganic fillers improves the electrolytic conductance as well as mechanical and thermal stability of gel-state polymer electrolytes. In this review, a historical overview of the developments in GPEs is first provided and subsequently detailed fillers applied in GPEs are discussed. The possible mechanisms behind the conductivity enhancement of inorganic fillers are also briefly discussed. Finally, inorganic filler/polymer GPEs studied for use in various battery systems, including Li-, $\mathrm{Na}-, \mathrm{Mg}-$, and $\mathrm{Zn}$-ion batteries, were reviewed.

Although there have been several studies regarding the mechanisms behind the ionic conductivity enhancement and improvement in electrochemical stability with the addition of fillers, further fundamental understanding should be continuously pursued with novel composite polymer electrolyte designs for the successful implementation of GPEs in highperformance lithium batteries, especially for industrial applications. To achieve this, both experimental and theoretical calculation approaches should be synergistically combined. On the experimental side, it is important to find the optimal composite GPE structure, wherein the interfacial volume between the polymer and filler is maximized and agglomeration of the constituents is minimized. This structural feature will be beneficial for ionic conductivity and electrochemical stability, thus improving the cyclic stability in various battery applications. Consideration of the appropriate interfacial structure between the gel electrolyte and the electrode is another important factor. Long and tortuous ion pathways greatly inhibit the utilization of active materials in the performance of Li-polymer batteries. A reduced internal and interfacial resistance at the cathode and electrolyte/electrode interface can significantly enhance the cycling performance and rate capability of LIBs, resulting in a higher energy density. Besides, optimization of the active material loading $\left(\mathrm{mg} \cdot \mathrm{cm}^{-2}\right)$ is another important consideration to realize the high energy density of the cell. Although a high thickness film which accompanies the high mass loading can increase the energy storage capacity of LIBs, it does not necessarily result in the high energy density. Since the energy density is proportional to the specific capacity, it is necessary to maximize the specific capacity to obtain the high energy density. Normally, when the film thickness is excessively high, the specific capacitance decreases due to the inefficient electrolyte ion diffusion through the electrode film. If the film thickness is too low, the reproducibility of measured capacity becomes degraded. Therefore, the appropriate film thickness (or mass loading) is required to increase the energy density. In previous studies with GPEs, the best mass loading condition is in the range of 0.35 to $3 \mathrm{mg} \mathrm{cm}^{-2}[104,114,120,155-157,165,175,176]$. In the theoretical calculations, a precise prediction of the overall structure of the constituents in the composite gel will be advantages in the design of GPE components; in particular, it can provide useful information regarding the appropriate content of inorganic filler for a given GPE system.

Finally, the preparation method utilized for GPEs needs to be considered in terms of simplicity and manufacturing costs. To apply newly developed GPEs to batteries in industry, facile and low-cost process should be utilized to prepare the GPEs. In addition, advanced fabrication approaches should be developed to apply the new GPE to microbatteries and flexible devices.

Author Contributions: Conceptualization, J.H. and V.P.H.H.; writing-original draft preparation, V.P.H.H.; writing-review and editing, S.S. and J.H.; supervision, J.H.; funding acquisition, J.H. All authors have read and agreed to the published version of the manuscript.

Funding: This research was also supported by Basic Science Research Capacity Enhancement Project through Korea Basic Science Institute (National Research Facilities and Equipment Center) grant funded by the Ministry of Education (2019R1A6C1010016) and Korea Institute of Energy Technology Evaluation and Planning (KETEP) and the Ministry of Trade, Industry \& Energy (MOTIE) of the Republic of Korea (No. 20194030202290).

Conflicts of Interest: The authors declare no conflict of interest. 


\section{References}

1. $\mathrm{Xu}, \mathrm{K}$. Nonaqueous liquid electrolytes for lithium-based rechargeable batteries. Chem. Rev. 2004, 104, 4303-4418. [CrossRef]

2. Nguyen, T.A.; Kim, I.T.; Lee, S.W. Chitosan-tethered iron oxide composites as an antisintering porous structure for highperformance Li-ion battery anodes. J. Am. Ceram. Soc. 2016, 99, 2720-2728. [CrossRef]

3. Mun, Y.S.; Pham, T.N.; Bui, V.K.H.; Tanaji, S.T.; Lee, H.U.; Lee, G.-W.; Choi, J.S.; Kim, I.T.; Lee, Y.-C. Tin oxide evolution by heat-treatment with tin-aminoclay (SnAC) under argon condition for lithium-ion battery (LIB) anode applications. J. Power Sources 2019, 437, 226946. [CrossRef]

4. Nguyen, T.L.; Park, D.; Kim, I.T. $\mathrm{Fe}_{\mathrm{x}} \mathrm{Sn}_{\mathrm{y}} \mathrm{O}_{\mathrm{z}}$ Composites as Anode Materials for Lithium-Ion Storage. J. Nanosci. Nanotechnol. 2019, 19, 6636-6640. [CrossRef]

5. Mun, Y.S.; Kim, D.; Kim, I.T. Electrochemical performance of FeSb 2 -P@C composites as anode materials for lithium-ion storage. J. Nanosci. Nanotechnol. 2018, 18, 1343-1346. [CrossRef]

6. Nguyen, T.L.; Kim, J.H.; Kim, I.T. Electrochemical performance of $\mathrm{Sn} / \mathrm{SnO} / \mathrm{Ni}_{3} \mathrm{Sn}$ composite anodes for lithium-ion batteries J. Nanosci. Nanotechnol. 2019, 19, 1001-1005. [CrossRef] [PubMed]

7. Pham, T.N.; Tanaji, S.T.; Choi, J.-S.; Lee, H.U.; Kim, I.T.; Lee, Y.-C. Preparation of Sn-aminoclay (SnAC)-templated Fe ${ }_{3} \mathrm{O}_{4}$ nanoparticles as an anode material for lithium-ion batteries. RSC Adv. 2019, 9, 10536-10545. [CrossRef]

8. Son, S.Y.; Hong, S.-A.; Oh, S.Y.; Lee, Y.-C.; Lee, G.-W.; Kang, J.W.; Huh, Y.S.; Kim, I.T. Crab-shell biotemplated SnO 2 composite anodes for lithium-ion batteries. J. Nanosci. Nanotechnol. 2018, 18, 6463-6468. [CrossRef] [PubMed]

9. Min, K.; Park, K.; Park, S.Y.; Seo, S.-W.; Choi, B.; Cho, E. Residual Li reactive coating with $\mathrm{Co}_{3} \mathrm{O}_{4}$ for superior electrochemical properties of $\mathrm{LiNi}_{0.91} \mathrm{Co}_{0.06} \mathrm{Mn}_{0.03} \mathrm{O}_{2}$ cathode material. J. Electrochem. Soc. 2018, 165, A79. [CrossRef]

10. Park, J.H.; Choi, B.; Kang, Y.S.; Park, S.Y.; Yun, D.J.; Park, I.; Shim, J.H.; Park, J.H.; Han, H.N.; Park, K. Effect of Residual Lithium Rearrangement on Ni-rich Layered Oxide Cathodes for Lithium-Ion Batteries. Energy Technol. 2018, 6, 1361-1369. [CrossRef]

11. Min, K.; Jung, C.; Ko, D.-S.; Kim, K.; Jang, J.; Park, K.; Cho, E. High-performance and industrially feasible Ni-rich layered cathode materials by integrating coherent interphase. ACS Appl. Mater. Interfaces 2018, 10, 20599-20610. [CrossRef] [PubMed]

12. Baskoro, F.; Wong, H.Q.; Yen, H.-J. Strategic structural design of a gel polymer electrolyte toward a high efficiency lithium-ion battery. ACS Appl. Energy Mater. 2019, 2, 3937-3971. [CrossRef]

13. Cheng, X.; Pan, J.; Zhao, Y.; Liao, M.; Peng, H. Gel polymer electrolytes for electrochemical energy storage. Adv. Energy Mater. 2018, 8, 1702184. [CrossRef]

14. Park, K.; Choi, B. Requirement of high lithium content in Ni-rich layered oxide material for Li ion batteries. J. Alloy. Compd. 2018, 766, 470-476. [CrossRef]

15. Han, D.; Park, K.; Park, J.-H.; Yun, D.-J.; Son, Y.-H. Selective doping of Li-rich layered oxide cathode materials for high-stability rechargeable Li-ion batteries. J. Ind. Eng. Chem. 2018, 68, 180-186. [CrossRef]

16. Park, K.; Kim, J.; Park, J.-H.; Hwang, Y.; Han, D. Synchronous phase transition and carbon coating on the surface of Li-rich layered oxide cathode materials for rechargeable Li-ion batteries. J. Power Sources 2018, 408, 105-110. [CrossRef]

17. Park, J.-H.; Park, K.; Han, D.; Yeon, D.-H.; Jung, H.; Choi, B.; Park, S.Y.; Ahn, S.-J.; Park, J.-H.; Han, H.N. Structure-and porosity-tunable, thermally reactive metal organic frameworks for high-performance Ni-rich layered oxide cathode materials with multi-scale pores. J. Mater. Chem. A 2019, 7, 15190-15197. [CrossRef]

18. Kang, Y.-S.; Kim, D.Y.; Yoon, J.; Park, J.; Kim, G.; Ham, Y.; Park, I.; Koh, M.; Park, K. Shape control of hierarchical lithium cobalt oxide using biotemplates for connected nanoparticles. J. Power Sources 2019, 436, 226836. [CrossRef]

19. Xu, K. Electrolytes and interphases in Li-ion batteries and beyond. Chem. Rev. 2014, 114, 11503-11618. [CrossRef] [PubMed]

20. Meyer, W.H. Polymer electrolytes for lithium-ion batteries. Adv. Mater. 1998, 10, 439-448. [CrossRef]

21. Zhang, J.; Tan, T.; Zhao, Y.; Liu, N. Preparation of ZnO nanorods/graphene composite anodes for high-performance lithium-ion batteries. Nanomaterials 2018, 8, 966. [CrossRef]

22. Caimi, S.; Klaue, A.; Wu, H.; Morbidelli, M. Effect of $\mathrm{SiO}_{2}$ nanoparticles on the performance of PVdF-HFP/ionic liquid separator for lithium-ion batteries. Nanomaterials 2018, 8, 926. [CrossRef]

23. Wen, L.; Sun, J.; An, L.; Wang, X.; Ren, X.; Liang, G. Effect of conductive material morphology on spherical lithium iron phosphate. Nanomaterials 2018, 8, 904. [CrossRef] [PubMed]

24. Alonso-Domínguez, D.; Pico, M.P.; Álvarez-Serrano, I.; López, M.L. New $\mathrm{Fe}_{2} \mathrm{O}_{3}$-Clay@ C nanocomposite anodes for Li-ion batteries obtained by facile hydrothermal processes. Nanomaterials 2018, 8, 808. [CrossRef]

25. Nacimiento, F.; Cabello, M.; Pérez-Vicente, C.; Alcántara, R.; Lavela, P.; Ortiz, G.F.; Tirado, J.L. On the Mechanism of Magnesium Storage in Micro-and Nano-Particulate Tin Battery Electrodes. Nanomaterials 2018, 8, 501. [CrossRef] [PubMed]

26. Mauger, A.; Julien, C.M.; Paolella, A.; Armand, M.; Zaghib, K. Building better batteries in the solid state: A review. Materials 2019, 12, 3892. [CrossRef]

27. Li, A.; Yuen, A.C.Y.; Wang, W.; De Cachinho Cordeiro, I.M.; Wang, C.; Chen, T.B.Y.; Zhang, J.; Chan, Q.N.; Yeoh, G.H. A Review on Lithium-Ion Battery Separators towards Enhanced Safety Performances and Modelling Approaches. Molecules 2021, $26,478$. [CrossRef] [PubMed]

28. Zhang, B.; Liu, Y.; Liu, J.; Sun, L.; Cong, L.; Fu, F.; Mauger, A.; Julien, C.M.; Xie, H.; Pan, X. “Polymer-in-ceramic” based poly (e-caprolactone)/ceramic composite electrolyte for all-solid-state batteries. J. Energy Chem. 2021, 52, 318-325. [CrossRef]

29. Chen, L.; Li, Y.; Li, S.-P.; Fan, L.-Z.; Nan, C.-W.; Goodenough, J.B. PEO/garnet composite electrolytes for solid-state lithium batteries: From "ceramic-in-polymer" to "polymer-in-ceramic". Nano Energy 2018, 46, 176-184. [CrossRef] 
30. Osada, I.; de Vries, H.; Scrosati, B.; Passerini, S. Ionic-liquid-based polymer electrolytes for battery applications. Angew. Chem. Int. Ed. 2016, 55, 500-513. [CrossRef]

31. Park, M.J.; Choi, I.; Hong, J.; Kim, O. Polymer electrolytes integrated with ionic liquids for future electrochemical devices. J. Appl. Polym. Sci. 2013, 129, 2363-2376. [CrossRef]

32. Wang, C.; Adair, K.R.; Liang, J.; Li, X.; Sun, Y.; Li, X.; Wang, J.; Sun, Q.; Zhao, F.; Lin, X. Solid-state plastic crystal electrolytes: Effective protection interlayers for sulfide-based all-solid-state lithium metal batteries. Adv. Funct. Mater. 2019, 29, 1900392. [CrossRef]

33. Wang, J.; Huang, G.; Chen, K.; Zhang, X.-B. A Porosity-Adjustable Plastic Crystal Electrolyte Enabled High-Performance All-Solid-State Lithium-Oxygen Batteries. Angew. Chem. Int. Ed. 2020, 132, 9468-9473. [CrossRef]

34. Tong, Z.; Wang, S.-B.; Jena, A.; Liu, C.-E.; Liao, S.-C.; Chen, J.-M.; Chang, H.; Hu, S.-F.; Guo, X.; Liu, R.-S. Matchmaker of Marriage between a Li Metal Anode and NASICON-Structured Solid-State Electrolyte: Plastic Crystal Electrolyte and Three-Dimensional Host Structure. ACS Appl. Mater. Interfaces 2020, 12, 44754-44761. [CrossRef]

35. Xue, Z.; He, D.; Xie, X. Poly (ethylene oxide)-based electrolytes for lithium-ion batteries. J. Mater. Chem. A 2015, 3, 19218-19253. [CrossRef]

36. Ichino, T.; Takeshita, Y.; Yamamoto, F.; Kato, H.; Mushiake, N.; Wani, T. Composite Polymer Electrolyte Membrane. U.S. Patent 5,858,264A, 1 December 1999.

37. Jeon, J.-H.; Ha, S.-H.; Cho, J.-J. Gel Polymer Electrolyte Composition, Gel Polymer Electrolyte and Electrochemical Device Comprising the Same. U.S. Patent 9,130,242B2, 30 May 2012.

38. Oliver, M.; Gies, P.J.; Pendalwar, S.L.; Coalson, C.E.; Eschbach, F.O. Polymer gel Electrolyte. U.S. Patent 5,639,573A, 17 June 1997.

39. Fleischmann, S.; Bunte, C.; Mikhaylik, Y.V.; Viner, V.G. Gel Electrolytes and Electrodes. U.S. Patent 9,755,268B2, 5 September 2017.

40. Park, C.-k.; Zhang, Z.; Sun, L.Y.; Chai, C. High Ionic Conductivity gel Polymer Electrolyte for Rechargeable Polymer Batteries. U.S. Patent 6,841,303B2, 26 September 2002.

41. Balsara, N.P.; Eitouni, H.B.; Gur, I.; Singh, M.; Hudson, W. Gel Polymer Electrolytes for Batteries. U.S. Patent 8,889,301B2, 18 November 2014.

42. Arya, A.; Sharma, A. Polymer electrolytes for lithium ion batteries: A critical study. Ionics 2017, 23, 497-540. [CrossRef]

43. Long, L.; Wang, S.; Xiao, M.; Meng, Y. Polymer electrolytes for lithium polymer batteries. J. Mater. Chem. A 2016, 4, 10038-10069. [CrossRef]

44. Dias, F.B.; Plomp, L.; Veldhuis, J.B. Trends in polymer electrolytes for secondary lithium batteries. J. Power Sources 2000, 88, 169-191. [CrossRef]

45. Marcinek, M.; Syzdek, J.; Marczewski, M.; Piszcz, M.; Niedzicki, L.; Kalita, M.; Plewa-Marczewska, A.; Bitner, A.; Wieczorek, P.; Trzeciak, T. Electrolytes for Li-ion transport-Review. Solid State Ion. 2015, 276, 107-126. [CrossRef]

46. Das, A.; Thakur, A.K.; Kumar, K. Raman spectroscopic study of ion dissociation effect in clay intercalated polymer blend nano composite electrolyte. Vib. Spectrosc. 2017, 92, 14-19. [CrossRef]

47. Zhang, Y.; Sheehan, C.J.; Zhai, J.; Zou, G.; Luo, H.; Xiong, J.; Zhu, Y.; Jia, Q. Polymer-embedded carbon nanotube ribbons for stretchable conductors. Adv. Mater. 2010, 22, 3027-3031. [CrossRef]

48. Hennaoui, F.; Belbachir, M. Green Synthesis of copolymer (PDMS-co-PEO) Catalyzed by an ecocatalyst Maghnite-H. Arch. Appl. Sci. Res. 2016, 8, 19-26.

49. Liu, X.; Peng, S.; Gao, S.; Cao, Y.; You, Q.; Zhou, L.; Jin, Y.; Liu, Z.; Liu, J. Electric-field-directed parallel alignment architecting 3D lithium-ion pathways within solid composite electrolyte. ACS Appl. Mater. Interfaces 2018, 10, 15691-15696. [CrossRef] [PubMed]

50. Hassoun, J.; Scrosati, B. Advances in anode and electrolyte materials for the progress of lithium-ion and beyond lithium-ion batteries. J. Electrochem. Soc. 2015, 162, A2582. [CrossRef]

51. Li, Q.; Chen, J.; Fan, L.; Kong, X.; Lu, Y. Progress in electrolytes for rechargeable Li-based batteries and beyond. Green Energy Environ. 2016, 1, 18-42. [CrossRef]

52. Meng, Q.; Hu, J. A review of shape memory polymer composites and blends. Compos. Part A Appl. Sci. Manuf. 2009, 40, 1661-1672. [CrossRef]

53. Park, J.S.; Chung, Y.-C.; Do Lee, S.; Cho, J.W.; Chun, B.C. Shape memory effects of polyurethane block copolymers cross-linked by celite. Fibers Polym. 2008, 9, 661-666. [CrossRef]

54. Ni, Q.-Q.; Zhang, C.-S.; Fu, Y.; Dai, G.; Kimura, T. Shape memory effect and mechanical properties of carbon nanotube/shape memory polymer nanocomposites. Compos. Struct. 2007, 81, 176-184. [CrossRef]

55. Mondal, S.; Jinlian, H. Shape memory studies of functionalized MWNT-reinforced polyurethane copolymers. Iran. Polym. J. 2006, 15, 135-142.

56. Li, Y.; Sun, Y.; Pei, A.; Chen, K.; Vailionis, A.; Li, Y.; Zheng, G.; Sun, J.; Cui, Y. Robust pinhole-free Li3N solid electrolyte grown from molten lithium. ACS Cent. Sci. 2018, 4, 97-104. [CrossRef]

57. Horowitz, Y.; Lifshitz, M.; Greenbaum, A.; Feldman, Y.; Greenbaum, S.; Sokolov, A.P.; Golodnitsky, D. Polymer/Ceramic Interface Barriers: The Fundamental Challenge for Advancing Composite Solid Electrolytes for Li-Ion Batteries. J. Electrochem. Soc. 2020, 167, 160514. [CrossRef]

58. Xu, B.; Zhai, H.; Liao, X.; Qie, B.; Mandal, J.; Gong, T.; Tan, L.; Yang, X.; Sun, K.; Cheng, Q. Porous insulating matrix for lithium metal anode with long cycling stability and high power. Energy Storage Mater. 2019, 17, 31-37. [CrossRef]

59. Park, K.; Goodenough, J.B. Dendrite-Suppressed Lithium Plating from a Liquid Electrolyte via Wetting of Li 3 N. Adv. Energy Mater. 2017, 7, 1700732. [CrossRef] 
60. Weston, J.; Steele, B. Effects of inert fillers on the mechanical and electrochemical properties of lithium salt-poly (ethylene oxide) polymer electrolytes. Solid State Ion. 1982, 7, 75-79. [CrossRef]

61. Kumar, B.; Scanlon, L.G. Polymer-ceramic composite electrolytes. J. Power Sources 1994, 52, 261-268. [CrossRef]

62. Zhou, J.; Fedkiw, P.S. Ionic conductivity of composite electrolytes based on oligo (ethylene oxide) and fumed oxides. Solid State Ion. 2004, 166, 275-293. [CrossRef]

63. Wang, X.-L.; Cai, Q.; Fan, L.-Z.; Hua, T.; Lin, Y.-H.; Nan, C.-W. Gel-based composite polymer electrolytes with novel hierarchical mesoporous silica network for lithium batteries. Electrochim. Acta 2008, 53, 8001-8007. [CrossRef]

64. Yang, C.-C.; Lian, Z.-Y.; Lin, S.; Shih, J.-Y.; Chen, W.-H. Preparation and application of PVDF-HFP composite polymer electrolytes in $\mathrm{LiNi}_{0.5} \mathrm{Co}_{0.2} \mathrm{Mn}_{0.3} \mathrm{O}_{2}$ lithium-polymer batteries. Electrochim. Acta 2014, 134, 258-265. [CrossRef]

65. Itoh, T.; Miyamura, Y.; Ichikawa, Y.; Uno, T.; Kubo, M.; Yamamoto, O. Composite polymer electrolytes of poly (ethylene oxide) $/ \mathrm{BaTiO}_{3} / \mathrm{Li}$ salt with hyperbranched polymer. J. Power Sources 2003, 119, 403-408. [CrossRef]

66. Pitawala, H.; Dissanayake, M.; Seneviratne, V.; Mellander, B.-E.; Albinson, I. Effect of plasticizers (EC or PC) on the ionic conductivity and thermal properties of the (PEO) 9 LiTf: $\mathrm{Al}_{2} \mathrm{O}_{3}$ nanocomposite polymer electrolyte system. J. Solid State Electrochem. 2008, 12, 783-789. [CrossRef]

67. Liu, Y.; Lee, J.Y.; Hong, L. Morphology, crystallinity, and electrochemical properties of in situ formed poly (ethylene oxide)/TiO 2 nanocomposite polymer electrolytes. J. Appl. Polym. Sci. 2003, 89, 2815-2822. [CrossRef]

68. Dey, A.; Karan, S.; De, S. Effect of nanofillers on thermal and transport properties of potassium iodide-polyethylene oxide solid polymer electrolyte. Solid State Commun. 2009, 149, 1282-1287. [CrossRef]

69. Ali, T.M.; Padmanathan, N.S. Effect of nanofiller $\mathrm{CeO}_{2}$ on structural, conductivity, and dielectric behaviors of plasticized blend nanocomposite polymer electrolyte. Ionics 2015, 21, 829-840.

70. Osińska, M.; Walkowiak, M.; Zalewska, A.; Jesionowski, T. Study of the role of ceramic filler in composite gel electrolytes based on microporous polymer membranes. J. Membr. Sci. 2009, 326, 582-588. [CrossRef]

71. Kumar, B. Heterogeneous electrolytes: Variables for and uncertainty in conductivity measurements. J. Power Sources 2008, 179, 401-406. [CrossRef]

72. Wieczorek, W.; Such, K.; Chung, S.; Stevens, J. Comparison of Properties of Composite Polymeric Electrolytes Based on the Oxymethylene-Linked Poly (ethylene oxide) $\mathrm{NaClO}_{4}$ Electrolyte with Polyacrylamide or. alpha.- $\mathrm{Al}_{2} \mathrm{O}_{3}$ Additives. J. Phys. Chem. 1994, 98, 9047-9055. [CrossRef]

73. Chung, S.; Wang, Y.; Persi, L.; Croce, F.; Greenbaum, S.; Scrosati, B.; Plichta, E. Enhancement of ion transport in polymer electrolytes by addition of nanoscale inorganic oxides. J. Power Sources 2001, 97, 644-648. [CrossRef]

74. Kim, K.M.; Ko, J.M.; Park, N.-G.; Ryu, K.S.; Chang, S.H. Characterization of poly (vinylidenefluoride-co-hexafluoropropylene)based polymer electrolyte filled with rutile $\mathrm{TiO}_{2}$ nanoparticles. Solid State Ion. 2003, 161, 121-131. [CrossRef]

75. Karlsson, C.; Best, A.; Swenson, J.; Howells, W.; Börjesson, L. Polymer dynamics in $3 \mathrm{PEG}-\mathrm{LiClO}_{4}-\mathrm{TiO}_{2}$ nanocomposite polymer electrolytes. J. Chem. Phys. 2003, 118, 4206-4212. [CrossRef]

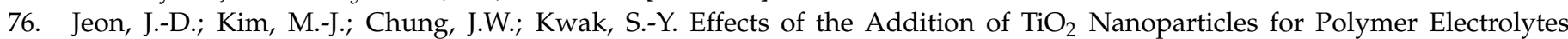
Based on Porous Poly (vinylidene fluoride-co-hexafluoropropylene)/Poly (ethylene oxide-co-ethylene carbonate) Membranes. TechConnect Briefs 2005, 2, 581-584.

77. Lin, C.; Hung, C.; Venkateswarlu, M.; Hwang, B. Influence of $\mathrm{TiO}_{2}$ nano-particles on the transport properties of composite polymer electrolyte for lithium-ion batteries. J. Power Sources 2005, 146, 397-401. [CrossRef]

78. Ahmad, S.; Saxena, T.; Ahmad, S.A. The effect of nanosized $\mathrm{TiO}_{2}$ addition on poly (methylmethacrylate) based polymer electrolytes. J. Power Sources 2006, 159, 205-209. [CrossRef]

79. Cho, B.-W.; Kim, D.H.; Lee, H.-W.; Na, B.-K. Electrochemical properties of gel polymer electrolyte based on poly (acrylonitrile)poly (ethylene glycol diacrylate) blend. Korean J. Chem. Eng. 2007, 24, 1037-1041. [CrossRef]

80. Walkowiak, M.; Osińska, M.; Jesionowski, T.; Siwińska-Stefańska, K. Synthesis and characterization of a new hybrid $\mathrm{TiO}_{2} / \mathrm{SiO}_{2}$ filler for lithium conducting gel electrolytes. Cent. Eur. J. Chem. 2010, 8, 1311-1317. [CrossRef]

81. Kurc, B. Gel electrolytes based on poly (acrylonitrile)/sulpholane with hybrid $\mathrm{TiO}_{2} / \mathrm{SiO}_{2}$ filler for advanced lithium polymer batteries. Electrochim. Acta 2014, 125, 415-420. [CrossRef]

82. Kurc, B.; Jesionowski, T. Modified $\mathrm{TiO}_{2}-\mathrm{SiO}_{2}$ ceramic filler for a composite gel polymer electrolytes working with $\mathrm{LiMn}_{2} \mathrm{O}_{4}$. J. Solid State Electrochem. 2015, 19, 1427-1435. [CrossRef]

83. Johari, N.; Kudin, T.; Ali, A.; Yahya, M. Effects of $\mathrm{TiO}_{2}$ on conductivity performance of cellulose acetate based polymer gel electrolytes for proton batteries. Mater. Res. Innov. 2011, 15, s229-s231. [CrossRef]

84. Zhou, L.; Wu, N.; Cao, Q.; Jing, B.; Wang, X.; Wang, Q.; Kuang, H. A novel electrospun PVDF/PMMA gel polymer electrolyte with in situ $\mathrm{TiO}_{2}$ for Li-ion batteries. Solid State Ion. 2013, 249, 93-97. [CrossRef]

85. Cao, J.; Wang, L.; Shang, Y.; Fang, M.; Deng, L.; Gao, J.; Li, J.; Chen, H.; He, X. Dispersibility of nano-TiO 2 on performance of composite polymer electrolytes for Li-ion batteries. Electrochim. Acta 2013, 111, 674-679. [CrossRef]

86. Jayanthi, S.; Kulasekarapandian, K.; Arulsankar, A.; Sankaranarayanan, K.; Sundaresan, B. Influence of nano-sized TiO 2 on the structural, electrical, and morphological properties of polymer-blend electrolytes PEO-PVC-LiClO4. J. Compos. Mater. 2015, 49, 1035-1045. [CrossRef]

87. Aydin, H.; Bozkurt, A. Nanocomposite polymer electrolytes comprising PVA-graft-PEGME/TiO 2 for Li-ion batteries. J. Mater. Res. 2014, 29, 625. [CrossRef] 
88. Song, D.; Xu, C.; Chen, Y.; He, J.; Zhao, Y.; Li, P.; Lin, W.; Fu, F. Enhanced thermal and electrochemical properties of PVDFHFP/PMMA polymer electrolyte by $\mathrm{TiO}_{2}$ nanoparticles. Solid State Ion. 2015, 282, 31-36. [CrossRef]

89. Yarmolenko, O.; Yudina, A.; Marinin, A.; Chernyak, A.; Volkov, V.; Shuvalova, N.; Shestakov, A. Nanocomposite network polymer gel-electrolytes: $\mathrm{TiO}_{2}$-and $\mathrm{Li}_{2} \mathrm{TiO}_{3}$-nanoparticle effects on their structure and properties. Russ. J. Electrochem. 2015, 51, 412-420. [CrossRef]

90. Wang, S.-H.; Lin, Y.-Y.; Teng, C.-Y.; Chen, Y.-M.; Kuo, P.-L.; Lee, Y.-L.; Hsieh, C.-T.; Teng, H. Immobilization of anions on polymer matrices for gel electrolytes with high conductivity and stability in lithium ion batteries. ACS Appl. Mater. Interfaces 2016, 8, 14776-14787. [CrossRef]

91. Kumar, P.S.; Sakunthala, A.; Govindan, K.; Reddy, M.; Prabu, M. Single crystalline $\mathrm{TiO}_{2}$ nanorods as effective fillers for lithium ion conducting PVdF-HFP based composite polymer electrolytes. RSC Adv. 2016, 6, 91711-91719. [CrossRef]

92. Jagadeesan, A.; Sasikumar, M.; Krishna, R.H.; Raja, N.; Gopalakrishna, D.; Vijayashree, S.; Sivakumar, P. High electrochemical performance of nano $\mathrm{TiO}_{2}$ ceramic filler incorporated PVC-PEMA composite gel polymer electrolyte for Li-ion battery applications. Mater. Res. Express 2019, 6, 105524. [CrossRef]

93. Sachdeva, A.; Singh, P.K. Modification of properties of polymer electrolyte by incorporation of titanium dioxide nanoparticles. Mol. Cryst. Liq. Cryst. 2019, 693, 97-106. [CrossRef]

94. Li, Z.; Su, G.; Gao, D.; Wang, X.; Li, X. Effect of $\mathrm{Al}_{2} \mathrm{O}_{3}$ nanoparticles on the electrochemical characteristics of P (VDF-HFP)-based polymer electrolyte. Electrochim. Acta 2004, 49, 4633-4639. [CrossRef]

95. Piotrowska, K.; Zalewska, A.; Syzdek, J.S.; Niedzicki, L.; Marcinek, M. Properties of PVdF/HFP Inorganic $\mathrm{Al}_{2} \mathrm{O}_{3} \mathrm{Filler} \mathrm{Modified}$ Gel Electrolytes. Ecs Trans. 2010, 25, 221. [CrossRef]

96. Egashira, M.; Yoshimoto, N.; Morita, M. The Effect of Alumina Filler on the Properties of Imidazolium Ionic Liquid Gel Electrolyte. Electrochem. Commun. 2010, 78, 423-426. [CrossRef]

97. Chand, N.; Rai, N.; Agrawal, S.; Patel, S. Morphology, thermal, electrical and electrochemical stability of nano aluminium-oxidefilled polyvinyl alcohol composite gel electrolyte. Bull. Mater. Sci. 2011, 34, 1297-1304. [CrossRef]

98. Sun, P.; Liao, Y.; Luo, X.; Li, Z.; Chen, T.; Xing, L.; Li, W. The improved effect of co-doping with nano-SiO $\mathrm{O}_{2}$ and nano- $\mathrm{Al}_{2} \mathrm{O}_{3}$ on the performance of poly (methyl methacrylate-acrylonitrile-ethyl acrylate) based gel polymer electrolyte for lithium ion batteries. RSC Adv. 2015, 5, 64368-64377. [CrossRef]

99. Wen, Y.; Li, G.; Zhang, P.; Xiong, G. Performance Improvement of Polyvinyl Formal Based Gel Polymer Electrolyte for Lithium-Ion Batteries by Coating $\mathrm{Al}_{2} \mathrm{O}_{3}$. J. Appl. Math. Phys. 2016, 4, 189-194. [CrossRef]

100. Kim, K.-W.; Kim, H.W.; Kim, Y.; Kim, J.-K. Composite gel polymer electrolyte with ceramic particles for $\mathrm{LiNi}_{1 / 3} \mathrm{Mn}_{1 / 3} \mathrm{Co}_{1 / 3} \mathrm{O}_{2}-$ $\mathrm{Li}_{4} \mathrm{Ti}_{5} \mathrm{O}_{12}$ lithium ion batteries. Electrochim. Acta 2017, 236, 394-398. [CrossRef]

101. Vishwakarma, V.; Jain, A. Enhancement of thermal transport in Gel Polymer Electrolytes with embedded $\mathrm{BN} / \mathrm{Al}_{2} \mathrm{O}_{3}$ nano-and micro-particles. J. Power Sources 2017, 362, 219-227. [CrossRef]

102. Jurado-Meneses, N.M.; Delgado-Rosero, M.I.; Meléndez-Lira, M.A. Structural and vibrational studies on composites polymer electrolytes (PEO) 10CF3COONa+x wt.\% $\mathrm{Al}_{2} \mathrm{O}_{3}$. Rev. Fac. Ing. Univ. Antioq. 2017, 83, 43-49. [CrossRef]

103. Maragani, N.; Vijaya Kumar, K. Structural and Conductivity Studies of PAN-based $\mathrm{Al}_{2} \mathrm{O}_{3}$ Nano Composite Gel Polymer Electrolytes. Iran. J. Mater. Sci. Eng. 2018, 15, 11-18.

104. Lei, D.; He, Y.-B.; Huang, H.; Yuan, Y.; Zhong, G.; Zhao, Q.; Hao, X.; Zhang, D.; Lai, C.; Zhang, S. Cross-linked beta alumina nanowires with compact gel polymer electrolyte coating for ultra-stable sodium metal battery. Nat. Commun. 2019, 10, 1-11. [CrossRef]

105. Mishra, K.; Arif, T.; Kumar, R.; Kumar, D. Effect of $\mathrm{Al}_{2} \mathrm{O}_{3}$ nanoparticles on ionic conductivity of PVdF-HFP/PMMA blend-based $\mathrm{Na}$-ion conducting nanocomposite gel polymer electrolyte. J. Solid State Electrochem. 2019, 23, 2401-2409. [CrossRef]

106. Świerczyński, D.; Zalewska, A.; Wieczorek, W. Composite polymeric electrolytes from the PEODME- $\mathrm{LiClO}_{4}-\mathrm{SiO}_{2} \mathrm{System}_{\text {. }}$ Chem. Mater. 2001, 13, 1560-1564. [CrossRef]

107. Kuo, C.-W.; Li, W.-B.; Chen, P.-R.; Liao, J.-W.; Tseng, C.-G.; Wu, T.-Y. Effect of plasticizer and lithium salt concentration in PMMA-based composite polymer electrolytes. Int. J. Electrochem. Sci. 2013.

108. Lee, Y.-S.; Ju, S.H.; Kim, J.-H.; Hwang, S.S.; Choi, J.-M.; Sun, Y.-K.; Kim, H.; Scrosati, B.; Kim, D.-W. Composite gel polymer electrolytes containing core-shell structured $\mathrm{SiO}_{2}(\mathrm{Li}+)$ particles for lithium-ion polymer batteries. Electrochem. Commun. 2012, 17, 18-21. [CrossRef]

109. Li, W.-l.; Tang, J.-j.; Li, B.-t. Preparation and Characterization of Composite Microporous Gel Polymer Electrolytes Containing $\mathrm{SiO}_{2}$ (Li+). J. Inorg. Organomet. Polym. Mater. 2013, 23, 831-838. [CrossRef]

110. Sethupathy, M.; Sethuraman, V.; Manisankar, P. Preparation of $\mathrm{PVDF} / \mathrm{SiO}_{2}$ composite nanofiber membrane using electrospinning for polymer electrolyte analysis. Soft Nanocsci. Lett. 2013, 3, 37-43. [CrossRef]

111. Shin, W.-K.; Cho, J.; Kannan, A.G.; Lee, Y.-S.; Kim, D.-W. Cross-linked composite gel polymer electrolyte using mesoporous methacrylate-functionalized $\mathrm{SiO}_{2}$ nanoparticles for lithium-ion polymer batteries. Sci. Rep. 2016, 6, 1-10. [CrossRef]

112. Nagajothi, A.; Kannan, R.; Rajashabala, S. Lithium ion conduction in plasticizer based composite gel polymer electrolytes with the addition of $\mathrm{SiO}_{2}$. Mater. Res. Innov. 2018, 22, 226-230. [CrossRef]

113. Huang, H.; Ding, F.; Zhong, H.; Li, H.; Zhang, W.; Liu, X.; Xu, Q. Nano-SiO2-embedded poly (propylene carbonate)-based composite gel polymer electrolyte for lithium-sulfur batteries. J. Mater. Chem. A 2018, 6, 9539-9549. [CrossRef] 
114. Tan, X.; Wu, Y.; Tang, W.; Song, S.; Yao, J.; Wen, Z.; Lu, L.; Savilov, S.V.; Hu, N.; Molenda, J. Preparation of Nanocomposite Polymer Electrolyte via In Situ Synthesis of $\mathrm{SiO}_{2}$ Nanoparticles in PEO. Nanomaterials 2020, 10, 157. [CrossRef]

115. Aravindan, V.; Vickraman, P.; Kumar, T.P. $\mathrm{ZrO}_{2}$ nanofiller incorporated PVC/PVdF blend-based composite polymer electrolytes (CPE) complexed with LiBOB. J. Membr. Sci. 2007, 305, 146-151. [CrossRef]

116. Suthanthiraraj, S.A.; Kumar, R.; Paul, B.J. Impact Of Zro 2 Nanoparticles On Ionic Transport And Electrochemical Properties Of Nanocomposite Gel Polymer Electrolyte: Ppg (4000)-Agcf3so3: $\mathrm{ZrO}_{2}$. Int. J. Nanosci. 2011, 10, 241-246. [CrossRef]

117. Sivakumar, M.; Subadevi, R.; Muthupradeepa, R. Studies on the effect of dispersoid $\left(\mathrm{ZrO}_{2}\right)$ in PVdF-co-HFP based gel polymer electrolytes. Am. Inst. Phys. 2013, 1536, 857-858.

118. Ramachandran, M.; Subadevi, R.; Wang, F.-M.; Liu, W.-R.; Sivakumar, M. Structural, morphology and ionic conductivity studies on composite P (S-MMA)-ZrO $\mathrm{ZO}_{2}$ Polymer electrolyte for Lithium Polymer battery. In Proceedings of the International Conference on Materials and Characterization Techniques, Vellore, India, 10-12 March 2014; pp. 1687-1689.

119. Chen, R.; Qu, W.; Qian, J.; Chen, N.; Dai, Y.; Guo, C.; Huang, Y.; Li, L.; Wu, F. Zirconia-supported solid-state electrolytes for high-safety lithium secondary batteries in a wide temperature range. J. Mater. Chem. A 2017, 5, 24677-24685. [CrossRef]

120. Xiao, W.; Wang, Z.; Zhang, Y.; Fang, R.; Yuan, Z.; Miao, C.; Yan, X.; Jiang, Y. Enhanced performance of P (VDF-HFP)-based composite polymer electrolytes doped with organic-inorganic hybrid particles $\mathrm{PMMA}_{\mathrm{ZrO}} \mathrm{Z}$ for lithium ion batteries. J. Power Sources 2018, 382, 128-134. [CrossRef]

121. Khoon, L.T.; Fui, M.-L.W.; Hassan, N.H.; Su'ait, M.S.; Vedarajan, R.; Matsumi, N.; Kassim, M.B.; Shyuan, L.K.; Ahmad, A. In situ sol-gel preparation of $\mathrm{ZrO}_{2}$ in nano-composite polymer electrolyte of PVDF-HFP/MG49 for lithium-ion polymer battery. J. Sol-Gel Sci. Technol. 2019, 90, 665-675. [CrossRef]

122. Sai Prasanna, C.M.; Austin Suthanthiraraj, S. PVC/PEMA-based blended nanocomposite gel polymer electrolytes plasticized with room temperature ionic liquid and dispersed with nano- $\mathrm{ZrO}_{2}$ for zinc ion batteries. Polym. Compos. 2019, 40, 3402-3411. [CrossRef]

123. Rajendran, S.; Mahendran, O.; Krishnaveni, K. Effect of $\mathrm{CeO}_{2}$ on Conductivity of PMMA/PEO Polymer Blend Electrolytes. J. New Mater. Electrochem. Syst. 2003, 6, 25-28.

124. Vijayakumar, G.; Karthick, S.; Priya, A.S.; Ramalingam, S.; Subramania, A. Effect of nanoscale CeO 2 on PVDF-HFP-based nanocomposite porous polymer electrolytes for Li-ion batteries. J. Solid State Electrochem. 2008, 12, 1135-1141. [CrossRef]

125. Vijayakumar, G.; Karthick, S.; Subramania, A. A new class of P (VdF-HFP)-CeO 2 -LiClO4-based composite microporous membrane electrolytes for Li-ion batteries. Int. J. Electrochem. 2011, 2011. [CrossRef]

126. Kumar, R.; Suthanthiraraj, S.A. Ion dynamics and segmental relaxation of $\mathrm{CeO}_{2}$ nanoparticles loaded soft-matter like gel polymer electrolyte. J. Non-Cryst. Solids 2014, 405, 76-82. [CrossRef]

127. Polu, A.R.; Kumar, R. Preparation and characterization of PEG-Mg $\left(\mathrm{CH}_{3} \mathrm{COO}\right)_{2}-\mathrm{CeO}_{2}$ composite polymer electrolytes for battery application. Bull. Mater. Sci. 2014, 37, 309-314. [CrossRef]

128. Lee, L.; Park, S.-J.; Kim, S. Effect of nano-sized barium titanate addition on PEO/PVDF blend-based composite polymer electrolytes. Solid State Ion. 2013, 234, 19-24. [CrossRef]

129. Jagadeesan, A.; Sasikumar, M.; Jeevani, R.; Therese, H.; Ananth, N.; Sivakumar, P. Fabrication of BaTiO 3 ceramic filler incorporated PVC-PEMA based blend nanocomposite gel polymer electrolytes for Li ion battery applications. J. Mater. Sci. Mater. Electron. 2019, 30, 17181-17194. [CrossRef]

130. Prabakaran, P.; Manimuthu, R.P.; Gurusamy, S. Influence of barium titanate nanofiller on PEO/PVdF-HFP blend-based polymer electrolyte membrane for Li-battery applications. J. Solid State Electrochem. 2017, 21, 1273-1285. [CrossRef]

131. Zhou, D.; Shanmukaraj, D.; Tkacheva, A.; Armand, M.; Wang, G. Polymer electrolytes for lithium-based batteries: Advances and prospects. Chem. Rev. 2019, 5, 2326-2352. [CrossRef]

132. Goodenough, J.B.; Kim, Y. Challenges for rechargeable Li batteries. Chem. Mater. 2010, 22, 587-603. [CrossRef]

133. Aziz, S.B.; Woo, T.J.; Kadir, M.; Ahmed, H.M. A conceptual review on polymer electrolytes and ion transport models. J. Sci. Adv. Mater. Devices 2018, 3, 1-17. [CrossRef]

134. Commarieu, B.; Paolella, A.; Daigle, J.-C.; Zaghib, K. Toward high lithium conduction in solid polymer and polymer-ceramic batteries. Curr. Opin. Electrochem. 2018, 9, 56-63. [CrossRef]

135. Kumar, M. A conceptual review on polymer gel electrolytes and its conduction mechanism. J. Pharm. Innov. 2018, 7, 194-198.

136. Mauger, A.; Julien, C.; Paolella, A.; Armand, M.; Zaghib, K. A comprehensive review of lithium salts and beyond for rechargeable batteries: Progress and perspectives. Mater. Sci. Eng. R Rep. 2018, 134, 1-21. [CrossRef]

137. Commarieu, B.; Paolella, A.; Collin-Martin, S.; Gagnon, C.; Vijh, A.; Guerfi, A.; Zaghib, K. Solid-to-liquid transition of polycarbonate solid electrolytes in Li-metal batteries. J. Power Sources 2019, 436, 226852. [CrossRef]

138. Chen, X.; Put, B.; Sagara, A.; Gandrud, K.; Murata, M.; Steele, J.A.; Yabe, H.; Hantschel, T.; Roeffaers, M.; Tomiyama, M. Silica gel solid nanocomposite electrolytes with interfacial conductivity promotion exceeding the bulk Li-ion conductivity of the ionic liquid electrolyte filler. Sci. Adv. 2020, 6, eaav3400. [CrossRef] [PubMed]

139. Liu, H.; Cheng, X.B.; Xu, R.; Zhang, X.Q.; Yan, C.; Huang, J.Q.; Zhang, Q. Plating/stripping behavior of actual lithium metal anode. Adv. Energy Mater. 2019, 9, 1902254. [CrossRef]

140. Sun, Y.; Liu, N.; Cui, Y. Promises and challenges of nanomaterials for lithium-based rechargeable batteries. Nat. Energy 2016, 1, 1-12. [CrossRef] 
141. Ye, F.; Zhang, X.; Liao, K.; Lu, Q.; Zou, X.; Ran, R.; Zhou, W.; Zhong, Y.; Shao, Z. A smart lithiophilic polymer filler in gel polymer electrolyte enables stable and dendrite-free Li metal anode. J. Mater. Chem. A 2020, 8, 9733-9742. [CrossRef]

142. Liu, S.; Imanishi, N.; Zhang, T.; Hirano, A.; Takeda, Y.; Yamamoto, O.; Yang, J. Effect of nano-silica filler in polymer electrolyte on $\mathrm{Li}$ dendrite formation in $\mathrm{Li} /$ poly (ethylene oxide) $-\mathrm{Li}\left(\mathrm{CF}_{3} \mathrm{SO}_{2}\right)_{2} \mathrm{~N} / \mathrm{Li}$. J. Power Sources 2010, 195, 6847-6853. [CrossRef]

143. Liu, R.; Wu, Z.; He, P.; Fan, H.; Huang, Z.; Zhang, L.; Chang, X.; Liu, H.; Wang, C.-a.; Li, Y. A self-standing, UV-cured semiinterpenetrating polymer network reinforced composite gel electrolytes for dendrite-suppressing lithium ion batteries. J. Mater. 2019, 5, 185-194. [CrossRef]

144. Kaboli, S.; Demers, H.; Paolella, A.; Darwiche, A.; Dontigny, M.; Clément, D.; Guerfi, A.; Trudeau, M.L.; Goodenough, J.B.; Zaghib, K. Behavior of solid electrolyte in Li-Polymer battery with NMC cathode via in-situ scanning electron microscopy. Nano Lett. 2020, 20, 1607-1613. [CrossRef]

145. Golozar, M.; Hovington, P.; Paolella, A.; Bessette, S.p.; Lagacé, M.; Bouchard, P.; Demers, H.; Gauvin, R.; Zaghib, K. In situ scanning electron microscopy detection of carbide nature of dendrites in Li-polymer batteries. Nano Lett. 2018, 18, 7583-7589. [CrossRef]

146. Golozar, M.; Paolella, A.; Demers, H.; Bessette, S.; Lagacé, M.; Bouchard, P.; Guerfi, A.; Gauvin, R.; Zaghib, K. In situ observation of solid electrolyte interphase evolution in a lithium metal battery. Commun. Chem. 2019, 2, 1-9. [CrossRef]

147. Wang, X.; Zhu, H.; Girard, G.M.; Yunis, R.; MacFarlane, D.R.; Mecerreyes, D.; Bhattacharyya, A.J.; Howlett, P.C.; Forsyth, M. Preparation and characterization of gel polymer electrolytes using poly (ionic liquids) and high lithium salt concentration ionic liquids. J. Mater. Chem. A 2017, 5, 23844-23852. [CrossRef]

148. Purkait, M.K.; Sinha, M.K.; Mondal, P.; Singh, R. Introduction to membranes. In Interface Science and Technology; Elsevier: Amsterdam, The Netherlands, 2018; Volume 25, pp. 1-37.

149. Liu, L.; Wang, Z.; Zhao, Z.; Zhao, Y.; Li, F.; Yang, L. PVDF/PAN/SiO 2 polymer electrolyte membrane prepared by combination of phase inversion and chemical reaction method for lithium ion batteries. J. Solid State Electrochem. 2016, 20, 699-712. [CrossRef]

150. Dahlin, R.L.; Kasper, F.K.; Mikos, A.G. Polymeric nanofibers in tissue engineering. Tissue Eng. Part B Rev. 2011, 17, 349-364. [CrossRef]

151. Sun, G.; Sun, L.; Xie, H.; Liu, J. Electrospinning of nanofibers for energy applications. Nanomaterials 2016, 6, 129. [CrossRef] [PubMed]

152. Cheng, Y.; Zhang, L.; Xu, S.; Zhang, H.; Ren, B.; Li, T.; Zhang, S. Ionic liquid functionalized electrospun gel polymer electrolyte for use in a high-performance lithium metal battery. J. Mater. Chem. A 2018, 6, 18479-18487. [CrossRef]

153. Li, H.; Ma, X.-T.; Shi, J.-L.; Yao, Z.-K.; Zhu, B.-K.; Zhu, L.-P. Preparation and properties of poly (ethylene oxide) gel filled polypropylene separators and their corresponding gel polymer electrolytes for Li-ion batteries. Electrochim. Acta 2011, 56, 2641-2647. [CrossRef]

154. Sato, T.; Morinaga, T.; Marukane, S.; Narutomi, T.; Igarashi, T.; Kawano, Y.; Ohno, K.; Fukuda, T.; Tsujii, Y. Novel solidstate polymer electrolyte of colloidal crystal decorated with ionic-liquid polymer brush. Adv. Mater. 2011, 23, 4868-4872. [CrossRef] [PubMed]

155. Guo, Q.; Han, Y.; Wang, H.; Xiong, S.; Sun, W.; Zheng, C.; Xie, K. Flame retardant and stable $\operatorname{Li}_{1.5} \mathrm{Al}_{0.5} \mathrm{Ge}_{1.5}\left(\mathrm{PO}_{4}\right)_{3}$-supported ionic liquid gel polymer electrolytes for high safety rechargeable solid-state lithium metal batteries. J. Phys. Chem. C 2018, 122, 10334-10342. [CrossRef]

156. Ma, F.; Zhang, Z.; Yan, W.; Ma, X.; Sun, D.; Jin, Y.; Chen, X.; He, K. Solid polymer electrolyte based on polymerized ionic liquid for high performance all-solid-state lithium-ion batteries. ACS Sustain. Chem. Eng. 2019, 7, 4675-4683. [CrossRef]

157. Wang, S.; Shi, Q.X.; Ye, Y.S.; Xue, Y.; Wang, Y.; Peng, H.Y.; Xie, X.L.; Mai, Y.W. Constructing desirable ion-conducting channels within ionic liquid-based composite polymer electrolytes by using polymeric ionic liquid-functionalized 2D mesoporous silica nanoplates. Nano Energy 2017, 33, 110-123. [CrossRef]

158. Bocchetta, P. Ionotropic gelation of chitosan for next-generation composite proton conducting flat structures. Molecules 2020, 25, 1632. [CrossRef]

159. Sacco, P.; Pedroso-Santana, S.; Kumar, Y.; Joly, N.; Martin, P.; Bocchetta, P. Ionotropic Gelation of Chitosan Flat Structures and Potential Applications. Molecules 2021, 26, 660. [CrossRef] [PubMed]

160. Kim, S.; Cho, M.; Lee, Y. Multifunctional chitosan-RGO network binder for enhancing the cycle stability of Li-S batteries. Adv. Funct. Mater. 2020, 30, 1907680. [CrossRef]

161. Zhao, X.; Yim, C.-H.; Du, N.; Abu-Lebdeh, Y. Crosslinked chitosan networks as binders for silicon/graphite composite electrodes in li-ion batteries. J. Electrochem. Soc. 2018, 165, A1110. [CrossRef]

162. Stephan, A.M.; Nahm, K.S.; Kulandainathan, M.A.; Ravi, G. Poly (vinylidene fluoride-hexafluoropropylene)(PVdF-HFP) based composite electrolytes for lithium batteries. Eur. Polym. J. 2006, 42, 1728-1734. [CrossRef]

163. Aravindan, V.; Vickraman, P. Nanoparticulate $\mathrm{AlO}(\mathrm{OH})_{n}$ filled polyvinylidenefluoride-co-hexafluoropropylene based microporous membranes for lithium ion batteries. J. Renew. Sustain. Energy 2009, 1, 023108. [CrossRef]

164. Chen, G.; Zhang, F.; Zhou, Z.; Li, J.; Tang, Y. A flexible dual-ion battery based on PVDF-HFP-modified gel polymer electrolyte with excellent cycling performance and superior rate capability. Adv. Energy Mater. 2018, 8, 1801219. [CrossRef]

165. Zhao, X.; Tao, C.-a.; Li, Y.; Chen, X.; Wang, J.; Gong, H. Preparation of gel polymer electrolyte with high lithium ion transference number using GO as filler and application in lithium battery. Ionics 2020, 26, 4299-4309. [CrossRef]

166. Liu, J.; Wu, X.; He, J.; Li, J.; Lai, Y. Preparation and performance of a novel gel polymer electrolyte based on poly (vinylidene fluoride)/graphene separator for lithium ion battery. Electrochim. Acta 2017, 235, 500-507. [CrossRef] 
167. Chen, Y.M.; Hsu, S.T.; Tseng, Y.H.; Yeh, T.F.; Hou, S.S.; Jan, J.S.; Lee, Y.L.; Teng, H. Minimization of Ion-Solvent Clusters in Gel Electrolytes Containing Graphene Oxide Quantum Dots for Lithium-Ion Batteries. Small 2018, 14, 1703571. [CrossRef]

168. Dyartanti, E.R.; Purwanto, A.; Widiasa, I.N.; Susanto, H. Ionic conductivity and cycling stability improvement of PVdF/nano-clay using PVP as polymer electrolyte membranes for LiFePO4 batteries. Membranes 2018, 8, 36. [CrossRef] [PubMed]

169. Gebert, F.; Knott, J.; Gorkin, R.; Chou, S.-L.; Dou, S.-X. Polymer electrolytes for sodium-ion batteries. Energy Storage Mater. 2021, 36, 10-30. [CrossRef]

170. Iturrondobeitia, A.; Goñi, A.; Gil de Muro, I.; Lezama, L.; Rojo, T. Physico-chemical and electrochemical properties of nanoparticulate $\mathrm{NiO} / \mathrm{C}$ composites for high performance lithium and sodium ion battery anodes. Nanomaterials $2017,7,423$. [CrossRef] [PubMed]

171. Ayandele, E.; Sarkar, B.; Alexandridis, P. Polyhedral oligomeric silsesquioxane (POSS)-containing polymer nanocomposites. Nanomaterials 2012, 2, 445-475. [CrossRef] [PubMed]

172. Ni'mah, Y.L.; Cheng, M.-Y.; Cheng, J.H.; Rick, J.; Hwang, B.-J. Solid-state polymer nanocomposite electrolyte of $\mathrm{TiO}_{2} / \mathrm{PEO} / \mathrm{NaClO} 4$ for sodium ion batteries. J. Power Sources 2015, 278, 375-381. [CrossRef]

173. Zhang, X.; Wang, X.; Liu, S.; Tao, Z.; Chen, J. A novel PMA/PEG-based composite polymer electrolyte for all-solid-state sodium ion batteries. Nano Res. 2018, 11, 6244-6251. [CrossRef]

174. Kumar, D.; Suleman, M.; Hashmi, S. Studies on poly (vinylidene fluoride-co-hexafluoropropylene) based gel electrolyte nanocomposite for sodium-sulfur batteries. Solid State Ion. 2011, 202, 45-53. [CrossRef]

175. Liu, Z.; Wang, X.; Chen, J.; Tang, Y.; Mao, Z.; Wang, D. Gel Polymer Electrolyte Membranes Boosted with Sodium-Conductive ß-Alumina Nanoparticles: Application for Na-Ion Batteries. ACS Appl. Energy Mater. 2021, 4, 623-632. [CrossRef]

176. Wang, X.; Liu, Z.; Tang, Y.; Chen, J.; Mao, Z.; Wang, D. PVDF-HFP/PMMA/TPU-based gel polymer electrolytes composed of conductive $\mathrm{Na}_{3} \mathrm{Zr}_{2} \mathrm{Si}_{2} \mathrm{PO}_{12}$ filler for application in sodium ions batteries. Solid State Ion. 2021, 359, 115532. [CrossRef]

177. Yi, Q.; Zhang, W.; Li, S.; Li, X.; Sun, C. Durable Sodium Battery with a Flexible $\mathrm{Na}_{3} \mathrm{Zr}_{2} \mathrm{Si}_{2} \mathrm{PO}_{12}-\mathrm{PVDF}-\mathrm{HFP}$ Composite Electrolyte and Sodium/Carbon Cloth Anode. ACS Appl. Mater. Interfaces 2018, 10, 35039-35046. [CrossRef]

178. Song, S.; Kotobuki, M.; Zheng, F.; Xu, C.; Savilov, S.V.; Hu, N.; Lu, L.; Wang, Y.; Li, W.D.Z. A hybrid polymer/oxide/ionic-liquid solid electrolyte for Na-metal batteries. J. Mater. Chem. A 2017, 5, 6424-6431. [CrossRef]

179. Yoo, H.D.; Shterenberg, I.; Gofer, Y.; Gershinsky, G.; Pour, N.; Aurbach, D. Mg rechargeable batteries: An on-going challenge. Energy Environ. Sci. 2013, 6, 2265-2279. [CrossRef]

180. Jäckle, M.; Helmbrecht, K.; Smits, M.; Stottmeister, D.; Groß, A. Self-diffusion barriers: Possible descriptors for dendrite growth in batteries? Energy Environ. Sci. 2018, 11, 3400-3407. [CrossRef]

181. Park, B.; Schaefer, J.L. Polymer Electrolytes for Magnesium Batteries: Forging Away from Analogs of Lithium Polymer Electrolytes and Towards the Rechargeable Magnesium Metal Polymer Battery. J. Electrochem. Soc. 2020, 167, 070545. [CrossRef]

182. Oh, J.-S.; Ko, J.-M.; Kim, D.-W. Preparation and characterization of gel polymer electrolytes for solid state magnesium batteries. Electrochim. Acta 2004, 50, 903-906. [CrossRef]

183. Pandey, G.; Agrawal, R.; Hashmi, S. Magnesium ion-conducting gel polymer electrolytes dispersed with nanosized magnesium oxide. J. Power Sources 2009, 190, 563-572. [CrossRef]

184. Pandey, G.; Agrawal, R.; Hashmi, S. Electrical and electrochemical properties of magnesium ion conducting composite gel polymer electrolytes. J. Phys. D Appl. Phys. 2010, 43, 255501. [CrossRef]

185. Pandey, G.; Agrawal, R.; Hashmi, S. Magnesium ion-conducting gel polymer electrolytes dispersed with fumed silica for rechargeable magnesium battery application. J. Solid State Electrochem. 2011, 15, 2253-2264. [CrossRef]

186. Pandey, G.; Agrawal, R.; Hashmi, S. Performance studies on composite gel polymer electrolytes for rechargeable magnesium battery application. J. Phys. Chem. Solids 2011, 72, 1408-1413. [CrossRef]

187. Sharma, J.; Hashmi, S. Magnesium ion-conducting gel polymer electrolyte nanocomposites: Effect of active and passive nanofillers. Polym. Compos. 2019, 40, 1295-1306. [CrossRef]

188. Hashmi, S. Enhanced zinc ion transport in gel polymer electrolyte: Effect of nano-sized ZnO dispersion. J. Solid State Electrochem. 2012, 16, 3105-3114.

189. Johnsi, M.; Suthanthiraraj, S.A. Preparation, zinc ion transport properties, and battery application based on poly (vinilydene fluoride-co-hexa fluoro propylene) polymer electrolyte system containing titanium dioxide nanofiller. High. Perform. Polym. 2015, 27, 877-885. [CrossRef] 